\title{
Small engine emissions testing laboratory development and emissions sampling system verification
}

\author{
Balaji B. Seward \\ West Virginia University
}

Follow this and additional works at: https://researchrepository.wvu.edu/etd

\section{Recommended Citation}

Seward, Balaji B., "Small engine emissions testing laboratory development and emissions sampling system verification" (2010). Graduate Theses, Dissertations, and Problem Reports. 4655.

https://researchrepository.wvu.edu/etd/4655

This Thesis is protected by copyright and/or related rights. It has been brought to you by the The Research Repository @ WVU with permission from the rights-holder(s). You are free to use this Thesis in any way that is permitted by the copyright and related rights legislation that applies to your use. For other uses you must obtain permission from the rights-holder(s) directly, unless additional rights are indicated by a Creative Commons license in the record and/ or on the work itself. This Thesis has been accepted for inclusion in WVU Graduate Theses, Dissertations, and Problem Reports collection by an authorized administrator of The Research Repository @ WVU. For more information, please contact researchrepository@mail.wvu.edu. 
Small Engine Emissions Testing Laboratory Development and Emissions Sampling System Verification

Balaji B. Seward

Thesis submitted to the

College of Engineering and Mineral Resources

at West Virginia University

in partial fulfillment of the requirements

for the degree of

Master of Science

in

Mechanical Engineering

W. Scott Wayne, Ph.D.

Andrew Nix, Ph.D.

Hailin Li, Ph.D.

Department of Mechanical and Aerospace Engineering

Morgantown, West Virginia

2010

Keywords: Emissions Testing, Small Engine Emissions Testing, Engine Lab Development, Raw Exhaust Sampling 


\section{ABSTRACT \\ Small Engine Emissions Testing Laboratory Development and Emissions Sampling System Verification \\ Balaji B Seward}

With the recent scrutiny of engine emissions and a focus towards higher fuel efficiencies, there has been an increase in demand for small, efficient engines and small engine emissions testing. Small engines have proven to provide high efficiency performance for systems including refrigeration units, generators, compressors and numerous other off-road applications. In the past, the existing emissions testing facilities at West Virginia University's (WVU) Center for Alternative Fuels, Engines and Emissions (CAFEE) have been focused towards the testing of heavy duty diesel engines.

In order to expand the emissions testing capabilities at CAFEE, a new small engine emissions testing laboratory was needed. Over a two year period a new small engine emissions laboratory (SEEL) was designed and built at CAFEE's Westover facility. The new SEEL used a $40 \mathrm{hp}$ alternating current (AC) dynamometer with an in-line slip ring torque sensor. It included full dynamometer and engine cooling capabilities. Custom built software provided the control algorithms to allow for engine mapping, steady state, and transient emissions tests. Safety systems including shaft guards and an automatic kill switch provided a safe working environment and would isolate damage in case of a mechanical failure.

The SEEL was designed to be used with existing raw and dilute emissions sampling systems. The raw emissions sampling system was recently developed at WVU and needed to be verified against a trusted dilute emissions sampling system in order to prepare it for testing with the SEEL. A set of tests were performed which included simultaneous sampling of one engine 
by both sampling systems. The results from these tests showed that raw sampling system CO, $\mathrm{CO}_{2}$, and $\mathrm{NO}_{\mathrm{x}}$ passed their verification criteria of $2 \%, 2 \%$, and $5 \%$ difference respectfully. The $\mathrm{HC}$ measurement systems did not pass the $10 \%$ verification criteria. The verification of $\mathrm{HC}$ was a complex issue that was beyond the scope of this study. 


\section{ACKNOWLEDGMENTS}

Throughout my undergraduate and graduate careers here at WVU, I have managed to make many friends and have been greatly influenced by many faculty, staff and students at the college. I will try to include those who have made the most impact on me, but I am sure I will forget a few and to them I apologize.

First I would like to thank Dr. Scott Wayne for giving me the opportunity to attend graduate school and work for him in the CAFEE center. Without the opportunity he gave me, I do not think that I would have been able to attend graduate school at WVU. Dr. Andrew Nix and Dr. Hailin Li have both played crucial roles in my work and I am grateful that they agreed to help me with my research and to be part of my committee. I can honestly say that my experiences working with them have spurred my interest in engines and emissions research. Thank you for the knowledge you have given me and for being positive role models in my graduate career.

I would like to thank Richard Atkinson for his extensive work on the software that now controls the small engine lab. He spent many hours writing and debugging the software that ties the small engine lab together. He also provided guidance with the installation of all the electronics in the lab and for that I am grateful.

I would like to thank Jacob Brown, Chet-Mun Liew and the other graduate students in the CAFEE center who have been there to share my hardships and to provide moral support. It is great to be able to work with people with whom I have so much in common. I will never forget the times spent together working in the lab and in classes. I can honestly say that my time here would have been much harder and less enjoyable if I had not been working with them.

The CAFEE staff at the ERC and Westover offices have been helpful to me throughout my time here as a graduate student. Some I have worked more closely with, but even those who 
I haven't worked closely with have always been willing to help and have given me great advice and support. These people include but are not limited to: Brad Ralston, Dan Carder, Ron Jarrett, Chris Rowe, and Jason England.

Finally, I would like to thank my parents who have always been very supportive of me no matter what directions I have taken. They have given me great guidance in life but still provided me with the freedom I needed to learn from my mistakes and to improve myself as a person. Thank you for teaching me computers at a young age and letting me tinker with your electronics. Thank you for being such caring parents and for being so concerned about my health and wellbeing. Thank you for keeping me involved with the violin and other things that kept my mind active and out of trouble. 


\section{TABLE OF CONTENTS}

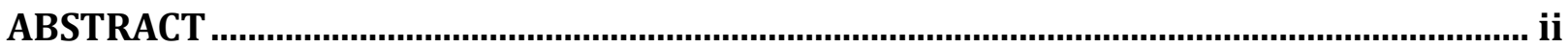

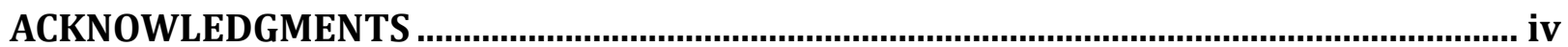

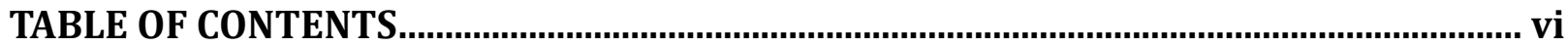

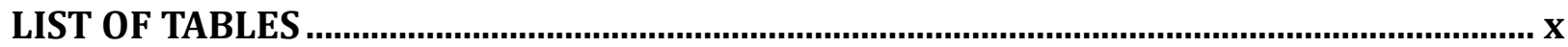

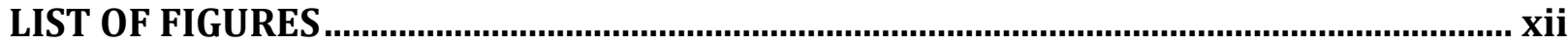

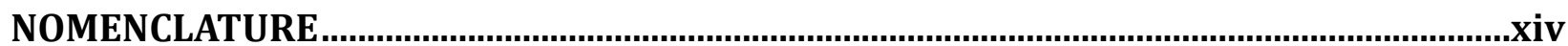

$1 \quad$ INTRODUCTION $\ldots \ldots \ldots \ldots \ldots \ldots$

2 OBJECTIVES................................................................................................................. 3

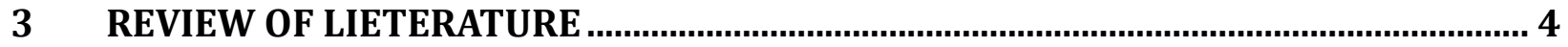

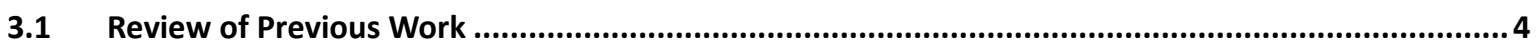

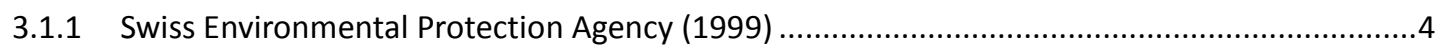

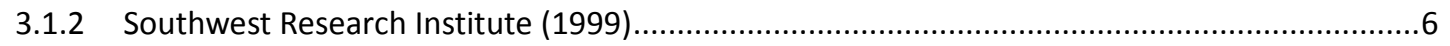

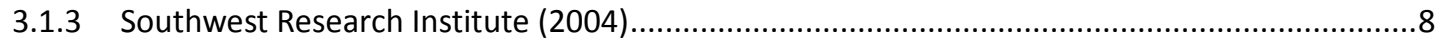

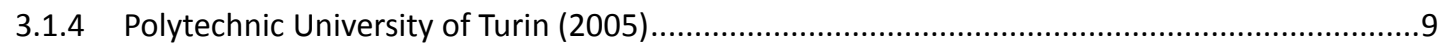

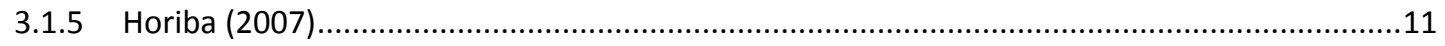

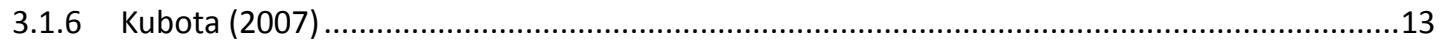

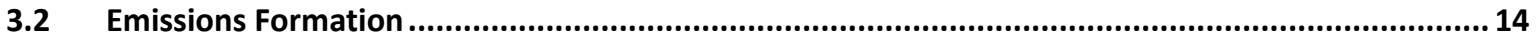

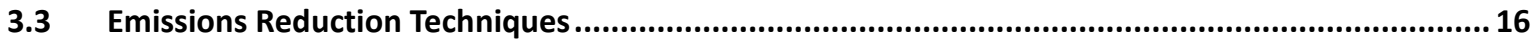

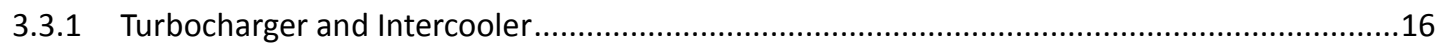

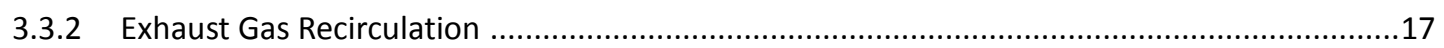

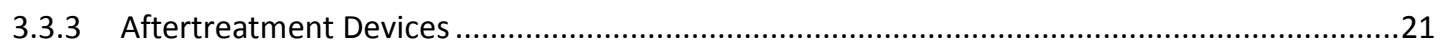

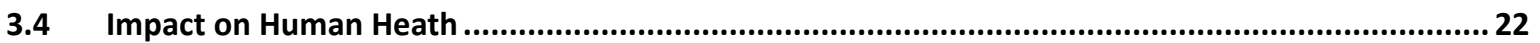

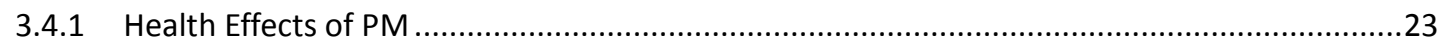

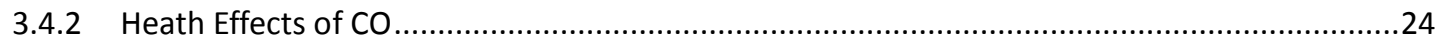




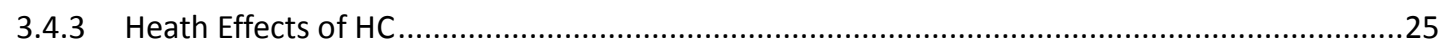

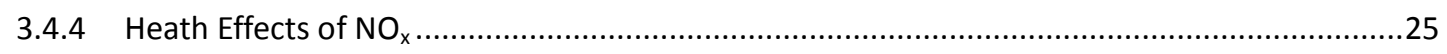

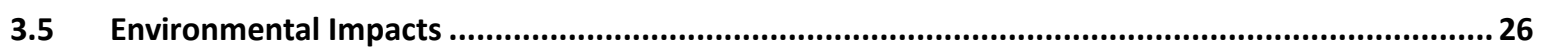

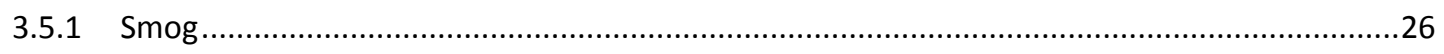

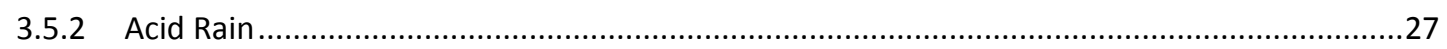

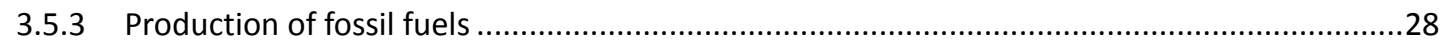

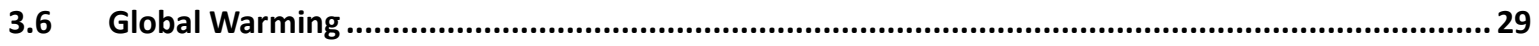

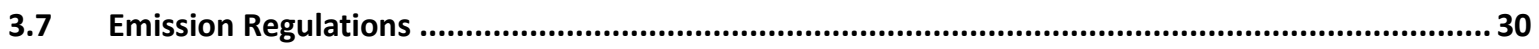

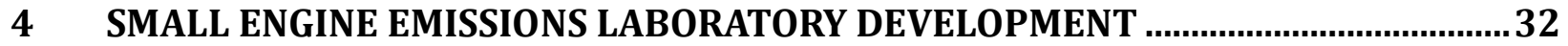

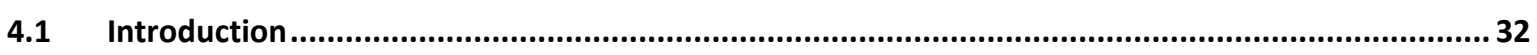

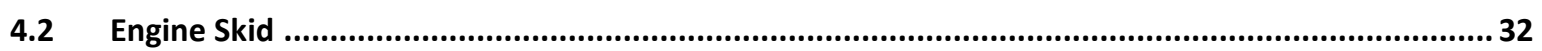

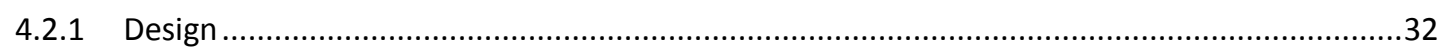

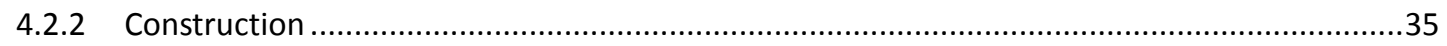

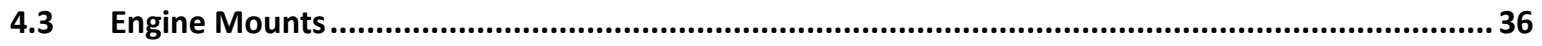

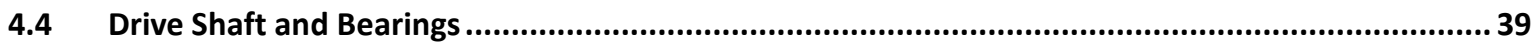

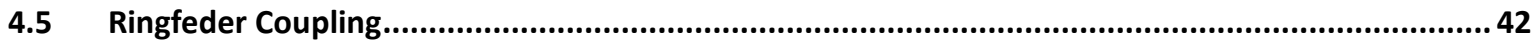

4.6 Vulcan Coupling and Adapter Plate ....................................................................................44

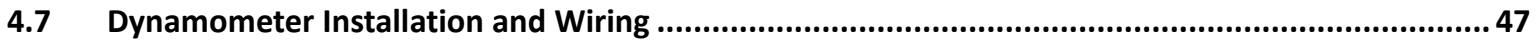

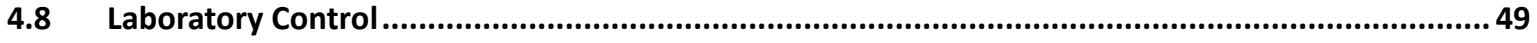

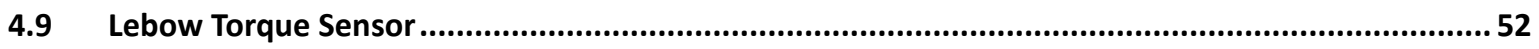

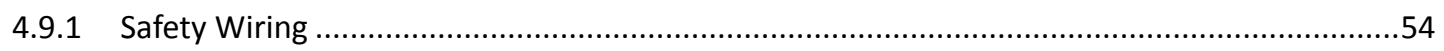

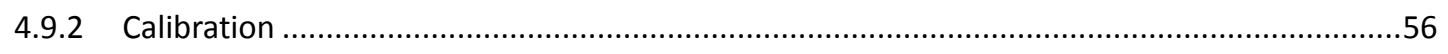

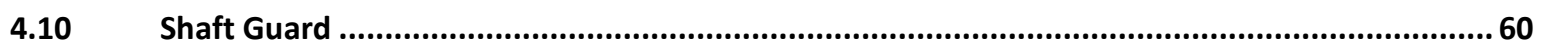

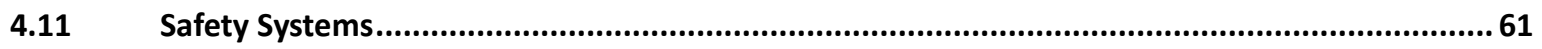

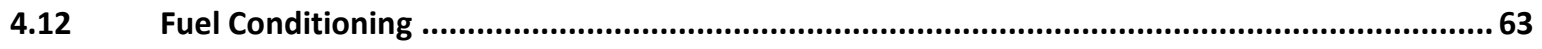

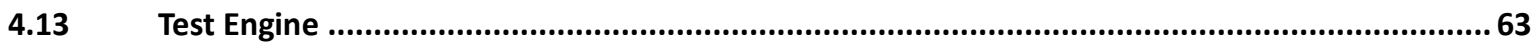




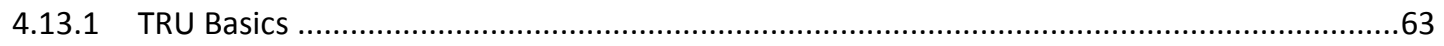

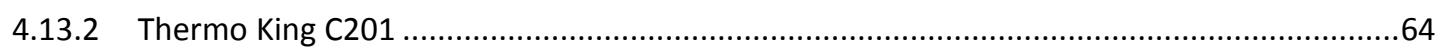

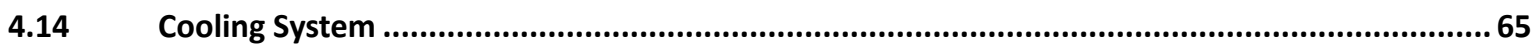

5 EXPERIMENTAL EQUIPMENT AND PROCEDURES FOR RAW LAB VERIFICATION 68

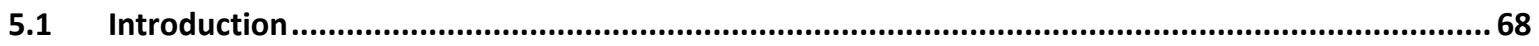

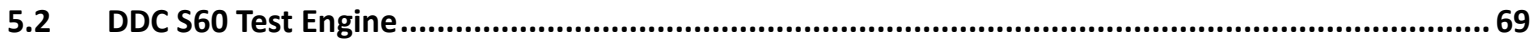

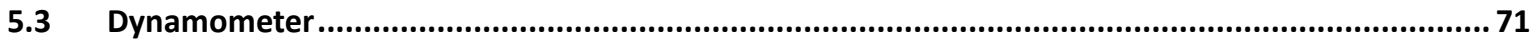

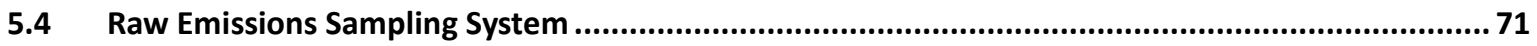

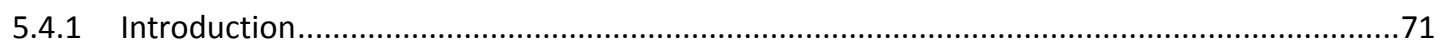

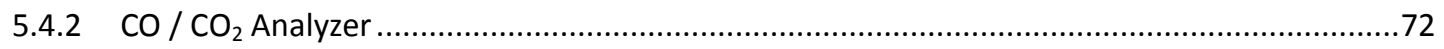

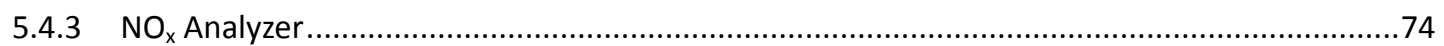

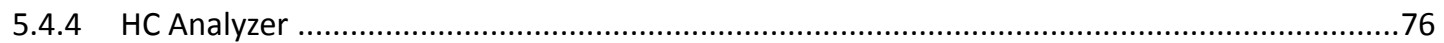

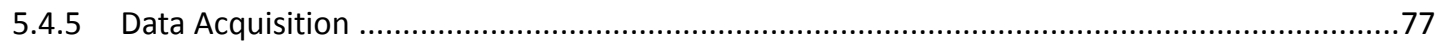

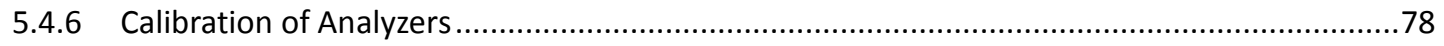

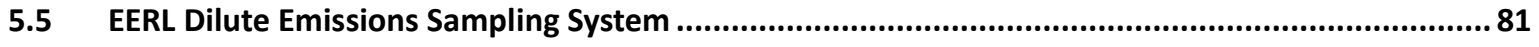

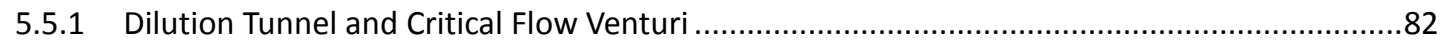

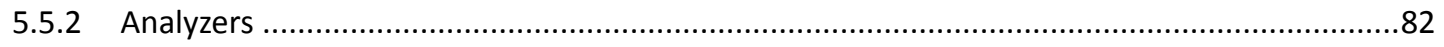

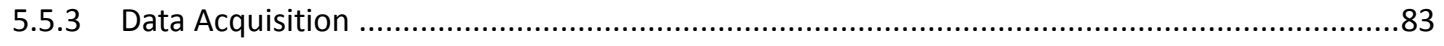

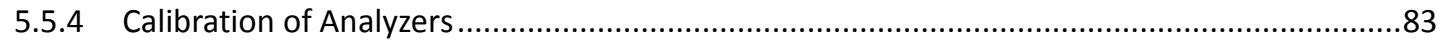

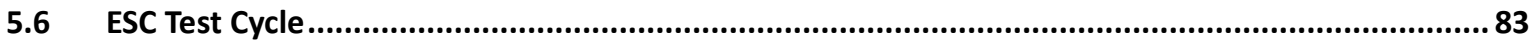

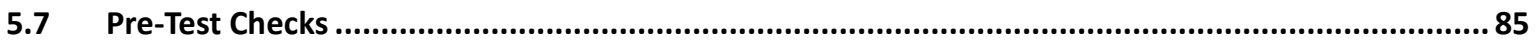

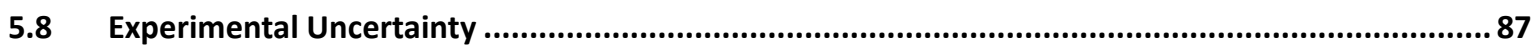

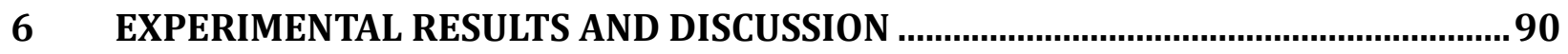

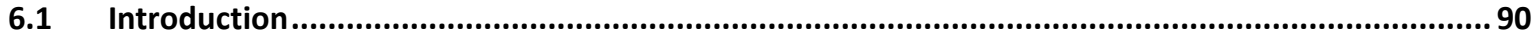

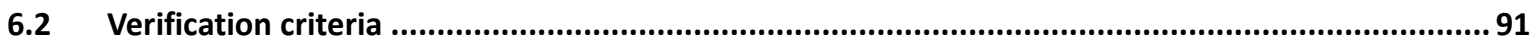

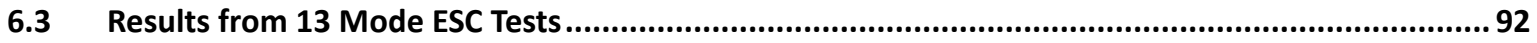




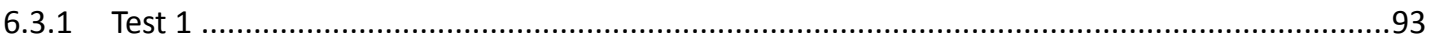

6.3.1.1 Comparison of Weighted Brake-Specific Emissions ......................................................93

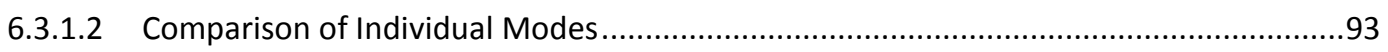

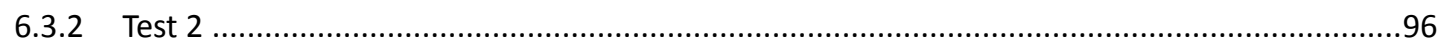

6.3.2.1 Comparison of Weighted Brake-Specific Emissions ......................................................

6.3.2.2 Comparison of Individual Modes ...............................................................................

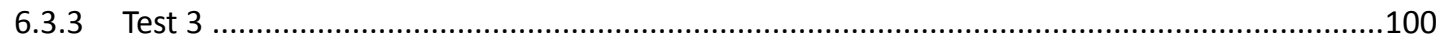

6.3.3.1 Comparison of Weighted Brake-Specific Emissions ......................................................100

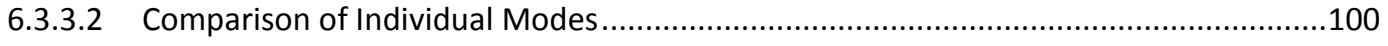

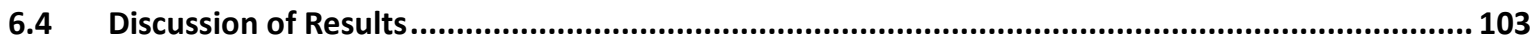

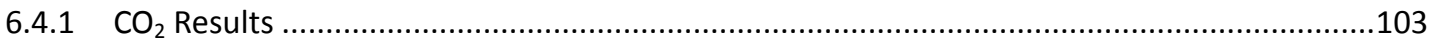

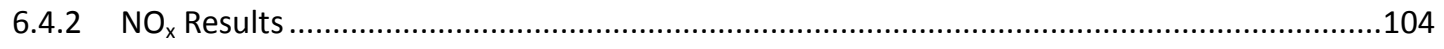

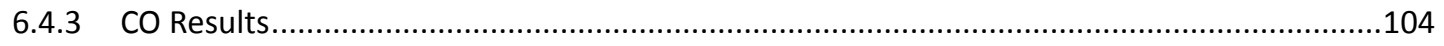

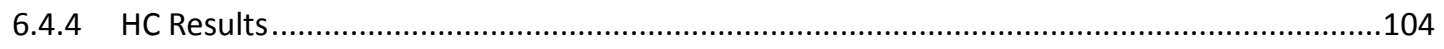

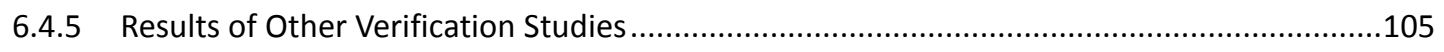

7 CONCLUSION AND RECOMMENDATIONS …….......................................................... 105

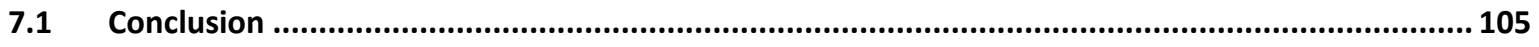

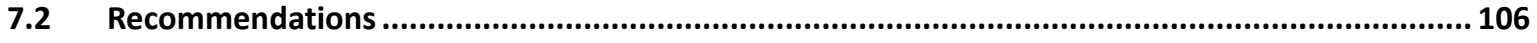

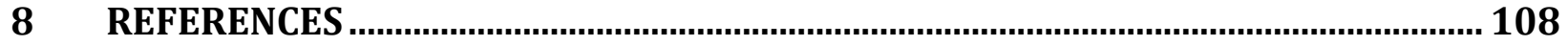




\section{LIST OF TABLES}

Table 1 - Swiss Environmental Protection Agency Emissions Results [2] 5

Table 2 - Southwest Research Institute (1999) Test Engine Information [5] 7

Table 3 - Summary of Emission Test Results [5] 7

Table 4 - Southwest Research Institute (2004) Test Engine Information [6] 8

Table 5 - Southwest Research Institute (2004) Effect of Three-Way Catalyst and Engine Ageing

on Emissions [6] 9

Table 6 - Characteristics of the Tested DI Diesel Engine [7] 10

Table 7 - Effects of the Variation of Compression Ratio and Injection Pressure on the Engine;

Comparison between Baseline and Final Configuration [7] 11

Table 8 - Horiba Test Conditions [8] 12

Table 9 - Kubota Engines Specifications [9] 13

Table 10 - The Effect of EGR on Smoke Emissions and the Oxygen to Fuel Ratio [1512] 20

Table 11 - Heath Effects Produced by CO [19] 25

Table 12 - Tier 1-3 Non-Road Diesel Engine Emission Standards (g/bhp-hr) [25] 31

Table 13 - Tier 4 Non-Road Diesel Engine Emission Standards (g/bhp-hr) [25] 31

Table 14 - Reliance Dynamometer Specifications 47

Table 15 - Speed Transducer Wiring $\quad 49$

Table 16 - Set Point File Example $\quad 51$

Table 17 - Lebow Torque Sensor Specifications

Table 18 - Physical Dimensions of the Lebow Torque Sensor 54

Table 19 - Weight of Calibration Components $\quad 57$

Table 20 - Isuzu Engine Specifications $\quad 64$ 
Table 21 - DDC S60 Test Engine Information

Table 22 - G.E. Dynamometer Specifications 71

Table 23 - Analyzer Information for the Raw Sampling System 72

$\begin{array}{ll}\text { Table } 24 \text { - Zero and Span Gases } & 79\end{array}$

Table 25 - $\mathrm{CO}_{2}$ Analyzer Calibration Results $\quad 79$

$\begin{array}{lr}\text { Table 26 - CO Analyzer Calibration Results } & 80\end{array}$

Table 27 - HC Analyzer Calibration Results $\quad 80$

Table $28-\mathrm{NO}_{\mathrm{x}}$ Analyzer Calibration Results $\quad 81$

Table 29 - Analyzer Information for EERL Dilute Measurement System 82

Table 30 - Calibration Results for the EERL Analyzers 83

Table 31 - ESC Test Cycle Details [35] 84

Table $32-\mathrm{NO}_{\mathrm{x}}$ Efficiency Test Results for Raw $\mathrm{Lab} \mathrm{NO}_{\mathrm{x}}$ Analyzer 86

Table $33-\mathrm{NO}_{\mathrm{x}}$ Efficiency Test Results for Dilute $\mathrm{Lab} \mathrm{NO}_{\mathrm{x}}$ Analyzer 86

Table 34 - Weighted Brake-Specific Emissions for Test 1

Table 35 - Errors for Individual Modes of Test 1

Table 36 - Weighted Brake-Specific Emissions for Test 2

Table 37 - Errors for Individual Modes of Test 2

$\begin{array}{ll}\text { Table } 38 \text { - Weighted Brake-Specific Emissions for Test } 3 & 100\end{array}$

Table 39 - Errors for Individual Modes of Test $1 \quad 101$ 


\section{LIST OF FIGURES}

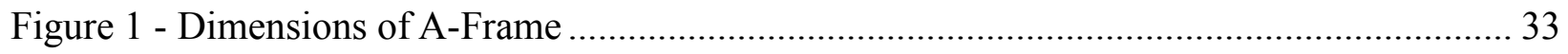

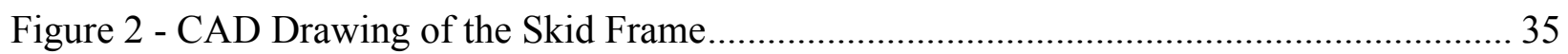

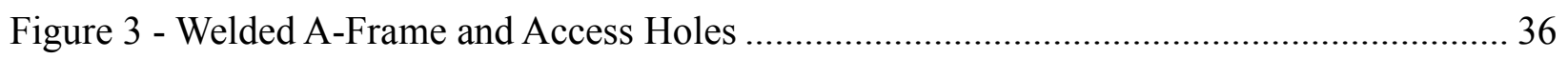

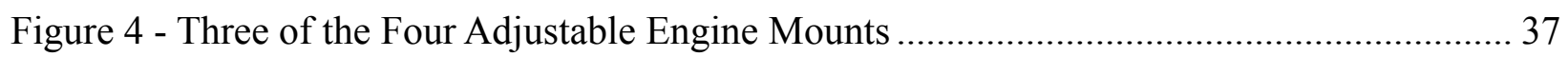

Figure 5 - Engine Mounting Bracket for the Eddie Current Test Engine ...................................... 38

Figure 6 - Engine Mounted on Channel Beams....................................................................... 39

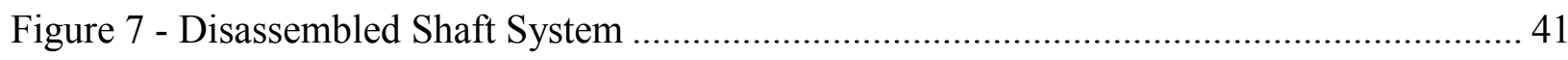

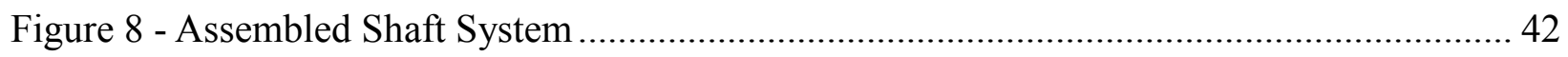

Figure 9 - Exploded View of a Trasco ES Backlash Free Coupling [27] ................................... 43

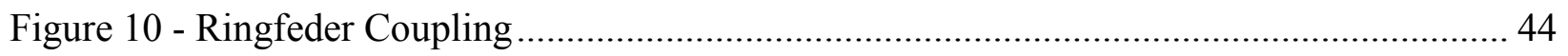

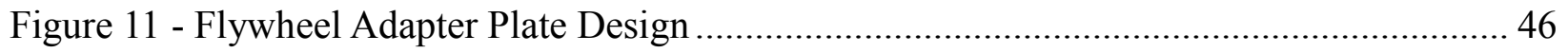

Figure 12 - Adapter Plate and Vulcan Coupling ……………................................................. 46

Figure 13 - Reliance Dynamometer Motor and Blower ............................................................ 48

Figure 14 - Dynamometer Blower Wiring Diagram ................................................................. 49

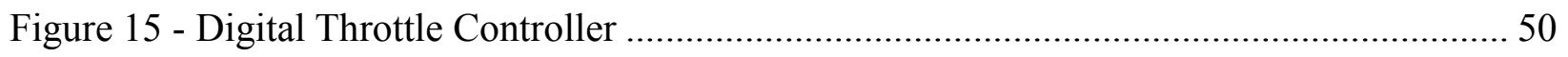

Figure 16 - Invertek Optidrive Plus Dynamometer Controller .................................................... 50

Figure 17 - Lebow Torque Sensor with Flanges ………………………………................... 53

Figure 18 - Torque Sensor Strain Gauge Wiring Diagram...................................................... 53

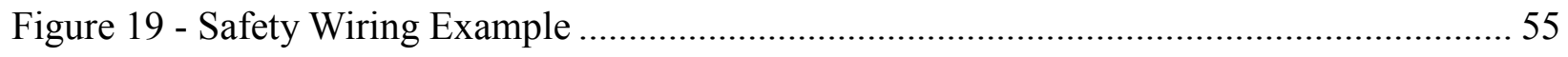

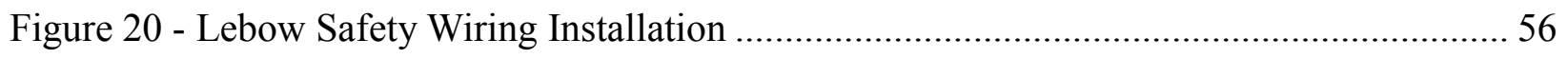

Figure 21 - Overhead View of Torque Calibration Setup ……..................................................... 58

Figure 22 - Lebow Torque Sensor Calibration Results ............................................................ 59 


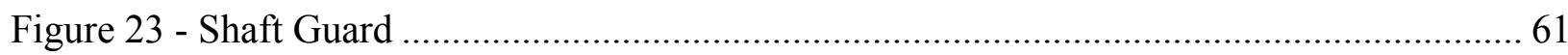

Figure 24 - Pressure Switch for Automatic Shut Off System ................................................... 62

Figure 25 - Thermo King Transportable Refrigeration Unit [29] ............................................... 64

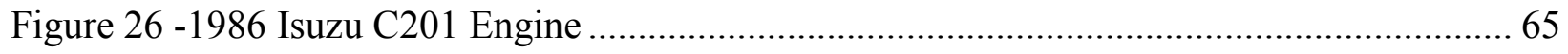

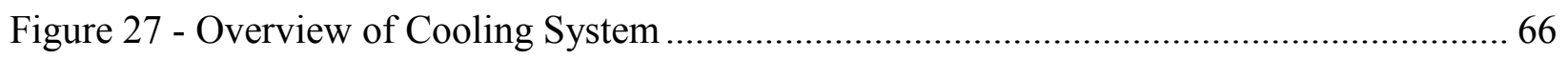

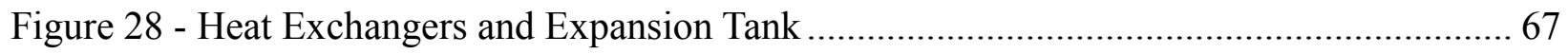

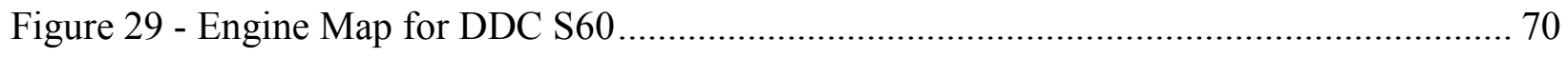

Figure 30 - $\mathrm{CO} / \mathrm{CO}_{2}$ Analyzer and Flow Control................................................................. 74

Figure 31 - NO/ $\mathrm{NO}_{\mathrm{x}}$ Analyzer, Filter and Flow Control......................................................... 76

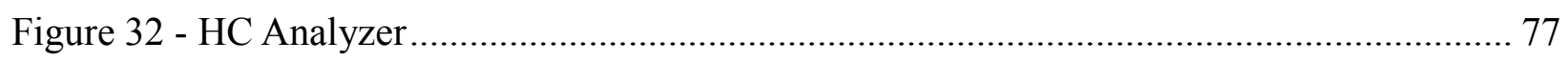

Figure 33 - Load and Speed during the ESC Test Cycle for the DDC S60 Engine ...................... 85

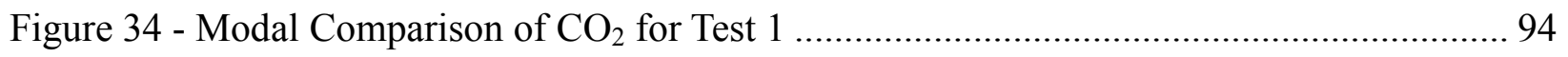

Figure 35 - Modal Comparison of CO for Test 1 ...................................................................... 95

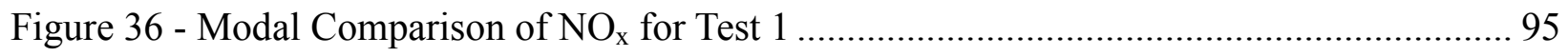

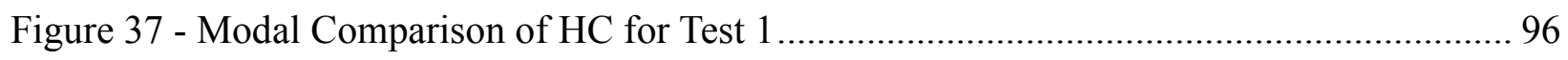

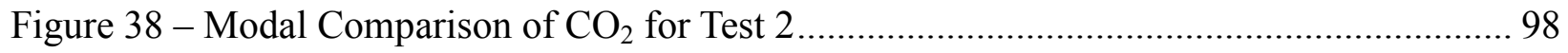

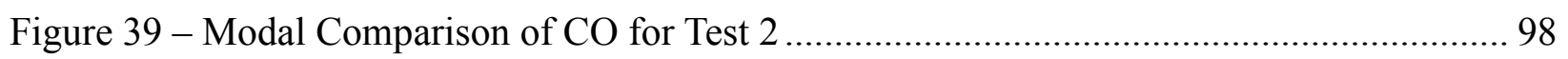

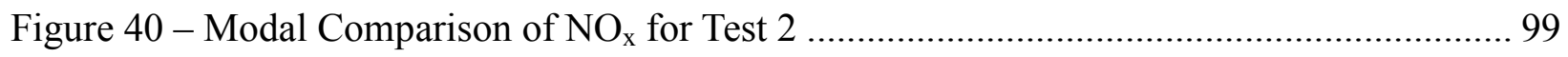

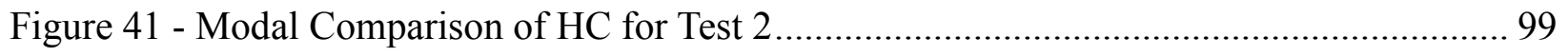

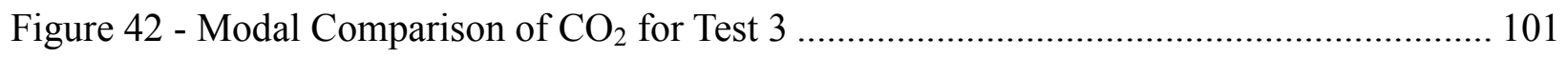

Figure 43 - Modal Comparison of CO for Test 3 ……........................................................... 102

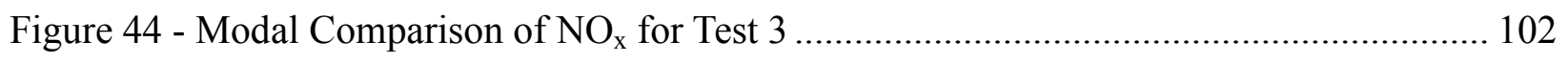

Figure 45 - Modal Comparison of HC for Test 3 ..................................................................... 103 


\section{NOMENCLATURE}

\begin{tabular}{|c|c|}
\hline $\mathrm{AC}$ & Alternating Current \\
\hline CAFEE & Center for Alternative Fuels, Engines and Emissions \\
\hline CARB & California Air Resource Board \\
\hline $\mathrm{cc}$ & Cubic Centimeter \\
\hline CFD & Computational Fluid Dynamics \\
\hline $\mathrm{CFV}$ & Critical Flow Venturi \\
\hline CVS & Constant Volume Sampler \\
\hline $\mathrm{CI}$ & Compression Ignition \\
\hline CLD & Chemiluminescence Detector \\
\hline $\mathrm{CO}$ & Carbon Monoxide \\
\hline $\mathrm{CO}_{2}$ & Carbon Dioxide \\
\hline CR & Compression Ratio \\
\hline DF & Dilution Factor \\
\hline DPF & Diesel Particulate Filter \\
\hline EERL & Engine and Emissions Research Laboratory \\
\hline EPA & Environmental Protection Agency \\
\hline EGR & Exhaust Gas Recirculation \\
\hline FEM & Finite Element Modeling \\
\hline FID & Flame Ionization Detection \\
\hline HFID & Heated Flame Ionization Detection \\
\hline $\mathrm{GC}$ & Gas Chromatography \\
\hline GHG & Green House Gas \\
\hline
\end{tabular}




\begin{tabular}{|c|c|}
\hline $\mathrm{HC}$ & Hydrocarbons \\
\hline HEI & Heath Effects Institute \\
\hline hp & Horse Power \\
\hline $\mathrm{hr}$ & Hour \\
\hline $\mathrm{H}_{2} \mathrm{O}$ & Water \\
\hline IARC & International Agency for Research on Cancer \\
\hline IC & Internal Combustion \\
\hline $\mathrm{kW}$ & Kilowatt \\
\hline $\mathrm{kWh}$ & Kilowatt-hour \\
\hline MAR & Maximum Allowable Response \\
\hline NDIR & Non-Dispersive Infrared Analyzer \\
\hline NIOSH & National Institute for Occupational Safety and Health \\
\hline $\mathrm{Nm}$ & Newton-Meter \\
\hline $\mathrm{NO}_{\mathrm{x}}$ & Oxides of Nitrogen \\
\hline PM & Particulate Matter \\
\hline $\mathrm{PM}_{2.5}$ & PM with diameter less than $2.5 \mu \mathrm{m}$ \\
\hline $\mathrm{PM}_{10}$ & PM with diameter less than $10 \mu \mathrm{m}$ \\
\hline ppm & Parts per Million \\
\hline QA & Quality Assurance \\
\hline RPM & Revolutions per Minute \\
\hline $\mathrm{sec}$ & Seconds \\
\hline SI & Spark Ignition \\
\hline SOI & Start of Injection \\
\hline
\end{tabular}




$\begin{array}{ll}\text { SMPS } & \text { Scanning Mobility Particle Analyzer } \\ \text { TEM } & \text { Transmission Electron Microscope } \\ \text { THC } & \text { Total Hydrocarbons } \\ \text { TPM } & \text { Total Particulate Matter } \\ \text { VOC } & \text { Volatile Organic Compounds } \\ \text { WHO } & \text { World Health Organization } \\ \text { WVU } & \text { West Virginia University }\end{array}$




\section{INTRODUCTION}

The United States Environmental Protection Agency (US EPA) and the California Air resources Board (CARB) both regulate the emissions from a variety of small engine types including generator sets, and transportable refrigeration units [1]. Recent regulations have further regulated the level of allowable emissions from these types of engines and have caused an increase in the demand for small engine emissions testing. At West Virginia University's Center for Alternative Fuels, Engines, and Emissions (CAFEE), small engine emissions testing capabilities were limited. The focus of past projects at CAFEE included heavy duty on-road vehicles and engines, locomotive testing, marine vehicle testing, chassis testing, and onboard vehicle emissions testing. The majority of the work performed at CAFEE had been focused towards research in these areas. There was an apparent lack of capabilities when it came to the testing of smaller engines. CAFEE desired to expand their testing capabilities and funding was acquired to construct a new small engine emissions testing laboratory.

Over a two year period, the Small Engine Emissions Laboratory (SEEL) was constructed at CAFEE's Westover facility. The initial phases included the design and acquisition of the needed equipment. Much of this was based upon existing components of other labs but required modification to meet the requirements of the new SEEL. A test engine and dynamometer were then acquired and installed on the newly built engine skid. The next step was to troubleshoot the electronics and write the software that would control the engine and dynamometer. Preparation then began for emissions testing that would act as a final verification of the completed lab.

The SEEL was designed to be used with any of the existing emissions sampling systems at CAFEE. These systems include the 2007 transportable emissions laboratory container, the transportable analytical trailer, the raw emissions sampling system, and the dilute measurement 
system located at CAFEEs Engines and Emissions Research Laboratory (EERL). The 2007 transportable emissions laboratory container was a new version of the transportable analytical trailer that included a transportable dilution tunnel and emissions sampling systems. It was requested that to verify the SEEL, testing should be performed with the raw emission sampling system and one of the dilute emissions sampling systems. Fellow graduate student Jacob Brown used the dilute measurement system of the transportable analytical trailer to commission the SEEL [2]. The raw emissions sampling system was not ready for the testing and so a set of verification tests were performed in order to prepare the raw emissions sampling system for testing with the SEEL. These tests compared the emissions data from the raw emissions sampling system against a verified dilute sampling system. These tests would give confidence in the raw sampling system so it may be used with the SEEL in the future. During these tests, both systems sampled from the exhaust stream of a 1992 DDC S60 12.7 liter diesel engine located at CAFEE's EERL facility. The error between the two data sets was then calculated using the data from the dilute emissions measurement system as the reference values. Verification criteria were set to establish an allowable difference between the systems. 


\section{OBJECTIVES}

The primary objectives of this project were to design and build a small engine emission laboratory. The test cell was designed to measure the brake-specific mass emissions from dieselfueled engines ranging in size from 1 liter in displacement up to approximately the size of a 5.9 liter Cummins B series engine. The lab was required to be able to provide cooling, control and physical accommodation for any engine in this size range. The specific objectives of this project were:

- To assess existing small engine emissions measuring equipment and methods at other institutions

- To fabricate a skid that will act as a frame to hold the engine and dynamometer

- To build a cooling system for the engine and dynamometer

- To obtain and install a test engine to be used for the commissioning process

- To use as much existing equipment and materials to reduce cost

- To demonstrate dynamometer and engine control capabilities

- To perform transient and steady state emissions testing using both a raw and dilute exhaust sampling systems

- To prepare the raw emissions sampling system for future testing with the SEEL by performing a set of verification tests 


\section{REVIEW OF LIETERATURE}

\subsection{Review of Previous Work}

Numerous organizations around the world have the capabilities to measure small engine emissions and performance characteristics. They vary in their capabilities and the scopes of their projects, but all seek to lower engine emissions or to show that existing emissions technology meets current standards. Discussed in this section are some of the past research projects that have dealt with small engine emissions.

\subsubsection{Swiss Environmental Protection Agency (1999)}

In order to comply with the Swiss Clean Air Act of 1998, the Swiss Environmental Protection Agency sought to reduce the emissions from small engines used in agricultural applications [2]. They performed tests on two engine designs used in an agricultural walk behind mower. Both of the 4-stroke SI engines were in the range of 8 - $10 \mathrm{~kW}(10.7-13.4 \mathrm{hp})$, one having a side-valve configuration and one having an overhead valve configuration. A commercially available 3-way catalytic converter system was implemented and a special gasoline formulation was tested in order to provide a reduction in emissions and fuel consumption. The special fuel was an aromatic free gasoline produced by the ASPEN Corporation according to the Swiss standard SN 181163 [4].

The first engine was a Briggs and Stratton Vanguard 2-cylinder engine rated at $9.2 \mathrm{~kW}$ at 3600 RPM. This engine used an overhead valve configuration. The second engine was a Briggs and Stratton single cylinder engine rated at $8.1 \mathrm{~kW}$ at $3600 \mathrm{RPM}$. This engine had an older side valve configuration. This older design was tested in order to document how the technical design improvements of the engines affected emissions. 
The test cycle used was the ISO 8187 Type G test, and was a steady state cycle that represented the typical use of these engines in the field. The emissions of carbon monoxide (CO), hydrocarbons $(\mathrm{HC})$ and oxides of nitrogen $\left(\mathrm{NO}_{\mathrm{x}}\right)$ were measured, as well as power and fuel consumption. The $\mathrm{CO}, \mathrm{HC}$ and $\mathrm{NO}_{\mathrm{x}}$ measurements were taken according to standard procedures using a raw sampling system. Volatile Organic Compound (VOC) measurements were restricted to the following tests points:

- Low idle at 1300 RPM

- $75 \%$ load at $2800 \mathrm{RPM}$

The testing for VOC was done by continuously drawing exhaust gas through a heated filter and diluting with nitrogen. The samples were collected in Tedlar bags and analyzed within four hours by means of gas chromatography (GC) with flame ionization detection (FID) using two different GC systems for the low and midrange HC [2]. Particulate matter (PM) was measured using a standard dilution tunnel with a dilution ratio of 1.5 and a temperature of less than $52^{\circ} \mathrm{C}$. Particulate number and particulate substance were analyzed using Scanning Mobility Particle Analyzer (SMPS) [2]. The results shown in Table 1 are the weighted averages according to the ISO 8187 G Cycle.

Table 1 - Swiss Environmental Protection Agency Emissions Results [2]

\begin{tabular}{|l|c|c|c|c|}
\hline $\begin{array}{c}\text { Emissions, Fuel } \\
\text { Consumption } \\
(\mathbf{g} / \mathbf{k W h})\end{array}$ & $\begin{array}{c}\text { Standard } \\
\text { fuel without } \\
\text { catalyst }\end{array}$ & $\begin{array}{c}\text { Standard fuel } \\
\text { with catalyst }\end{array}$ & $\begin{array}{c}\text { Alcylate } \\
\text { gasoline without } \\
\text { catalyst }\end{array}$ & $\begin{array}{c}\text { Alcylate gasoline } \\
\text { with catalyst }\end{array}$ \\
\hline $\mathrm{HC}$ & 9.1 & 0.7 & 9.0 & 0.7 \\
\hline $\mathrm{NO}_{\mathrm{x}}$ & 3.5 & 6.3 & 2.3 & 4.5 \\
\hline $\mathrm{CO}$ & 280 & 13.1 & 273 & 10.2 \\
\hline
\end{tabular}

These results show that the catalytic converter reduced the $\mathrm{HC}$ emissions by $92 \%$ and the $\mathrm{CO}$ by $96 \%$. The increase in $\mathrm{NO}_{\mathrm{x}}$ was accepted as a consequence of the lean air fuel mixture. 
There was a $10 \%$ improvement in fuel consumption.

In summary, the 3-way catalytic converter reduced the exhaust gas emissions significantly. The use of the non-aromatic gasoline also curtailed VOC emissions to a few percent [2]. The OVH-engine showed no serious emissions of ultrafine particulate [2]. At the time, alcylate gasoline was comparatively expensive to normal gasoline. In addition, the absolute fuel consumption of these engines is very small and so the cost of fuel is not significant.

\subsubsection{Southwest Research Institute (1999)}

Emission tests were performed on four small SI engines by the Southwest Research Institute [5]. The goal of the tests was to make sure that the engines would meet the California Air Resource Board's (CARB) proposed 1999 emissions standards. Baseline tests were compared against tests done after modifications were performed to help the engines meet the standards. The four engines were model year 1997, high sale volume CARB-certified engines. Information for the engines is shown in Table 2.

Because the engines were new, they were broken in before doing the baseline testing. This was done by operating each engine according to the manufacturer's recommended break in period. The engines were tested using a dilute sampling system. A 2-mode cycle was used for the handheld engine and a 6-mode cycle was used for the non-handheld engines. Duplicate emission tests were conducted on each engine.

The techniques used to reduce emissions were air/fuel ratio optimization via carburetor modifications and catalytic after treatment. After the implementation of the emissions reduction strategies, all four engines met CARB's original 1999 tier 2 emissions standards [5]. The results from the four engines are shown in Table 3. 
Table 2 - Southwest Research Institute (1999) Test Engine Information [5]

\begin{tabular}{|c|c|c|c|c|c|c|}
\hline \multicolumn{1}{|c|}{ Engine } & \multicolumn{3}{c|}{ Equipment } \\
\hline Type & Manu. & Model & Displ. (cc) & Type & Manu. & Model \\
\hline Non-handheld OHV & Honda & GX-160 & 163 & $\begin{array}{c}\text { Pressure } \\
\text { washer }\end{array}$ & $\begin{array}{c}\text { Northern } \\
\text { Hydraulics }\end{array}$ & $\begin{array}{c}\text { Northstar } \\
157890 \mathrm{~A}\end{array}$ \\
\hline Hon-handheld SV & $\begin{array}{c}\text { Briggs } \\
\text { and } \\
\text { Stratton }\end{array}$ & 9 & 148 & $\begin{array}{c}\text { Lawn } \\
\text { edger }\end{array}$ & $\begin{array}{c}\text { Power } \\
\text { Trim Co. }\end{array}$ & 150 \\
\hline Handheld 2-Stroke & Ryobi & $990 \mathrm{R}$ & 26 & $\begin{array}{c}\text { String } \\
\text { trimmer }\end{array}$ & Ryobi & 990R \\
\hline
\end{tabular}

Table 3 - Summary of Emission Test Results [5]

\begin{tabular}{|l|c|c|c|c|c|}
\hline \multirow{2}{*}{ Engine } & \multirow{2}{*}{ Test } & \multicolumn{3}{|c|}{ Emissions (g/hp-hr) } \\
\cline { 2 - 6 } & & $\mathbf{H C}$ & $\mathbf{C O}$ & $\mathbf{N O}$ & $\mathbf{H C}+\mathbf{N O}_{\mathbf{x}}$ \\
\hline \multirow{3}{*}{ Honda } & Baseline & 6.00 & 200 & 1.54 & 7.54 \\
\hline \multirow{3}{*}{ Briggs and Stratton } & Developmental Raw Results & 2.78 & 65.6 & 0.25 & 3.03 \\
\cline { 2 - 6 } & Reduction from Baseline (\%) & $\mathbf{5 4}$ & $\mathbf{6 7}$ & $\mathbf{8 4}$ & $\mathbf{6 0}$ \\
\cline { 2 - 6 } & Baseline & 10.3 & 357 & 1.75 & 12.0 \\
\cline { 2 - 6 } & Developmental Raw Results & 2.24 & 64.2 & 0.90 & 3.14 \\
\cline { 2 - 6 } & Reduction from Baseline (\%) & $\mathbf{7 8}$ & $\mathbf{8 2}$ & $\mathbf{4 9}$ & $\mathbf{7 4}$ \\
\hline \multirow{3}{*}{ Ryobi } & Baseline & 29.3 & 467 & 0.90 & 0.56 \\
\hline \multirow{3}{*}{ Handheld 2 Stroke } & Developmental Raw Results & 2.68 & 87 & 0.35 & 0.13 \\
\cline { 2 - 6 } & Reduction from Baseline (\%) & $\mathbf{9 1}$ & $\mathbf{8 1}$ & $\mathbf{6 1}$ & $\mathbf{7 7}$ \\
\cline { 2 - 6 } & Baseline & 113 & 233 & 0.72 & 3.85 \\
\cline { 2 - 6 } & Developmental Raw Results & 19 & 63.2 & 1.05 & 0.05 \\
\cline { 2 - 6 } & Reduction from Baseline (\%) & $\mathbf{8 3}$ & $\mathbf{7 3}$ & $\mathbf{- 4 6}$ & $\mathbf{9 9}$ \\
\hline
\end{tabular}

In summary, these emission tests show that CARB's originally proposed 1999 emission standards for small off road engines were readily achieved through air/fuel ratio control and catalytic exhaust after treatment [5]. The cost of the after treatment devices was low while still providing satisfactory results. With the small size of the catalytic converters, the size of the engine packages would remain the same or increase slightly, while the weight of the engine package would increase slightly. 


\subsubsection{Southwest Research Institute (2004)}

In 2004, the Southwest Research Institute performed a study seeking to reduce the emissions of small off-road engines [6]. The goal of the study was to determine if currently available catalyst technology could provide a 50 percent or greater reduction in $\mathrm{HC}$ and $\mathrm{NO}_{\mathrm{x}}$ for the engines throughout their anticipated service lives. Five engines were selected for the tests, all of which met the current California Air Resources Board (CARB) Tier II standards for small off-road engines.

The five engines selected included four that would be used in a walk behind mower, one used in a riding mower and one used in a constant-speed generator. All of the engines except the one used in a riding mower, were single cylinder engines. All were naturally aspirated, air cooled, four-stroke, carbureted engines with overhead valves. The information for the five engines is shown in Table 4. The catalysts used for the testing were all three-way formulations on metallic substrates. In order to maintain an overall small profile for the engine, all catalysts were integrated into stock mufflers.

Table 4 - Southwest Research Institute (2004) Test Engine Information [6]

\begin{tabular}{|l|c|c|c|c|}
\hline \multicolumn{1}{|c|}{ Mfg. } & Application & Model & Displ. (cc) & Power (hp) \\
\hline $\begin{array}{l}\text { Briggs and } \\
\text { Stratton }\end{array}$ & $\begin{array}{c}\text { Walk-behind } \\
\text { Mower }\end{array}$ & YBSXS.1901VE Intek & 190 & 6.5 \\
\hline Tecumseh & $\begin{array}{c}\text { Walk-behind } \\
\text { Mower }\end{array}$ & YTPXS.1951AA OVRM 120 & 195 & 6.5 \\
\hline Honda & $\begin{array}{c}\text { Walk-behind } \\
\text { Mower }\end{array}$ & 2HNXS.1611AK GCV160 & 160 & 5.5 \\
\hline Kawasaki & $\begin{array}{c}\text { Riding } \\
\text { Mower }\end{array}$ & YKAX6752QA FH601V & 675 & 19 \\
\hline Honda & Generator & $\begin{array}{c}\text { 2HNX.3892AK GX- } \\
\text { 340QA2 }\end{array}$ & 340 & 11 \\
\hline
\end{tabular}

Steady state emissions tests were performed on the engines, at certain intervals over the 
ageing process. The Briggs and Stratton, Tecumseh, and Honda GCV160 engines were aged for 250 hours with emissions testing performed at 0,125 , and 250 hours. The Kawasaki and Honda GX340 engines were aged for 500 hours with emissions testing at $0,125,250$ and 500 hours. As evident from the results of the emissions tests shown in Table 5, the emissions reduction techniques were proven to be a success [6]. All engines showed a significant reduction in $\mathrm{HC}+$ $\mathrm{NO}_{\mathrm{x}}$

Table 5 - Southwest Research Institute (2004) Effect of Three-Way Catalyst and Engine Ageing on Emissions [6]

\begin{tabular}{|l|c|c|c|c|c|c|c|c|}
\cline { 2 - 9 } \multicolumn{1}{c|}{} & \multicolumn{9}{c|}{ Test Interval (hours) } \\
\cline { 2 - 10 } \multicolumn{1}{c|}{} & \multicolumn{2}{c|}{$\mathbf{0}$} & \multicolumn{2}{c|}{$\mathbf{1 2 5}$} & \multicolumn{2}{c|}{$\mathbf{2 5 0}$} & \multicolumn{2}{c|}{$\mathbf{5 0 0}$} \\
\hline $\begin{array}{l}\text { HC+NO } \\
\text { (g/bhp-hr) }\end{array}$ & Stock & $\begin{array}{c}\text { Low- } \\
\text { Emission }\end{array}$ & Stock & $\begin{array}{c}\text { Low- } \\
\text { Emission }\end{array}$ & Stock & $\begin{array}{c}\text { Low- } \\
\text { Emission }\end{array}$ & Stock & $\begin{array}{c}\text { Low- } \\
\text { Emission }\end{array}$ \\
\hline Briggs and Stratton & 9.2 & 4.1 & 14.9 & 8.2 & 16.2 & 9.8 & - & - \\
\hline Tecumseh & 6.8 & 2.4 & 10.1 & 4.5 & 10.4 & 2.9 & - & - \\
\hline Honda GCV160 & 8.4 & 2.3 & 10.4 & 2.1 & 10.7 & 2.4 & - & - \\
\hline Kawasaki FH601V & 7.5 & 1.5 & 6.8 & 1.7 & 8.4 & 1.9 & 7.6 & 2.4 \\
\hline Honda GX - 340 & 6.5 & 1.8 & 6.7 & 2.3 & 7.6 & 1.8 & 7.9 & 2.7 \\
\hline
\end{tabular}

\subsubsection{Polytechnic University of Turin (2005)}

In 2005, a study was performed at the Polytechnic University of Turin in order to determine the effect of variation of compression ratio and injection pressure on the emissions and performance of a small displacement off-road diesel engine [7]. The general purpose of the study was to reduce tailpipe emissions in order to meet the regulations that were expected to come into effect in the near future. The focus was to make an improvement in both the PM and $\mathrm{NO}_{\mathrm{x}}$ emissions while keeping fuel consumption and combustion noise at acceptable levels. The engine selected for this study was a direct injection, diesel engine and its main characteristics are given in Table 6. 
Table 6 - Characteristics of the Tested DI Diesel Engine [7]

\begin{tabular}{|l|c|}
\hline Type & Diesel 4 stroke \\
\hline Cylinder Arrangement & 2 in-line \\
\hline Displacement & $954 \mathrm{~cm}^{3}$ \\
\hline Bore & $90 \mathrm{~mm}$ \\
\hline Stroke & $75 \mathrm{~mm}$ \\
\hline Baseline CR & $19: 01$ \\
\hline Number of Valves & 2 valves per cylinder \\
\hline Fuel Metering System & Direct Injection with Common Rail \\
\hline Air Metering System & Naturally aspirated \\
\hline Maximum Power & $15.8 \mathrm{~kW} @ 3600 \mathrm{rpm}$ \\
\hline Maximum Torque & 44Nm@ 2600 rpm \\
\hline
\end{tabular}

The injection parameters for the engine were controlled by a computer that was connected to the engine control unit (ECU). A piezoelectric pressure transducer, along with a Kistler charge amplifier was used to measure the in-cylinder pressure. Fuel consumption was measured using a gravimetric fuel meter. PM was measured using an AVL 425S smoke meter. The $\mathrm{CO}$ and $\mathrm{CO}_{2}$ measurements were made with a Non-Dispersive Infrared Analyzer (NDIR) analyzer. A paramagnetic analyzer was used for the $\mathrm{O}_{2}$ measurements. A Chemiluminescence Detector (CLD) analyzer was used for the $\mathrm{NO}_{\mathrm{x}}$ measurements. A Flame Ionization Detection (FID) analyzer was used for the HC measurements. All gaseous emissions were measured using a Fisher-Rosemount raw gas analyzer [7].

The compression ratio (CR) of the engine was varied by using a different piston that had a deeper bowl, with the same bowl architecture. The baseline compression ratio was 19, and the CR of the deeper bowl piston was 17.5:1. For each compression ratio, tests were performed where the start of injection (SOI) was varied from $5^{\circ}$ before top dead center (BTDC) to $13^{\circ}$ BTDC in order to obtain PM versus $\mathrm{NO}_{\mathrm{x}}$ trade-off curves. Results from these tests showed that for both CR setups, $\mathrm{NO}_{\mathrm{x}}$ emissions increased as the $\mathrm{SOI}$ increased. The $\mathrm{CR}$ of 17.5 produced an average of $1.7 \mathrm{~g} / \mathrm{kWh}$ of $\mathrm{NO}_{\mathrm{x}}$ more than the $\mathrm{CR}$ of 19 . PM was affected by the changes in CR 
and SOI inversely compared to the $\mathrm{NO}_{\mathrm{x}}$ relationship. PM decreased as SOI increased for both CR setups. The CR of 17.5 produced an average of $2.0 \mathrm{~g} / \mathrm{kWh}$ of PM less than the CR of 19 . These sets of data allow for a relationship between $\mathrm{PM}$ and $\mathrm{NO}_{\mathrm{x}}$ to be established for both $\mathrm{CR}$ and SOI variations. Three different injection pressures levels of 400, 550, and 700 bar were also tested while keeping the low compression ratio of 17.5:1. PM and $\mathrm{NO}_{\mathrm{x}}$ were recorded during the series of test in which the SOI was also varied.

In conclusion, a large reduction in $\mathrm{PM}$ was obtained while keeping $\mathrm{NO}_{\mathrm{x}}$ constant. A slightly higher level of combustion noise was measured. The brake specific fuel consumption showed a significant increase but considering the small amount of power delivered by the engine, the percentage increase in BSFC resulted in a modest increase of the absolute fuel consumption, and therefore can be regarded as acceptable. Table 7 shows the change in $\mathrm{NO}_{\mathrm{x}}$, $\mathrm{PM}$, noise and BSFC between the two configurations.

Table 7 - Effects of the Variation of Compression Ratio and Injection Pressure on the Engine; Comparison between Baseline and Final Configuration [7]

\begin{tabular}{|l|l|}
\hline$\Delta \mathrm{NO}_{\mathrm{x}}(\%)$ & $\sim 0 \%$ \\
\hline$\Delta \mathrm{PM}(\%)$ & $-53 \%$ \\
\hline$\Delta$ Combustion Noise $(\mathrm{dBA})$ & $+0.7 \mathrm{dBa}$ \\
\hline$\Delta$ BSFC $(\%)$ & $+6.5 \%$ \\
\hline
\end{tabular}

\subsubsection{Horiba (2007)}

The goal of the study conducted by Horiba was to investigate the particulate emissions from small off-road engines [8]. A particle counting system was developed according to the European Particle Measurement Program. The study was limited to counting only solid and volatile particle emissions from a small diesel engine used in an electric generator. It was found that the small diesel engine used in the generator emitted a very large number of volatile particles 
depending on the operating condition [8].

The engine was operated at different conditions including idle, $100 \mathrm{~W}, 200 \mathrm{~W}$, and $400 \mathrm{~W}$ load. For each load point, the engine speed was kept constant at $3600 \mathrm{rpm}$. The conditions for the test are shown in Table 8, where PND1 is the first stage diluter, PND2 is the second stage diluter, and $\mathrm{EU}$ is the evaporation unit.

Table 8 - Horiba Test Conditions [8]

\begin{tabular}{|l|c|c|c|c|}
\hline Speed (rpm) & 3600 & 3600 & 3600 & 3600 \\
\hline Load $(\mathrm{W})$ & 0 & 100 & 200 & 400 \\
\hline PND1 T $\left({ }^{\circ} \mathrm{C}\right)$ & $30-150$ & $30-150$ & $30-150$ & $30-150$ \\
\hline PND1 DF & 40 & 40 & 40 & 40 \\
\hline EU T $\left({ }^{\circ} \mathrm{C}\right)$ & $50-350$ & $50-350$ & $50-350$ & $50-350$ \\
\hline PND2 T $\left({ }^{\circ} \mathrm{C}\right)$ & 30 & 30 & 30 & 30 \\
\hline PND2 DF & 45 & 45 & 45 & 45 \\
\hline
\end{tabular}

For the test discussed here, the PND1 dilution air was set to $150^{\circ} \mathrm{C}$ and the evaporator unit temperature was set to $350^{\circ} \mathrm{C}$ [8]. It was assumed that the particles present were solid only. It was clear from the data that solid particle emissions increased with an increase in operating load. This can be associated with the reduction of the air/fuel ratio. When the engine was being run at a constant speed and the load increased, the amount of fuel being injected increased, which caused the formation of local rich mixture and therefore the solid particle emission increased [8]. This test showed the relationship between the EU temperature and particle emissions under different load conditions. For this set of tests the dilution air temperature was $150^{\circ} \mathrm{C}$. From this data, it was determined that the condition when the EU temperature and PND1 dilution air temperatures were 350 and $150^{\circ} \mathrm{C}$ respectively, was when the maximum soot occurred. However, it was clear that when the EU temperature decreased under the idling condition, there was a huge volatile particle formation [8].

In conclusion, it can be safely said that solid and volatile particle emissions can be 
affected by controlling the dilution air temperature and the evaporation unit temperature. It is possible to remove almost all of the volatile particles from the exhaust by diluting it under high temperatures followed by re-heating the sample. Although the diesel powered engine used in this study emitted high volatile particles at almost all operating conditions, the solid particles increased with an increase in operating load and the volatile particles decreased with an increase in operating load [8].

\subsubsection{Kubota (2007)}

In this paper, Kubota introduced a set of technologies for use with a new in-direct injection (IDI) diesel engine [9]. According to Kubota, IDI engines were the mainstream design for small industrial diesel engines. They stated that the characteristics of this type of engine include high power density as well as low emissions. The engine optimized the combustion and injection systems and therefore reduces PM emission in the high torque region at low and middle engine speeds [9]. The specifications for the two test engines are shown in Table 9.

Table 9 - Kubota Engines Specifications [9]

\begin{tabular}{|l|c|c|}
\hline Model & D1105 & D1305 \\
\hline No. of Cylinders & 3 & 3 \\
\hline Bore x Stroke (mm) & $78 \times 78.4$ & $78 \times 88.0$ \\
\hline Displacement (L) & 1.123 & 1.261 \\
\hline $\begin{array}{l}\text { Brake Horsepower Gross } \\
\text { Intermittent (kW/rpm) }\end{array}$ & $18.5 / 3000$ & $27.7 / 3000$ \\
\hline Length x Width x Height $(\mathrm{mm})$ & $498 \times 396 \times 605$ & $498 \times 396 \times 591$ \\
\hline
\end{tabular}

In order to increase the power density of the engine and keep low emissions, certain modifications were made to the engines. The displacement was increased by lengthening the stroke while still maintaining the compact dimensions of the engine. Improvements of the cooling performance had to be achieved in order to secure sufficient durability of the engine with 
its higher output. A new cooling channel was introduced because the conventional drilled holes between the cylinders did not have enough cooling performance. Computational fluid dynamic (CFD) models were used to optimize the cooling channel's design while balancing the cooling performance with cylinder rigidity [9].

Because of the high-durability, the low cost and compactness requirements of small diesel engines, it was difficult to use advanced emission reduction devices. Therefore, it was more realistic to optimize combustion and injection systems in order to achieve emission regulations. Combustion gas flow control including gas flow in the swirl chamber was analyzed and optimized in order to reduce PM emissions [9]. Also, a new injector was tested which proved to reduce PM emission by increasing fuel penetration into the chamber. The new injector was shown to reduce PM emission by $33 \%$ in the peak torque region [9]. As a result of these multiple emission reduction techniques, PM emissions were drastically reduced by approximately $50 \%$.

\subsection{Emissions Formation}

In an internal combustion engine, the formation of emissions is not simple. There are many variables that affect the final outcome of the combustion process. Complex chemical reactions control the formation process of each chemical species and are very sensitive to many environmental factors. These reactions occur when ambient air is drawn into the engine and is mixed with vaporized fuel which then combusts and forms new gases while expanding and releasing heat. In a traditional spark ignition (SI) engine, the fuel is mixed with the ambient air before entering the cylinder. In a compression ignition (CI) engine, the fuel is injected directly into the cylinder after the intake air has been compressed to a high temperature and pressure.

Equation 1 shows the major compounds involved in combustion for a typical hydrocarbon fuel. This is a general equation and does not show the actual mass balance of 
elements throughout the process. There are actually more products produced than shown in this general equation. The equation assumes only oxygen and nitrogen in the intake air but in reality, there are many more gases due to exhaust gas recirculation (EGR) and other naturally occurring elements. There are trace amounts of sulfur and other elements in fuels, which can produce sulfur dioxide and other compounds. Additional products that may form during combustion are; $\mathrm{OH}, \mathrm{NO}, \mathrm{NO}_{2}, \mathrm{O}, \mathrm{H}, \mathrm{HC}$, and $\mathrm{PM}$. $\mathrm{NO}_{\mathrm{x}}$ is the collective quantity of $\mathrm{NO}$ and $\mathrm{NO}_{2}$. The elements of the exhaust gas that are regulated include $\mathrm{CO}, \mathrm{NO}_{\mathrm{x}}, \mathrm{HC}$, and $\mathrm{PM} . \mathrm{CO}_{2}$ is not regulated but has recently become a concern due to its association with global warming.

$$
\begin{aligned}
& \text { Equation } 1-\text { Basic Chemical Equation for Combustion } \\
& \mathrm{C}_{X} \mathrm{H}_{X}+\mathrm{O}_{2}+\mathrm{N}_{2} \rightarrow \mathrm{H}_{2} \mathrm{O}+\mathrm{CO}+\mathrm{CO}_{2}+\mathrm{O}_{2}+\mathrm{N}_{2}+\mathrm{NO}_{x}
\end{aligned}
$$

There are many factors that will determine the composition of the exhaust gases. These factors include but are not limited to: composition of the fuel, temperature of combustion, and the air to fuel ratio. Differences in diesel and gasoline engine designs inherently cause different conditions during combustion and therefore different emissions. CI and SI engines typically operated at different air to fuel ratios which affects the combustion process and also the exhaust gas composition. Diesel engine exhaust has considerable amounts of oxygen $\left(\mathrm{O}_{2}\right)$ because of the lean air to fuel ratio, with minimal amounts of $\mathrm{CO}$ and $\mathrm{HC}$. Spark ignition engines produce $\mathrm{CO}$, and $\mathrm{HC}$ when running rich and emit $\mathrm{O}_{2}$ when running lean [10]

The actual formation of the each exhaust gas occurs at a different time during the combustion and exhaust process. The primary combustion process is responsible for the formation of exhaust components such as $\mathrm{CO}$ and organic compounds. The environment after the combustion process is responsible for the formation of $\mathrm{NO}_{\mathrm{x}}$ and $\mathrm{SO}_{2}$ [10]. One important emission component that is not part of the chemical combustion process is $\mathrm{HC}$. 
$\mathrm{HC}$ emissions originate from unburned air-fuel mixtures that escape the combustion process. Most of the $\mathrm{HC}$ escapes by being forced into crevices and small areas around the cylinder during the compression stroke. The combustion flame is not able to enter these small spaces. These gases survive the main combustion process and are released from the crevices during the expansion and exhaust strokes. Another source of $\mathrm{HC}$ emissions is from thin films of oil left on the cylinder wall. Oil can absorb $\mathrm{HC}$ before combustion and then release it after combustion, allowing a portion of the total $\mathrm{HC}$ to be left unburned [10]. The third source of HC occurs when the combustion flame goes out before as it approaches the cylinder wall. This leaves a thin layer of unburned $\mathrm{HC}$ around the cylinder wall.

\subsection{Emissions Reduction Techniques}

When most people think of emission reduction techniques, they usually think of active reduction techniques such as after-treatment devices, but in reality, there are many ways to reduce engine emissions. Passive reduction methods such the optimization of engine parameters such as fuel injection pressure, injection timing and the optimization of the combustion system can drastically reduce emissions. Both active and passive techniques play an important role in the reduction of engine emissions and are both discussed here.

\subsubsection{Turbocharger and Intercooler}

A turbocharger is a device that compresses the intake air of the engine. It does this by using otherwise wasted energy in the exhaust gas. The exhaust passes through a turbine which is on the same shaft as a compressor for the intake air. The compressor then spins and provides additional pressure to the intake system. This allows for more fuel and air to be forced into the engine, causing an increase in power. Cooling of the air after the compressor is important. The compression process causes the air to increase in temperature and will offset the previously 
mentioned benefits if an intercooler is not used. The lower air intake temperature increases the density of the air and allows for more air and fuel to be compressed into the combustion chamber.

Traditionally, turbochargers are known for their ability to increase the performance and efficiency of the engine. What is also true about them is that they can indirectly have a positive impact on the emissions of the engine. It has been found that it is possible to use smaller engines while still receiving the necessary power because of the increase in efficiency and power density that turbocharging provides. This means that the combination of turbocharging and engine downsizing has many advantages in not only emission reduction but also engine efficiency and power. It has been shown that turbocharging on both diesel and gasoline engines can provide a cost effective way of reducing emissions [12].

\subsubsection{Exhaust Gas Recirculation}

EGR has proven to be a very successful $\mathrm{NO}_{\mathrm{x}}$ reduction technique. An exhaust gas recirculation system is a system that reroutes a small amount of gas from the exhaust system. The gas is then cooled and reintroduced back to the intake manifold. The gas mixes with the intake air and then enters the combustion chamber and mixes with the fuel for combustion. The small amount of exhaust gas, which can be considered to be mostly $\mathrm{N}_{2}, \mathrm{CO}$ and $\mathrm{H}_{2} \mathrm{O}$, replaces a small amount of air consisting of mostly $\mathrm{O}_{2}$ and $\mathrm{N}_{2}$. In general, up to $30 \%$ of exhaust gas can be recirculated [10].

An EGR system will have many effects on the combustion process of a diesel engine, but will have two main effects on the levels of certain exhaust gases. The EGR system significantly affects the levels of $\mathrm{NO}_{\mathrm{x}}$ emissions as well as PM and soot emissions. Both of these exhaust components are considered to be problematic pollution contributors and are not wanted. 
Engine efficiency, fuel economy, engine emissions and engine knock are all important issues affected by EGR. The extent to which EGR affects the combustion process and the previously mentioned emissions components, is determined by what percentage of the intake mixture is recirculated gas, and by the amount of heat that is removed from the hot exhaust gas. The cooling of the EGR gas through a heat exchanger is extremely important when ensuring the maximum benefits to the engine. Without cooling the EGR gas, the high temperature of the exhaust gas would offset some of the desirable effects that the system is designed to provide. In effect, a properly cooled EGR system can prove to be a great mechanism to lower harmful emissions with an acceptable penalty to fuel efficiency, power or other important engine parameters.

The main parameter that determines the level of $\mathrm{NO}_{\mathrm{x}}$ emissions is the combustion flame temperature. When an EGR system substitutes carbon dioxide and water for oxygen and nitrogen in the intake air mixture, the combustion flame temperature decreases. The specific heat capacity of both carbon dioxide and water are both greater than those of nitrogen and oxygen [14]. Because of this, the use of EGR causes the average heat capacity of the intake mixture to increase. This increase in heat absorbing capacity of the combustion lowers the flame temperature of combustion. This change in temperature causes a profound effect on the $\mathrm{NO}_{\mathrm{x}}$ emissions because the $\mathrm{NO}_{\mathrm{x}}$ formation mechanism is extremely sensitive to temperature. For example: a $20^{\circ} \mathrm{C}$ reduction of flame temperature could reduce the $\mathrm{NO}_{\mathrm{x}}$ concentration in the exhaust by as much as $20 \%$ [14]. It has been shown that by lowering the temperature of the intake air by only $6^{\circ} \mathrm{C}$, the exhaust $\mathrm{NO}_{\mathrm{x}}$ emissions decrease by approximately 50 parts per million (ppm) [14].

In addition to lowering the flame temperature through increasing the heat absorbing 
capacity, EGR also reduces the flame temperature by another method. The oxygen replacement by carbon dioxide and water reduces the availability of the oxygen for the combustion process, and causes a reduction of the oxygen to fuel ratio. This reduction in oxygen concentration in the combustion chamber interferes with the fuel oxidation rate and reduces the flame temperature; this in turn reduces the $\mathrm{NO}_{\mathrm{x}}$ production [15].

The reduction in flame temperature due to the reduction of oxygen availability is the dominant $\mathrm{NO}_{\mathrm{x}}$ suppressing mechanism. Wilson et al. estimated that with $30 \% \mathrm{EGR}$, the flame temperature would be suppressed by $11 \%$ due to the reduction in oxygen concentration and $2 \%$ due to the increase in the mean value of the specific heat capacity [14]. Exhaust smoke and particulate levels are generally considered to increase with the use of exhaust gas recirculation. The first reason is that the lower percentage of oxygen in the combustion process reduces soot oxidation. The second reason for the increased level of soot production is that the reduction in flame temperature reduces the soot oxidation rate and therefore results in a larger amount of soot emitted by the combustion process [15]. Table 10 shows the relationship between the increase in EGR and the smoke emissions. 
Table 10 - The Effect of EGR on Smoke Emissions and the Oxygen to Fuel Ratio [1512]

\begin{tabular}{|c|c|c|c|c|c|}
\hline $\begin{array}{c}\text { Load } \\
(\mathrm{Nm})\end{array}$ & $\begin{array}{c}\text { EGR } \\
(\%)\end{array}$ & $\begin{array}{c}\text { Fuel Flow } \\
(\mathrm{kg} / \mathrm{hr})\end{array}$ & $\begin{array}{c}\text { Air/Fuel } \\
(\mathrm{kg} / \mathrm{kg})\end{array}$ & $\begin{array}{c}\mathrm{O}_{2} / \text { fuel } \\
(\mathrm{kg} / \mathrm{kg})\end{array}$ & $\begin{array}{c}\text { Smoke } \\
(\text { Bosch })\end{array}$ \\
\hline 200 & 0 & 9.20 & 22.92 & 5.27 & 2.0 \\
\hline 200 & 2 & 9.31 & 20.07 & 4.65 & 3.6 \\
\hline 120 & 1.2 & 5.88 & 29.41 & 6.81 & 1.0 \\
\hline 120 & 7.6 & 6.08 & 24.31 & 5.80 & 1.7 \\
\hline 120 & 14.8 & 6.20 & 20.06 & 4.89 & 3.8 \\
\hline 80 & 8.7 & 4.14 & 33.30 & 8.10 & 0.5 \\
\hline 80 & 16.9 & 4.29 & 26.92 & 6.79 & 0.9 \\
\hline 80 & 24 & 4.41 & 22.02 & 5.62 & 2.4 \\
\hline 40 & 24 & 2.67 & 36.59 & 10.15 & 0.6 \\
\hline 40 & 34.6 & 2.77 & 29.26 & 8.74 & 0.7 \\
\hline 40 & 37.7 & 2.67 & 27.62 & 8.20 & 2.3 \\
\hline
\end{tabular}

Another significant effect from EGR on soot oxidation rates is its ability to cause a decrease in combustion flame temperature. Although this decrease in flame temperature causes a decrease in the rate of oxidation and therefore a higher rate of soot emissions, the high temperature of the EGR gas can counter act the effect of lowering the flame temperature due to the lowering of the heat capacity. The solution to this is not to decrease the EGR to eliminate soot production, but to cool the gas through a heat exchanger. Cooling the exhaust gas will allow for a normal intake temperature while still lowering the flame temperature due to carbon dioxide and water replacing oxygen and nitrogen through the EGR system. Cooled EGR also makes it possible to have more air enter the engine and so PM can also be reduced.

In conclusion, the process of exhaust gas recirculation in diesel engines has many advantages in emission control. It also has some slight negative effects on some emissions, power generation and therefore fuel consumption. By increasing the heat absorbing capacity and by reducing the oxygen availability, EGR reduces the flame temperature of combustion and 
therefore reduces the rate of $\mathrm{NO}_{x}$ production. This reduction in oxygen availability also slows the soot oxidation rate and causes an increase in smoke and particulate matter emissions.

\subsubsection{Aftertreatment Devices}

Aside from engine design modifications and systems such as EGR, it is possible to reduce pollutants from the exhaust gases using after treatment devices. Different devices will remove different components of the exhaust gas depending upon their design and engine operating conditions. Catalytic converters can help to reduce $\mathrm{HC}, \mathrm{CO}$ and $\mathrm{NO}_{\mathrm{x}}$. More specifically, oxidizing catalysts help reduce $\mathrm{HC}$ and $\mathrm{CO}$, while reducing catalysts help reduce

$\mathrm{NO}_{\mathrm{x}}$. Three-way catalysts for SI engines help reduce all three pollutants. Thermal reactors help reduce $\mathrm{HC}$ and $\mathrm{CO}$, and filters or particulate traps help remove PM [10].

Three-way catalytic converters are most common in SI engines due to their ability to reduce $\mathrm{HC}, \mathrm{CO}$ and $\mathrm{NO}_{\mathrm{x}}$ all at once. Certain conditions must exist for all three pollutants to be efficiently removed. This high efficiency is achieved when the engine runs close to or at a stoichiometric air to fuel ratio [10].

Thermal reactors are devices that enhance the oxidation of $\mathrm{CO}$ and $\mathrm{HC}$ after passage through the exhaust port. A thermal reactor is an enlarged exhaust manifold that bolts directly onto the cylinder head. This reactor helps mix the exhaust gases with additional air which is injected into the exhaust manifold. This helps makes the temperature and composition of the gases more uniform which will in turn allow sufficient time for the HC and CO to oxidize [10]. Thermal reactors are typically used with SI engines. $\mathrm{NO}_{\mathrm{x}}$ emissions are not affected by thermal reactors and so they do not benefit CI engines which already produce low levels of HC.

Diesel particulate filters (DPF) are mostly used with diesel engines because of the high amounts of PM they emit. Types of particulate filters include: ceramic monoliths, alumna-coated 
wire mesh, ceramic foam, ceramic fiber mat, woven silica-fiber rope wound on a porous tube. Each of these has different inherent pressure loss and filtering efficiency. Once PM becomes accumulated on the DPF to the point where it clogs the flow, a regeneration process is needed to burn off the PM. For Diesel PM, the ignition temperature is between $500^{\circ} \mathrm{C}$ and $600^{\circ} \mathrm{C}[10]$. This temperature is above the temperature of diesel exhaust and so one of two things must be done. Either the gas moving through the DPF must be heated or the ignition temperature must be lowered. When the gas is heated in order to regenerate the DPF, this is called positive regeneration. When the ignition temperature is lowered through catalytic coating materials, this is called catalytic regeneration. Using these techniques, PM emissions from the engine can be reduced by $70 \%$ or more [10].

\subsection{Impact on Human Heath}

One of the primary concerns of the United States Environmental Protection Agency (EPA) and the California Air Resources Board (CARB) are the health effects of each of the components of the emissions of internal combustion (IC) engines. Current emissions regulations concentrate on four major components; $\mathrm{HC}, \mathrm{PM}, \mathrm{CO}$, and $\mathrm{NO}_{\mathrm{x}} . \mathrm{CO}_{2}$ is becoming more of a concern because of its association with global warming, but is not yet regulated [16].

The National Institute for Occupational Safety and Health (NIOSH), the International Agency for Research on Cancer (IARC), the Health Effects Institute (HEI), the World Health Organization (WHO) have all acknowledged potential health effects from contact with diesel exhaust [11].

Certain elements of the exhaust gas are of more immediate concern to people with direct exposure to the gas. PM and $\mathrm{CO}$ can have immediate negative effects on humans and are discussed in the following sections. The other elements of the exhaust do impact humans but do 
so indirectly through the environment.

\subsubsection{Health Effects of PM}

Even though the measurement of PM was not performed during the emissions tests discussed in this thesis, the heath affects of PM will still be discussed. PM is a significant contributor to heath issues and has been shown to cause damage to the human respiratory system in many ways. The damage done by PM to the human respiratory system depends upon factors including the number of particles, size, and total mass. The effects associated with these parameters include reduced lung function, general respiratory problems and even death [13].

It has been found that the primary factor as to whether or not a particle gets deposited into the lungs or not, is the particle size [17]. Particles with a diameter greater than $10 \mu \mathrm{m}$ do not enter the respiratory system beyond the entranceways but still can cause problems there. People who breathe through their nose can trap more particles than those who breathe through their mouth. Large particles are more easily trapped in the nasal passages for numerous reasons including the hairs that exist in the entranceway. Smaller particles will more effectively pass further into the lungs regardless of inhalation method and are therefore more dangerous.

The three diseases associated with exposure to PM include asthma, bronchitis, and cancer [13]. PM not only can worsen a preexisting asthma condition, but can also initiate asthma problems in people who have had no previous condition. Preexisting bronchitis conditions have been shown to worsen with exposure to PM. This occurs when the airways of the respiratory system produce mucus in response to PM exposure. Usually, the mucus naturally clears but after prolonged exposure, the airways begin to fill due to excess mucus production. Cancer is the most serious of these three diseases [13]. The cells that come in contact with PM become damaged and prolonged exposures eventually result in cancer. Cancer occurs when the 
reproduction of damages cells causes DNA errors in the new cells. These new cells cannot perform their functions properly and cause tumors to develop.

\subsubsection{Heath Effects of $\mathrm{CO}$}

$\mathrm{CO}$ is a colorless, odorless, tasteless, and very toxic gas produced mostly from SI engines [18]. This has proven to be a very bad combination because it makes it hard for someone to know if they are breathing the gas unless they are feeling the symptoms of $\mathrm{CO}$ poisoning. People run the risk of $\mathrm{CO}$ poisoning if they are exposed to high concentrations of $\mathrm{CO}$. This may happen from running an engine in a garage or any poorly ventilated space. Being in heavy traffic for a long time may cause some people to experience mild symptoms of $\mathrm{CO}$ poisoning.

$\mathrm{CO}$ results from the incomplete combustion of fossil fuels or other carbon containing materials such as tobacco, charcoal, or wood. CO formation is enhanced when combustion occurs with insufficient oxygen present, which is common in spark ignition engines. Although $\mathrm{CO}$ occurs naturally in the atmosphere at low levels, its concentration in industrial areas and traffic-congested cities can be ten to one thousand times greater [18].

At very high concentrations, $\mathrm{CO}$ causes death from lack of oxygen in the blood. At lower concentrations, oxygen deprivation damages tissues and affects a variety of physiological functions. Some studies have suggested that automobile accidents occur more frequently among drivers experiencing prolonged exposure to traffic pollution [18]. The symptoms of CO poisoning at different concentrations are show in Table 11. 
Table 11 - Heath Effects Produced by CO [19]

\begin{tabular}{|l|l|}
\hline Concentration & Symptoms \\
\hline $35 \mathrm{ppm}$ & Headache and dizziness within six to eight hours of exposure \\
\hline $100 \mathrm{ppm}$ & Headache in two to three hours \\
\hline $200 \mathrm{ppm}$ & Headache within three hours; loss of judgment \\
\hline $400 \mathrm{ppm}$ & Headache within two hours \\
\hline $800 \mathrm{ppm}$ & Dizziness, nausea, and convulsions within 45 min \\
\hline $1,600 \mathrm{ppm}$ & Headache, tachycardia, dizziness, and nausea within 20 min, death within 2 hours \\
\hline $3,200 \mathrm{ppm}$ & Headache, dizziness and nausea in five to ten minutes, Death within 30 minutes \\
\hline $6,400 \mathrm{ppm}$ & Headache and dizziness in two minutes. Death within 20 minutes. \\
\hline $12,800 \mathrm{ppm}$ & Unconsciousness after 3 breaths. Death within three minutes. \\
\hline
\end{tabular}

\subsubsection{Heath Effects of $\mathrm{HC}$}

The health effects of $\mathrm{HC}$ are primarily linked to its association with smog formation. Smog is formed when $\mathrm{HC}$ and $\mathrm{NO}_{\mathrm{x}}$ are present in air and form smog with the help of sunlight. The health effects of smog are discussed in Section 3.5.1. In addition to the health effects of smog, HCs can also cause health problems independently. The primary problem with exposure to $\mathrm{HC}$ is that it replaces oxygen in the air which the body needs. This leads to the general condition called hypoxia which means the body has an inadequate supply of oxygen. This will initially lead to headaches and shortness of breath, and later lead to seizures, coma and eventually death [20].

\subsubsection{Heath Effects of $\mathrm{NO}_{\mathrm{x}}$}

Similar to $\mathrm{HCs}$, the health effects of $\mathrm{NO}_{\mathrm{x}}$ are primarily linked to its association with smog. Those effects are also discussed in Section 3.5.1. Studies have also shown health effects associated with $\mathrm{NO}_{\mathrm{x}}$ alone. Short-term exposures to high concentrations of $\mathrm{NO}_{\mathrm{x}}$ result in respiratory issues especially asthma [21]. $\mathrm{NO}_{\mathrm{x}}$ exposures will worsen respiratory diseases such as emphysema and bronchitis. These issues which are associated with $\mathrm{NO}_{\mathrm{x}}$ emissions are similar 
to the issues caused by smog.

\subsection{Environmental Impacts}

Ever since the industrial revolution in the late $18^{\text {th }}$ century, the burning of fossil fuels has had an apparent impact on the environment. This impact is not only evident in the obvious areas like air pollution, but also has a tremendous indirect impact on the land, water, and health of the people living around it. Although the combustion products of these fuels have done a tremendous amount of damage to the planet and the people living on it, it must be understood that these pollutants are all a byproduct of the energy usage that has allowed us to advance as a society. We have chosen to use cheap energy to improve our standard of living and as a result, we have cause irreversible damage to the environment we live in. This section will discuss the effect of the major constituents of fossil fuel combustion products on the environment and how that affects humans.

It must be noted that although $\mathrm{CO}_{2}$ has been recognized as a global warming gas, it is not a traditional pollutant in the sense that it is toxic to humans or the environment. Many government agencies have labeled $\mathrm{CO}_{2}$ and other green house gases as pollutants in order to regulate them and combat global warming. The State of California considers greenhouse gases (GHGs) to be air pollutants and has asked CARB to adopt cost effective regulations for GHG emissions from motor vehicles [1]. This section will only focus on the impacts of the typical pollutants and will leave $\mathrm{CO}_{2}$ and global warming to be discussed in a later section.

\subsubsection{Smog}

The first apparent problem that arose from the industrial revolution and its production of emissions, was the visible pollution called smog [18]. Smog is a form of particulate pollution which is responsible for loss of visibility in many areas around America. More specifically, 
smog is sulfur based particles that produce atmospheric haze. The larger particles may be washed away by rain, but lighter, smaller ones can remain airborne for extended periods of time [18].

Smog is not only a byproduct of the sulfur from coal burning power plants, but is also caused by $\mathrm{HC}$ and $\mathrm{NO}_{\mathrm{x}}$ and the chemical reactions they go through in the atmosphere with sunlight. Polluted air in urban areas will get its red or brown color from this smog that is formed from these reactions. In addition to smog, these reactions will also cause oxidation that will convert $\mathrm{NO}$ into more harmful $\mathrm{NO}_{2}[18]$. The other pollutants that are important for smog formation are $\mathrm{HC}$ [18]. These are produced from incomplete combustion as described previously and from other sources. The storage and handling of gasoline and diesel fuels produce $\mathrm{HC}$ in the atmosphere. Other products such as paints, inks, dry cleaning fluids and other chemicals will evaporate into the atmosphere as well [18].

Besides the reduction in visibility, there are many negative health effects caused by smog. Smog can irritate the respiratory system and can cause coughing and irritation in the throat. People may experience an uncomfortable sensation in their chest which can last for a few hours and may even become painful. Smog will reduce volume of air that you draw in with a full breath and the speed at which you are able to blow it out. When smog levels are high, more asthmatics have asthma attacks that require a doctor's attention or the use of additional medication. Also, asthmatics are more severely affected by the reduced lung function and irritation in the respiratory system [22].

\subsubsection{Acid Rain}

In addition to smog, $\mathrm{NO}_{\mathrm{x}}$ also contributes to acid rain and water quality deterioration. $\mathrm{NO}_{\mathrm{x}}$ and sulfur dioxide react with the moisture in the ambient air to form acids. After these 
reactions, they will fall to earth as acidic rain, fog, snow, or dry particles. It can be carried by the wind for hundreds of miles. Acid rain can damage forests, causes deterioration of cars, building and historical monuments, and causes lakes and streams to become acidic and unsuitable for many fish [21].

Many of the effects of acid rain are indirect. The acid rain will change the acidity of the soil and therefore affect how plants grow which will also then affect the animals that live in the area. Certain crops are affected by acid rain which causes the farmers to then resort to increasing fertilizer to make up the difference.

\subsubsection{Production of fossil fuels}

The environmental impact of using fossil fuels starts from the extraction of oil or coal from the ground. Although drilling for oil can have less of an impact compared to coal extraction, it still can be devastating and energy intensive especially in the case of extracting oil from tar sands. Both the exploration for oil and extraction of oil are done with little concern for the environment and the local people who will be most affected. The ignition of oil wells during the Persian Gulf War produced air pollution at a rate of ten times that of all US industrial and power generating activities [18]. Although this is not common, it is related to oil production and is an indirect product.

The processing of oil after extraction is energy intensive and produces large amounts of pollutants. Refineries in the United States are the second largest source of sulfur dioxide and the third largest source of nitrogen oxides of all industrial sources. Areas surrounding these refineries experience noticeable air quality degradation [18].

The production and distribution of fossil fuels will continue to use large amounts of resources and pollute the environment even before the use of the fossil fuels. This is an inherent 
problem with fossil fuels and will show to be an increasingly large problem as these fuels become harder to find and more energy intensive to extract. In Canada, oil companies have recently started extracting oil from tar sands which is a very energy intensive process. Coal companies have recently started mining via a process called mountaintop removal. As the name infers, this involves the removal of the top of the mountain to gain access to the coal seam deep in the earth. The material removed from the mountain top is dumped into the valleys. It requires large amounts of energy to remove this large amount of material and is extremely bad for the environment. The valleys are filled with the material from the mountains and all plant and animal life is eliminated.

\subsection{Global Warming}

There was little concern for the temperature of the earth until the United Nation's Intergovernmental Panel on Climate Change (IPCC) released a report concluding that the warming of the earth is undoubtedly occurring and is being driven by human activities. This report has been viewed as controversial, but its vast amount of scientific data cannot be ignored. They have concluded that since 1750 human activities have caused a global increase in concentration of $\mathrm{CO}_{2}$, methane and nitrous oxide. These concentrations far exceed pre-industrial levels. They have found that the increase in $\mathrm{CO}_{2}$ is primarily due to the use of fossil fuels while the increases in methane and nitrous oxide are from agriculture [23].

In 2007, the U.S. transportation sector contributed $33 \%$ of the total $\mathrm{CO}_{2}$ emitted from fossil fuel combustion. This was the largest portion emitted by any single economic sector. From 1990 to 2007, the emissions from this sector increased by 29\%. Sixty percent of the total emissions came from personal vehicle use with the remaining $40 \%$ coming from other transportation including air travel and heavy duty vehicles [24]. 
It is not clear as to what exact problems will arise in the future from these greenhouse gases, but we are certain that they are not good for the environment and humans in general. Fossil fuel production and use since the industrial revolution has had measureable effects on humans and the environment. It is very important that these industries undergo strict regulations in order to curb these emissions. The well being of us and our children will depend on how well we are able to regulate ourselves. They may not be the most economically positive decisions at the moment, but they will pay off over time.

\subsection{Emission Regulations}

Regulations for small engines have been set in place by the US EPA since 1998 [25]. At that time, the EPA signed into regulation, Tier 1 through Tier 3 emissions standards for small offroad engines that were to be phased in from 2000-2008. In 2004, the EPA introduced Tier 4 standards which were to be phased in from 2008-2015. Tier 1-3 standards were intended to be met with limited use of aftertreatment devices. Instead, they were to be met through advanced engine design. Tier 4 standards include requirements that $\mathrm{PM}$ and $\mathrm{NO}_{\mathrm{x}}$ levels be reduced by approximately $90 \%$. This reduction can be achieved with a combination of advanced engine design and aftertreatment devices. These standards are applicable to all engines which fall under the EPA's definition of the off-road engine. This definition includes engines which are installed on equipment which is portable. This includes engines installed on self propelled equipment and equipment which is being propelled while in operation. Examples of such equipment include;

portable generators, forklifts, lawn maintenance equipment, and farm tractors. Exemptions from this category include engines used in locomotives, marine vessels, and underground mining equipment. The Tier 1-3 and Tier 4 standards are shown in Table 12 and Table 13. 
Table 12 - Tier 1-3 Non-Road Diesel Engine Emission Standards (g/bhp-hr) [25]

\begin{tabular}{|c|c|c|c|c|c|c|c|}
\hline Engine Power & Tier & Year & CO & HC & NMHC+ NO $_{\mathbf{x}}$ & NO & PM \\
\hline \multirow{2}{*}{$\mathrm{hp}<11$} & Tier 1 & 2000 & 6 & - & 7.8 & - & 0.75 \\
\cline { 2 - 8 } & Tier 2 & 2005 & 6 & - & 5.6 & - & 0.6 \\
\hline \multirow{2}{*}{$11 \leq \mathrm{hp}<25$} & Tier 1 & 2000 & 4.9 & - & 7.1 & - & 0.6 \\
\cline { 2 - 8 } & Tier 2 & 2005 & 4.9 & - & 5.6 & - & 0.6 \\
\hline \multirow{2}{*}{$25 \leq \mathrm{hp}<50$} & Tier 1 & 1999 & 4.1 & - & 7.1 & - & 0.6 \\
\cline { 2 - 8 } & Tier 2 & 2004 & 4.1 & - & 5.6 & - & 0.45 \\
\hline \multirow{3}{*}{$50 \leq \mathrm{hp}<100$} & Tier 1 & 1998 & - & - & - & 6.9 & - \\
\cline { 2 - 8 } & Tier 2 & 2004 & 3.7 & - & 5.6 & - & 0.3 \\
\cline { 2 - 8 } & Tier 3 & 2008 & 3.7 & - & 3.5 & - & $*$ \\
\hline \multirow{3}{*}{$100 \leq \mathrm{hp}<175$} & Tier 1 & 1997 & - & - & - & 6.9 & - \\
\cline { 2 - 8 } & Tier 2 & 2003 & 3.7 & - & 6.6 & - & 0.22 \\
\cline { 2 - 8 } & Tier 3 & 2007 & 3.7 & - & 4 & - & $*$ \\
\hline
\end{tabular}

Table 13 - Tier 4 Non-Road Diesel Engine Emission Standards (g/bhp-hr) [25]

\begin{tabular}{|c|c|c|c|c|c|c|}
\hline Engine Power & Year & CO & NMHC & $\mathrm{NMHC}+\mathrm{NO}_{\mathrm{x}}$ & $\mathrm{NO}_{\mathbf{x}}$ & PM* \\
\hline $\mathrm{hp}<11$ & 2008 & 6 & - & 5.6 & - & 0.3 \\
\hline $11 \leq \mathrm{hp}<25$ & 2008 & 4.9 & - & 5.6 & - & 0.3 \\
\hline \multirow{2}{*}{$25 \leq \mathrm{hp}<50$} & 2008 & 4.1 & - & 5.6 & - & 0.22 \\
\hline & 2013 & 4.1 & - & 3.5 & - & 0.022 \\
\hline \multirow{2}{*}{$50 \leq \mathrm{hp}<75$} & 2008 & 3.7 & - & 3.5 & - & 0.22 \\
\hline & 2013 & 3.7 & - & 3.5 & - & 0.022 \\
\hline $75 \leq \mathrm{hp}<175$ & $\begin{array}{l}2012- \\
2014\end{array}$ & 3.7 & 0.14 & - & 0.3 & 0.015 \\
\hline
\end{tabular}




\section{SMALL ENGINE EMISSIONS LABORATORY DEVELOPMENT}

\subsection{Introduction}

This chapter will discuss the development of the SEEL, and test engine which was used for the commissioning process. A lot of the work done on the small engine emissions testing laboratory was completed in collaboration with fellow graduate student Jacob Brown. His input was received on many of my projects, and help was provided to him on his projects as well. In this chapter, the primary discussion will focus on the work which had been completed with minimal help and involvement from other people. However, the other components of the laboratory development, including the work of Jacob Brown [2], will be briefly discussed in order to provide a complete overview.

\subsection{Engine Skid}

\subsubsection{Design}

The design of the engine skid was based upon requirements including desired physical dimensions and limitations set by the equipment that the skid would hold. One of these requirements was that the skid had to moveable by a fork lift from either side. By using square tubing with open ends, the skid could be picked up with a fork lift. After checking the range of motion of fork lift arms, the width of the new skid from outside edge to outside edge was chosen to be 38.25 inches. See Figure 1 for additional dimensions.

A second requirement was that the skid be able to be lifted from above. This required Drings to be attached to the frame. Four rings were welded to the four corners of the skid frame. Two additional rings were welded near the approximate center of gravity of the frame. The center of gravity was determined by placing the skid on a length of steel tubing. The tubing was moved until the frame was balanced. This location was then marked for the position of the last 
two tie-down rings. This design allowed for a majority of the skid weight to be held by the two middle rings with the outside ones being used for additional stability.
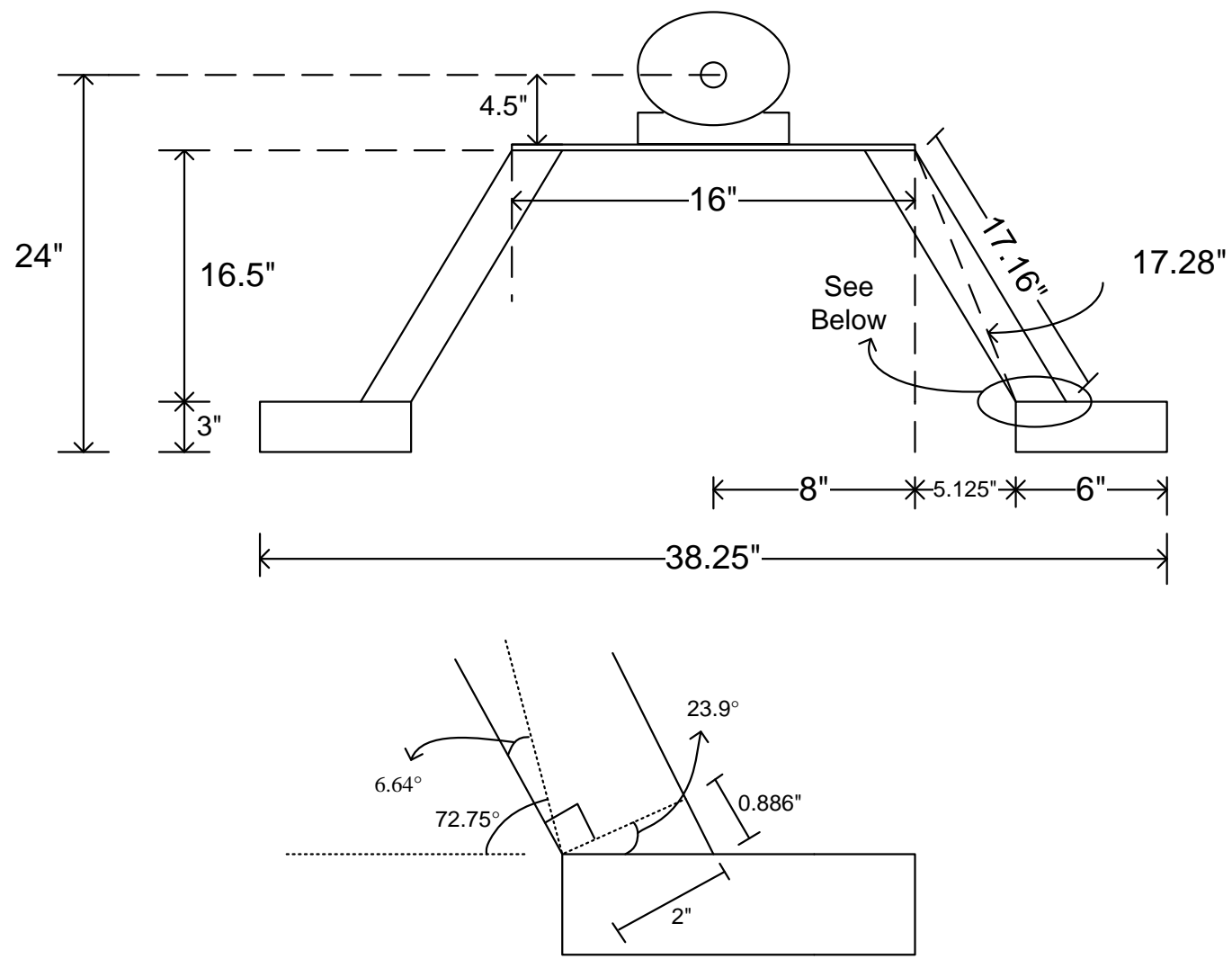

Figure 1 - Dimensions of A-Frame

The next requirement for the skid was for it to have an A-frame design. This meant that for the portion of the skid that would hold the dynamometer and shaft assembly, it all must be supported by an A shaped frame. This design was chosen due to its strength and the flat surface it provided to the dynamometer and shaft system. In order to design the A-frame, numerous dimensions of the skid had to be defined. The most important information affecting the design of the A-frame included; the height of the A-frame from the ground, the width of the top of the Aframe, the width of the base of the A-frame, the length of the skid, and the distance along the skid frame at which the A frame stopped to allow room for the engine. The height of the Aframe on the skid was designed to be high enough so that the dynamometer was at waist level or 
slightly below. In order to find this height, it was defined that the distance from the centerline of the shaft assembly to bottom of the skid must be two feet. In order to meet this height requirement of the frame, the exact dimensions of the dynamometer and the other parts of the frame had to be known. From the technical drawing of the dynamometer it was determined that the distance from the centerline of the shaft to the bottom of the base of the dynamometer was 4.5 inches. Using this information as well as noting that the height of the base square section beam was 3 inches, it was determined that the height of the A-frame from the top of the square section beams to the bottom of the dynamometer must be 16.5 inches.

The next variable dimension in the design of the A frame was the width of the top. The components that would rest on top of the frame determined the width of the A-frame. These components included the dynamometer, bearings, Lebow torque sensor and shaft guard. Also a shaft guard that covered the drive shaft assembly needed to rest on the top of the A-frame and so the required width was wider than the bearings and other components of the shaft assembly including the torque sensor. Additional space was incorporated in order to provide workspace for tools while servicing the shaft, dynamometer or engine. The width of the base of the dynamometer was 8.75 inches and the width of the inside of the shaft guard was 8 inches which allowed for clearance from the bearings, and left space on the outside for the mounting feet that bolted the shield to the top of the A-frame. The top of the frame was set to a width of 16 inches, which provided approximately 3.5 inches of clearance on either side of the electric motor and the shaft guard. The dimensions of the skid cross sections are shown in Figure 1. A CAD drawing of the frame is shown in Figure 2. 

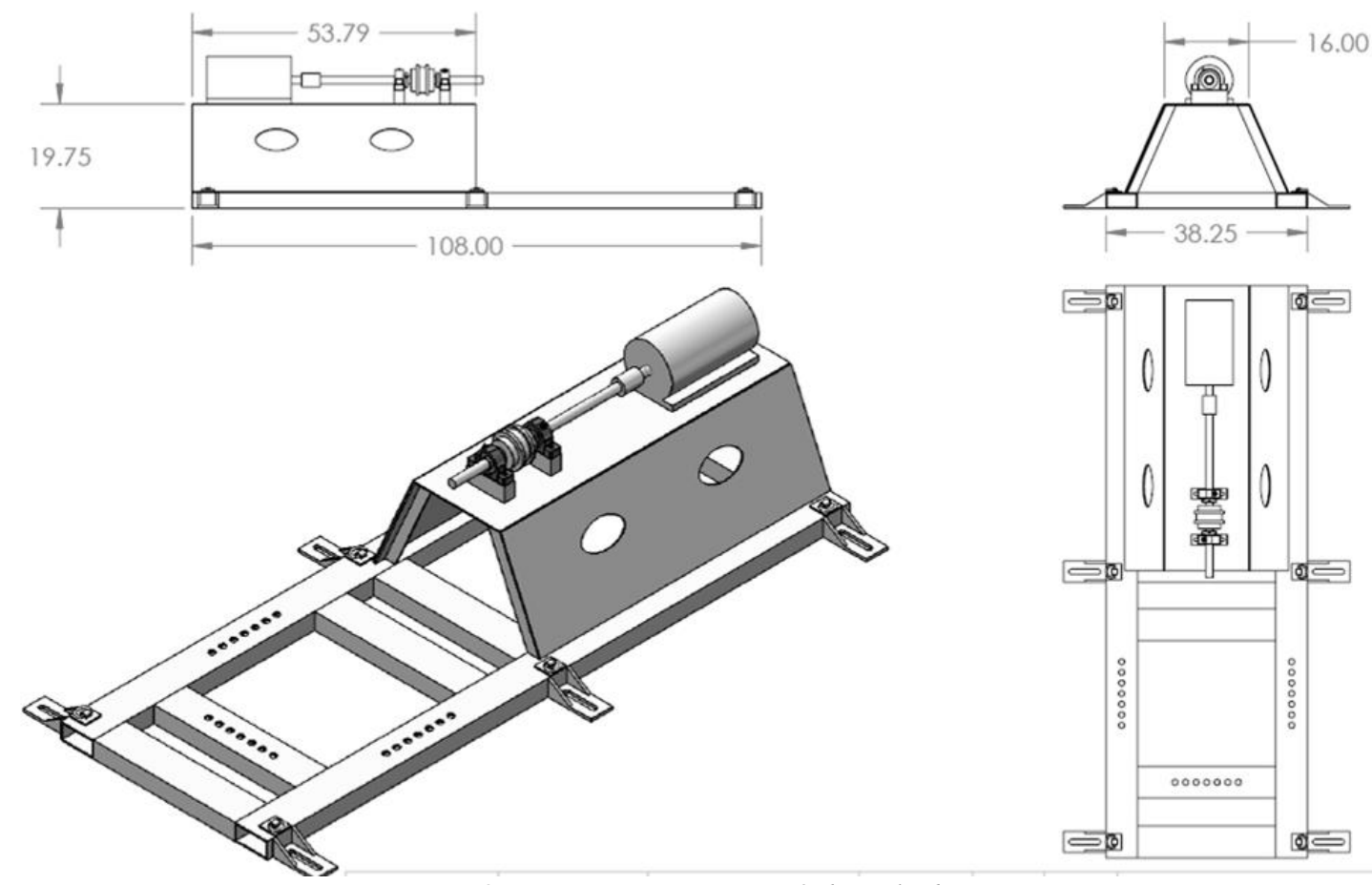

Figure 2 - CAD Drawing of the Skid Frame

\subsubsection{Construction}

With the basic dimensions of the skid finalized, the order was placed for the steel that would make up the outside of the A-frame. The top and side of the A-frame consisted of one piece of steel that was bent in two places. This was then welded to a support structure. Choosing to use one piece instead of three separate pieces lowered the welding time and provided a smoother transition from the top of the frame to the sides. To make it easier to access the underside of the top of the A-frame, 4 access holes were cut out of the side of the frame. The welded frame is shown in Figure 3. Final touches to the skid were needed once the A-frame was welded. Grinding and smoothing the welded surfaces was necessary to remove burs. Holes were drilled to allow for mounting of the dynamometer and shaft guard. The tie-down rings were welded to the square base beams. Holes were cut out of the top of the frame where the wiring would be run for the torque sensor and dynamometer. The square tubing of the base of the skid needed places for the engine mounts to attach. A series of threaded holes along the 
length of the square beams would serve this purpose and allow for a adjustable positioning of the engine mounts. After the majority of the work was completed on the frame, it received a coat of grey paint.

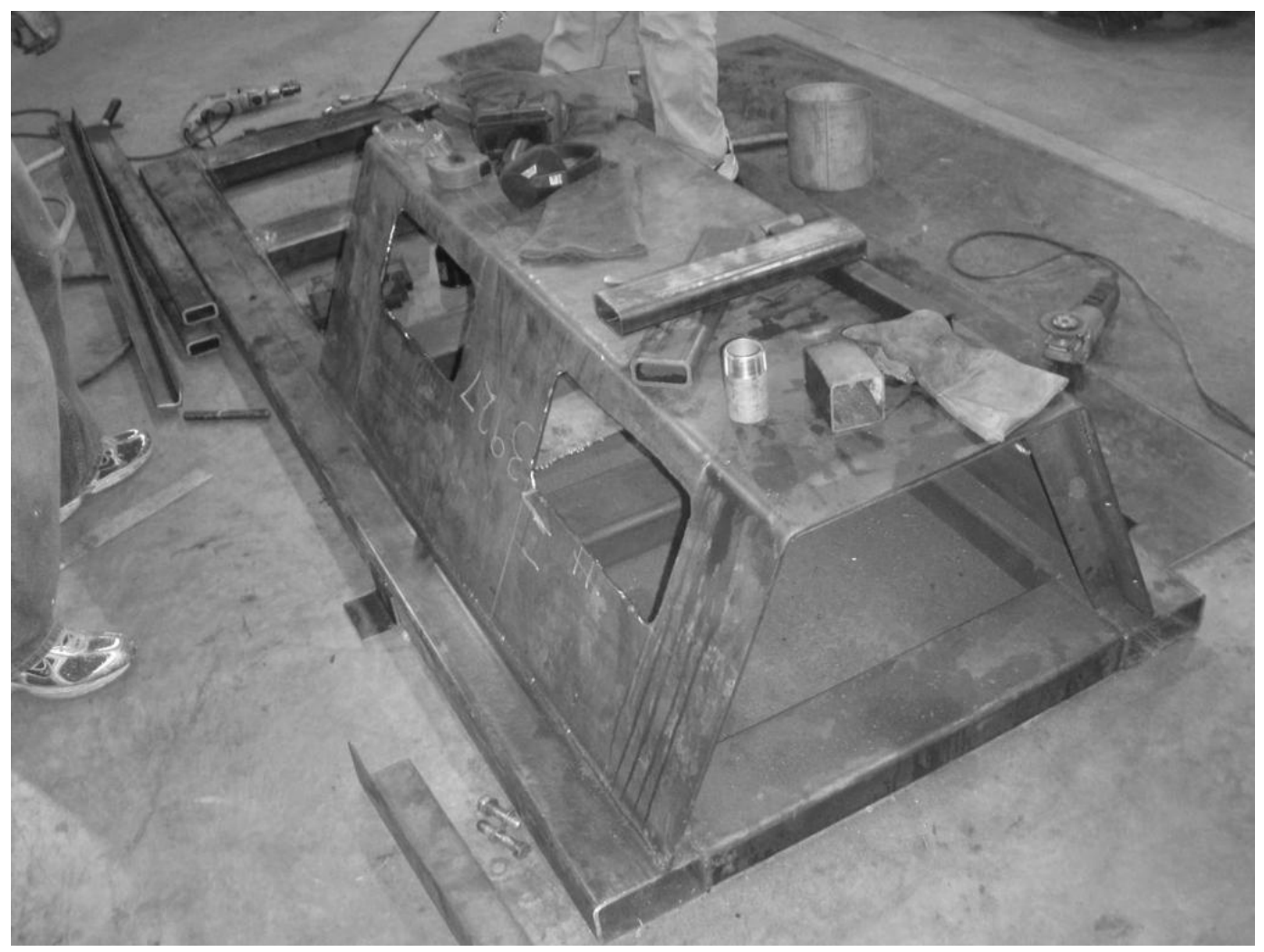

Figure 3 - Welded A-Frame and Access Holes

\subsection{Engine Mounts}

The adjustable engine mounts were constructed out of steel tubing, cut into 8 inch long sections. Acme threaded nuts were then welded to the top of the tubing to accommodate a threaded rod for height adjustment. The base of the tubing was welded to rectangular sections of half inch steel plating. These plates provided the bolting surface with slots to allow for movement of the mounts along the skid frame. Triangular braces were cut and welded to the sides of the tubing in order to provide robust support and prevent breaking at the base. Rubber 
vibration dampers were mounted on a second rod which threads into top of the larger threaded rod. These dampers were then secured from the top by another set of smaller acme nuts. Three of the four mounts that were constructed are shown in Figure 4. Most engines can be mounted using three mounts because most engines have only one mount at the front of the engine. Once a test engine was selected for commissioning, it was noticed that this engine was designed with a different mounting system. It was determined that it was better to use all four of the mounts to simplify the engine mounting process for the new engine. The four mounts can be seen in Figure 6.

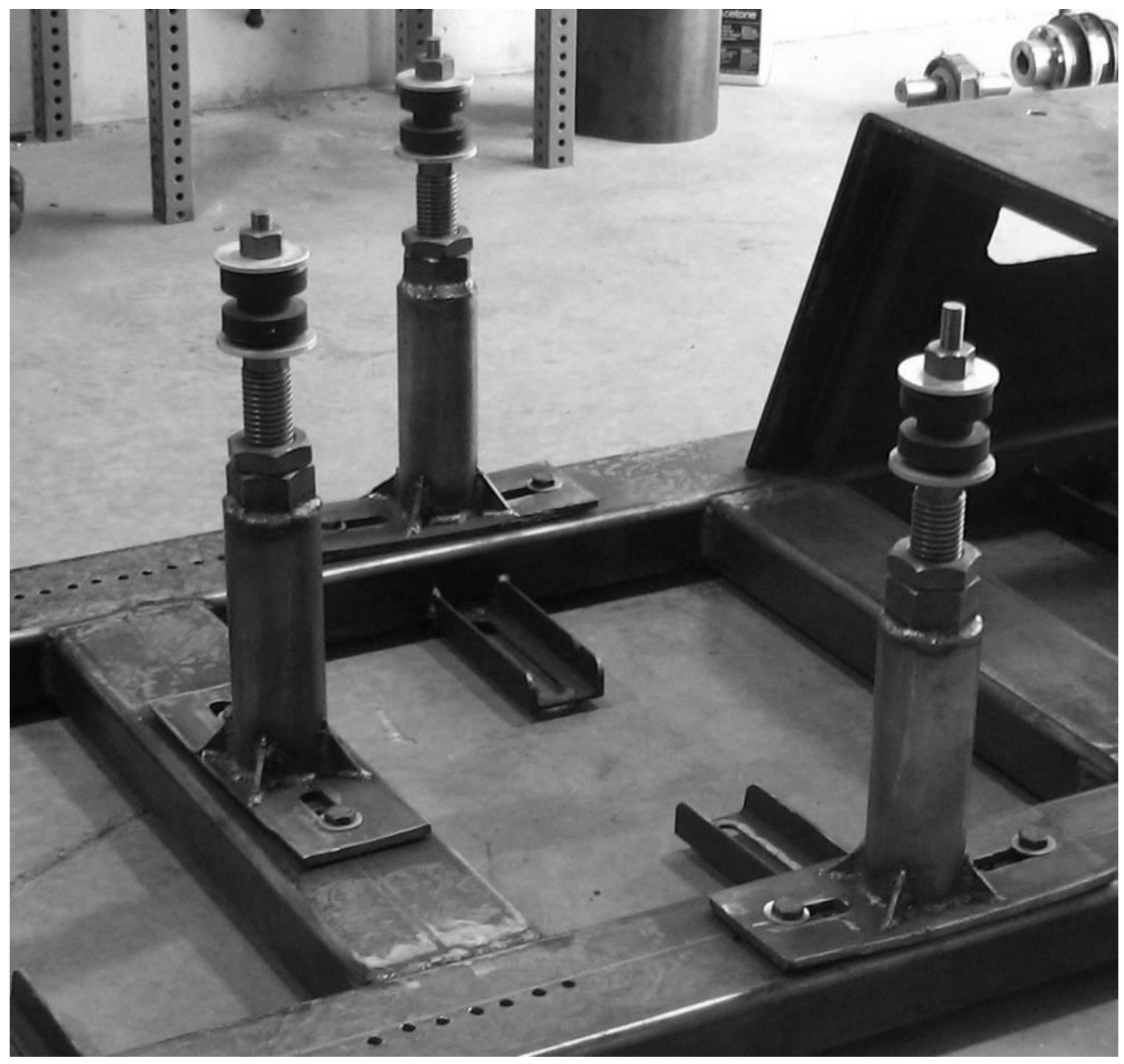

Figure 4 - Three of the Four Adjustable Engine Mounts 
It is common for a complex engine mounting bracket to be constructed because of the discrepancy between the engine mounting points and the adjustable skid engine mounts. An example of one of these brackets is shown in Figure 5. For the test engine used to commission the SEEL, the mounting locations were located at the four corners of the engine. The mounting bracket was constructed using two steel channel beams. One section was used for the front two mounts and the other for the back two. The adjustable engine mounts attached near the outside of the beams with the engine being supported in-between.

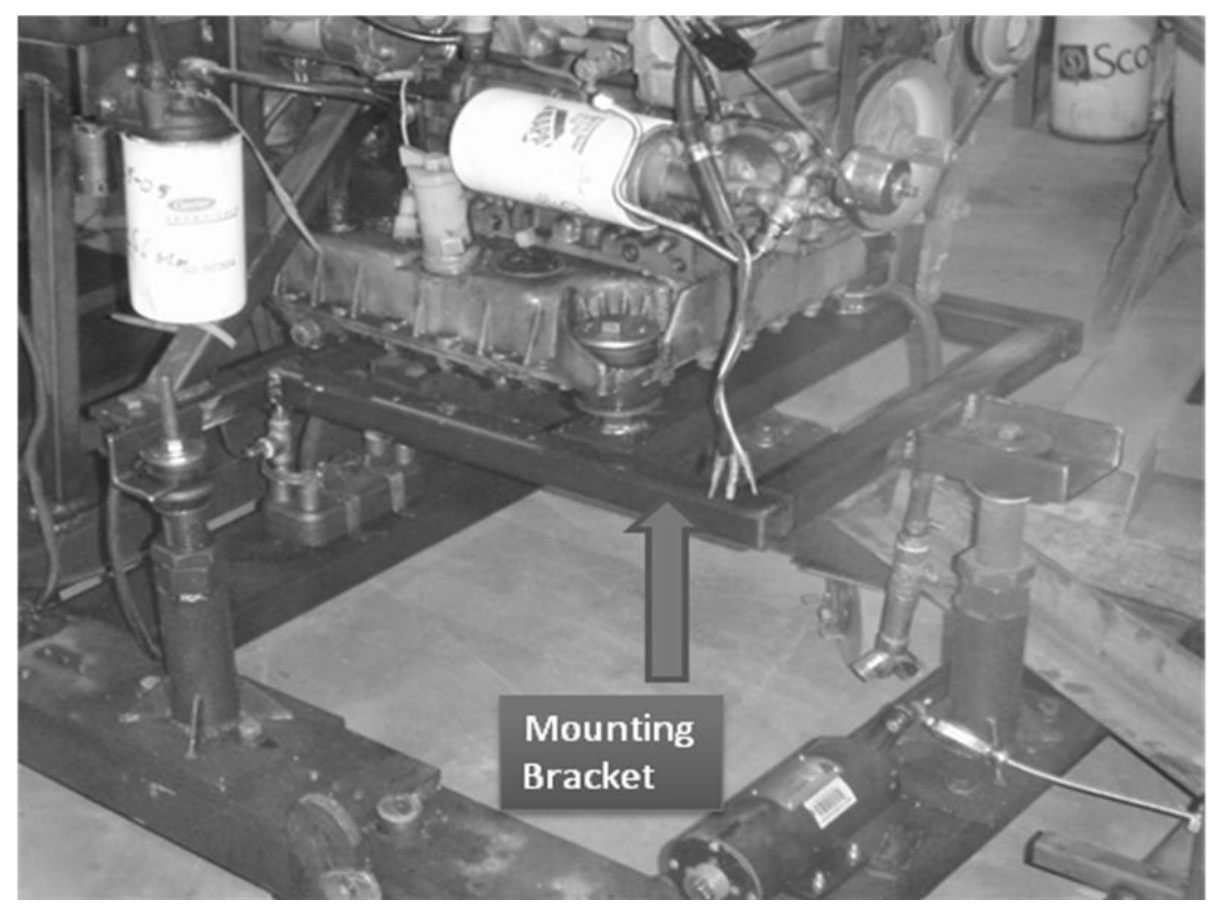

Figure 5 - Engine Mounting Bracket for the Eddie Current Test Engine

Holes were then drilled in the beams for the adjustable mounts and engine mounting locations. The hole locations for the adjustable mounts were first cut with a hole saw because of the large diameter of the rubber dampeners. With the beams mounted to the dampeners, the engine was positioned, holes for the engine mounting locations were drilled and the engine was secured to the skid. The position of the engine on the beams was important to the assembly of the shaft system. The universal joint of the shaft system required the centerline of the connecting 
shaft and the engine centerline be offset in order to prevent premature wear of the universal joint. Figure 6 shows the engine mounted on the channel beams.

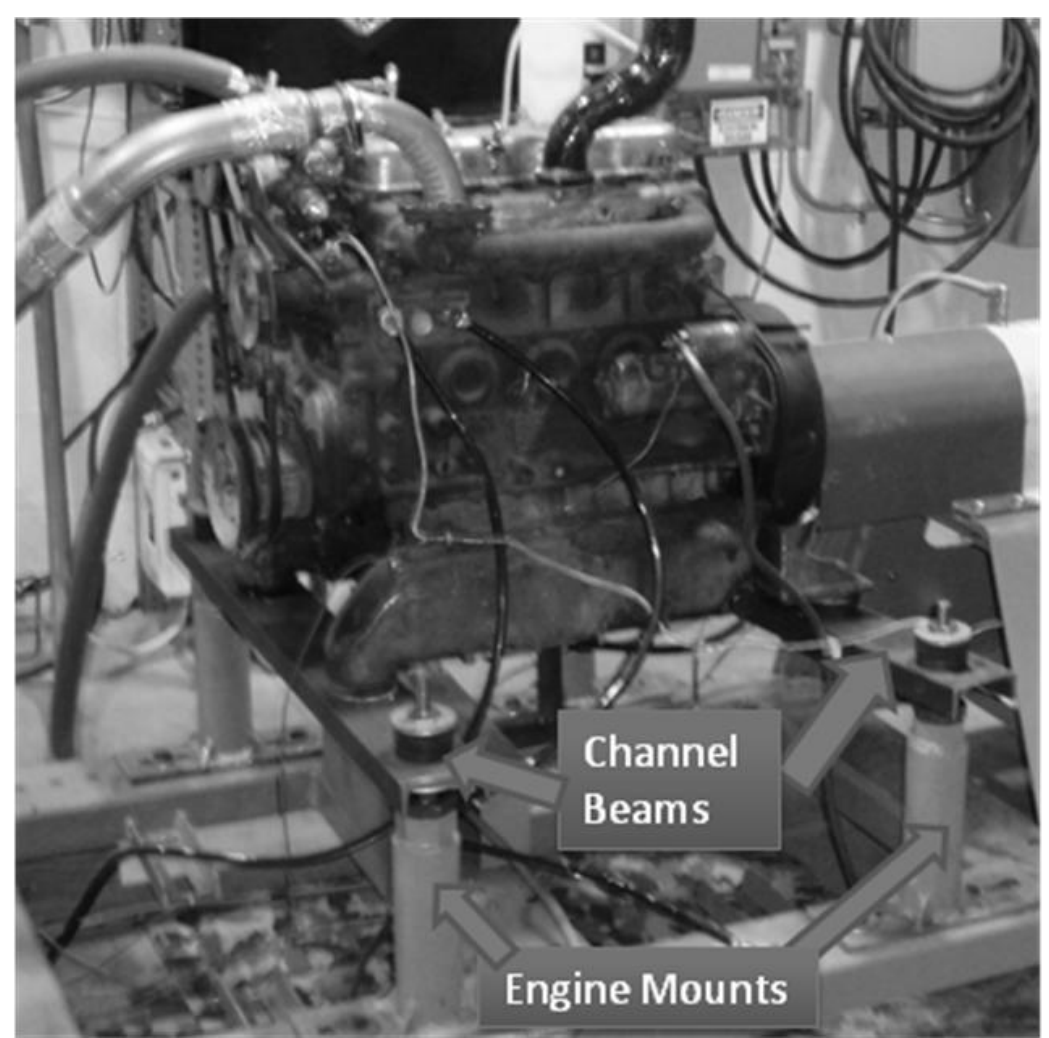

Figure 6 - Engine Mounted on Channel Beams

\subsection{Drive Shaft and Bearings}

The drive shaft system had two functions; the first was to connect the engine to the dynamometer and the second was to support the Lebow slip ring torque sensor. Before designing the shaft system for the SEEL, the shaft systems of other CAFEE dynamometers were analyzed. These systems included flexible couplings at the dynamometer and engine interfaces, as well as bearings, and universal joints. The design of the new shaft system also required that the Lebow torque sensor be positioned between two bearings. A flexible coupling made by Ringfeder was used between the dynamometer and the shaft, and a Vulcan torsional dampener coupling was used between the engine flywheel and the universal joint. A 1.375 inch shaft was selected as this 
was the same size shaft as the shaft of the dynamometer. With the size of the shaft set, it was then possible to select the rest of the shaft components. The bearings and flanges will be discussed here while the Ringfeder and Vulcan couplings will be discussed in Sections 4.5 and 4.6 respectively.

The bearings chosen for this shaft system were S-200 pillow block bearings made by Dodge which is part of the Baldor Electric Company. These bearings included a patented Labyrinth Seal. This seal design worked very well in high speed applications while still being able to handle high temperature and a dirty environment. These seals included corrosion resistant elements and the close proximity of the seals to the bearing ensures grease purge of contaminants [26]. The bearings were designed with large rollers which give more contact area than standard pillow block bearings of this size. Each of these bearings allowed for 2 degrees of static or dynamic misalignment. In order to compensate for thermal expansion and other forces that might cause the shaft to move slightly, one of the two bearings included the ability to translate in the axial direction a distance of $3 / 8^{\text {th }}$ of an inch. To take full advantage of this expansion capability, it was important to make sure that the bearing mounts were installed taking this expansion into account. If not careful, the bearing could be installed while already expanded and would in effect only allow for shrinkage, not expansion. The disassembled components of the shaft system are shown in Figure 7. 


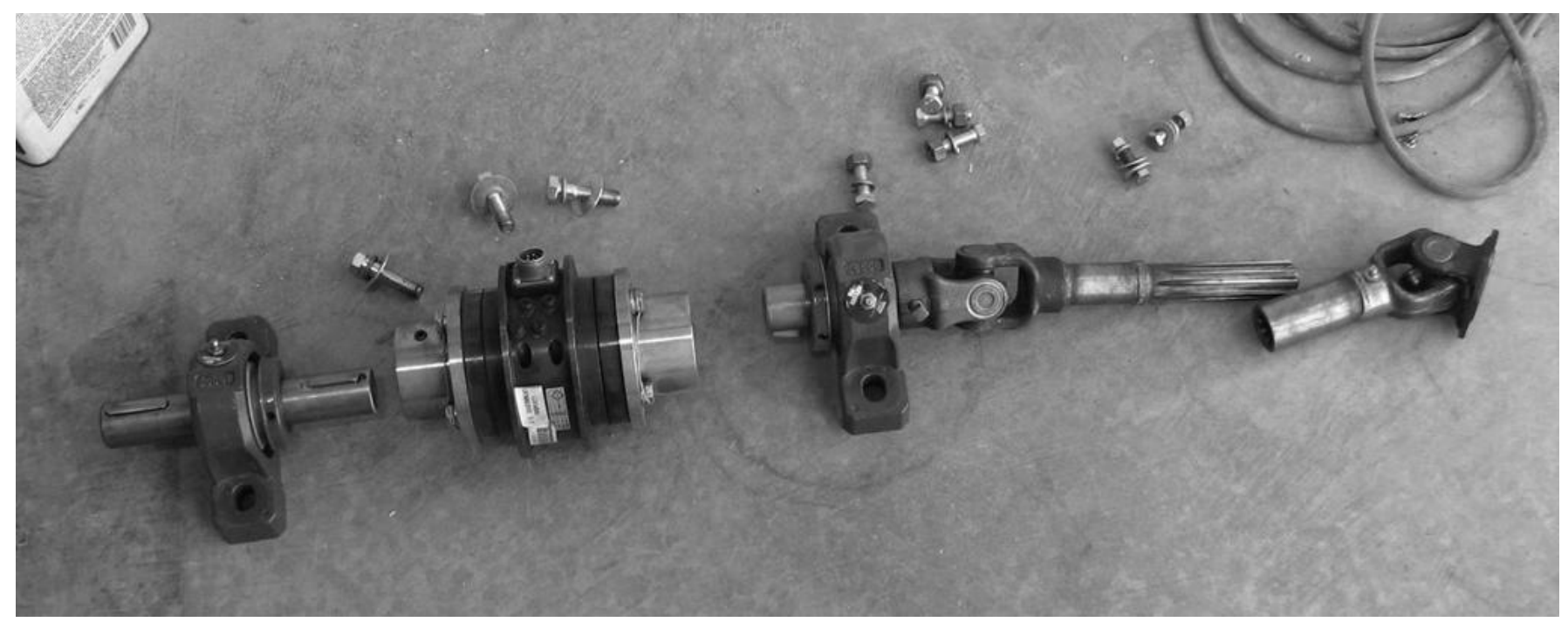

Figure 7 - Disassembled Shaft System

The layout of the bearings on the top of the A-frame was based upon the available space and the clearance that was needed between the bearings and the other components. Ample space was given to the Ringfeder coupling while making sure the bearings were well supported near the center of the space on top of the A-frame. The bearings were placed on both sides and as close as possible to the Lebow torque sensor because the weight of the torque cell was the main source of load on the bearings. The flanges and torque cell together weighed more than $20 \mathrm{lb}$.

In order to elevate the bearings to match the height of the shaft coming from the dynamometer, bearing mounts were designed and welded to the A-Frame. A simple design of steel bocks with threaded mounting holes was used for these mounts. These blocks provided the exact height needed for the shaft system to align correctly. The bearing mounts and assembled shaft system are shown in Figure 8. 


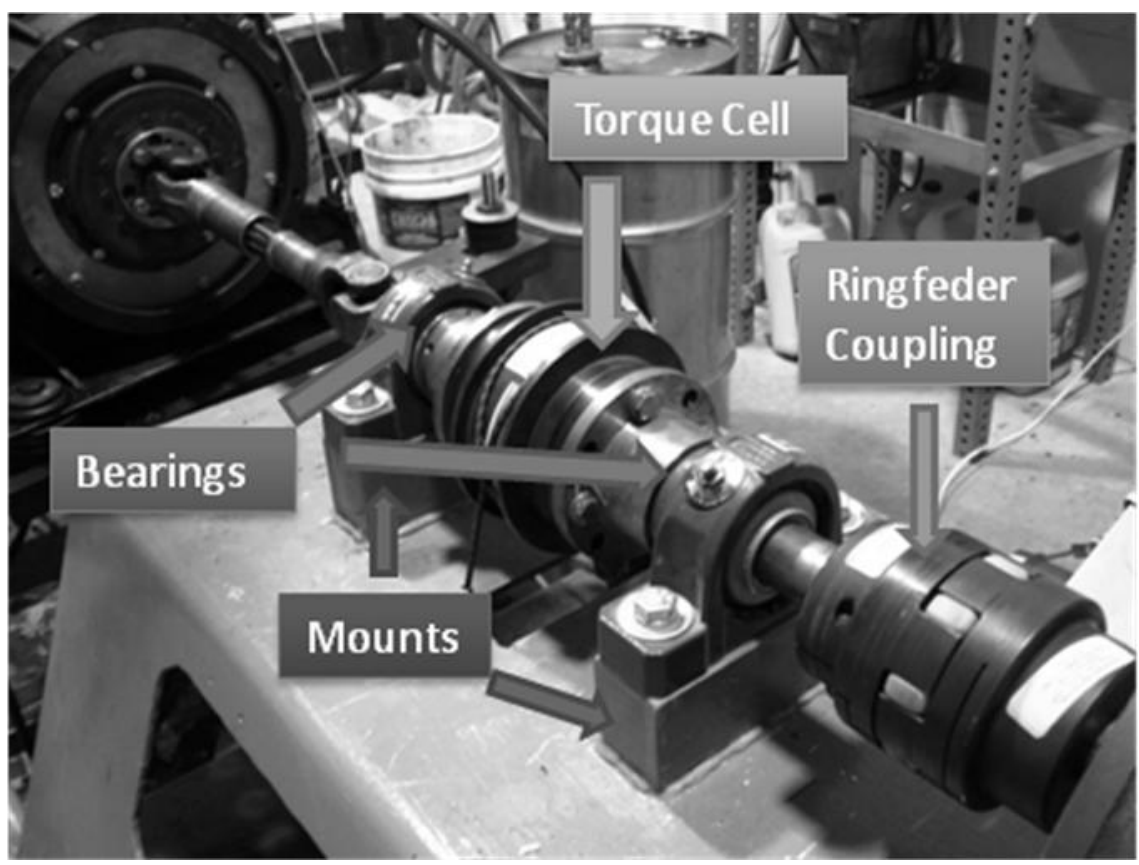

Figure 8 - Assembled Shaft System

\subsection{Ringfeder Coupling}

A coupling was needed to connect the dynamometer to the main shaft holding the torque sensor. Flexible couplings have numerous advantages and are well suited for this application. A flexible coupling allows for small discrepancies in the alignments of the shafts. It compensates for the centerlines of the two shafts not being directly in line with each other. The coupling chosen for this application is a Trasco ${ }^{\circledR}$ ES backlash free coupling made by Ringfeder. This coupling can compensate for axial, radial and angular misalignments. The coupling was composed of two steel hubs connected with a rubber element known as the spider. Because of the spider, the coupling would dampen vibrations and allow for slight misalignments between the two shafts. Spiders of different hardnesses could be easily installed to allow for more or less resistance to movement between the two shafts. An exploded view of a Trasco coupling is shown in Figure 9. 


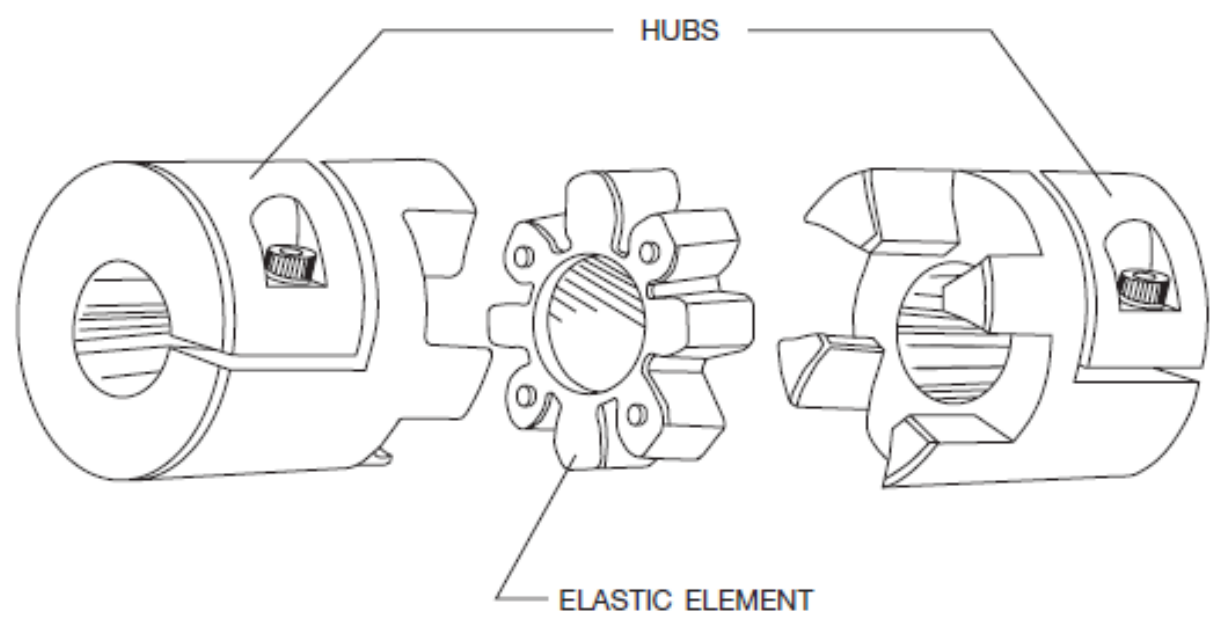

Figure 9 - Exploded View of a Trasco ES Backlash Free Coupling [27]

The size of the coupling chosen was based upon the anticipated torque from the dynamometer and the dynamometer shaft size. The output shaft of the dynamometer has a 1.375 " diameter which corresponded to the size 48 coupling. Selecting the M-Type coupling with clamping hubs allowed for easy assembly and servicing. This type of coupling can be ordered with or without a keyway. It was a good idea to use a keyway for this type of application. The shaft that the coupling was mated to had a keyway and it is only logical to put this keyway to use. A keyway will prevent slipping of the coupling on the shaft which would occur from vibrations or an under-torqued clamping bolt.

According to some engineers at CAFEE, this type of coupling has been known to have the elastic element fail. This is especially true for small engines which can produce significant vibrations. These vibrations can put large amounts of stress on the couplings and can cause the elastic elements to fail. Because of this possibility, two spiders of different hardnesses were ordered with the one coupling. Having two spiders was a good idea for many reasons. If the 
harder spider did not provide sufficient dampening, then the softer spider could be used. In the event that one of the elements would fail, the second spider could easily replace the failed one and allow for the emissions tests to continue.

The coupling chosen for the dynamometer was a size 48 steel hub coupling. One spider of 92 shore hardness (Sh.) and another of $98 \mathrm{Sh}$. were purchased. The $92 \mathrm{Sh}$. spider was yellow and the 98 Sh. spider was red. The yellow 92 Sh. spider can be seen in Figure 10. This coupling had a nominal transmittable torque of $310 \mathrm{Nm}$. The red $98 \mathrm{Sh}$. elastic element had a nominal transmittable torque of $525 \mathrm{Nm}$. The coupling assembled to the shaft system can be seen in Figure 8.

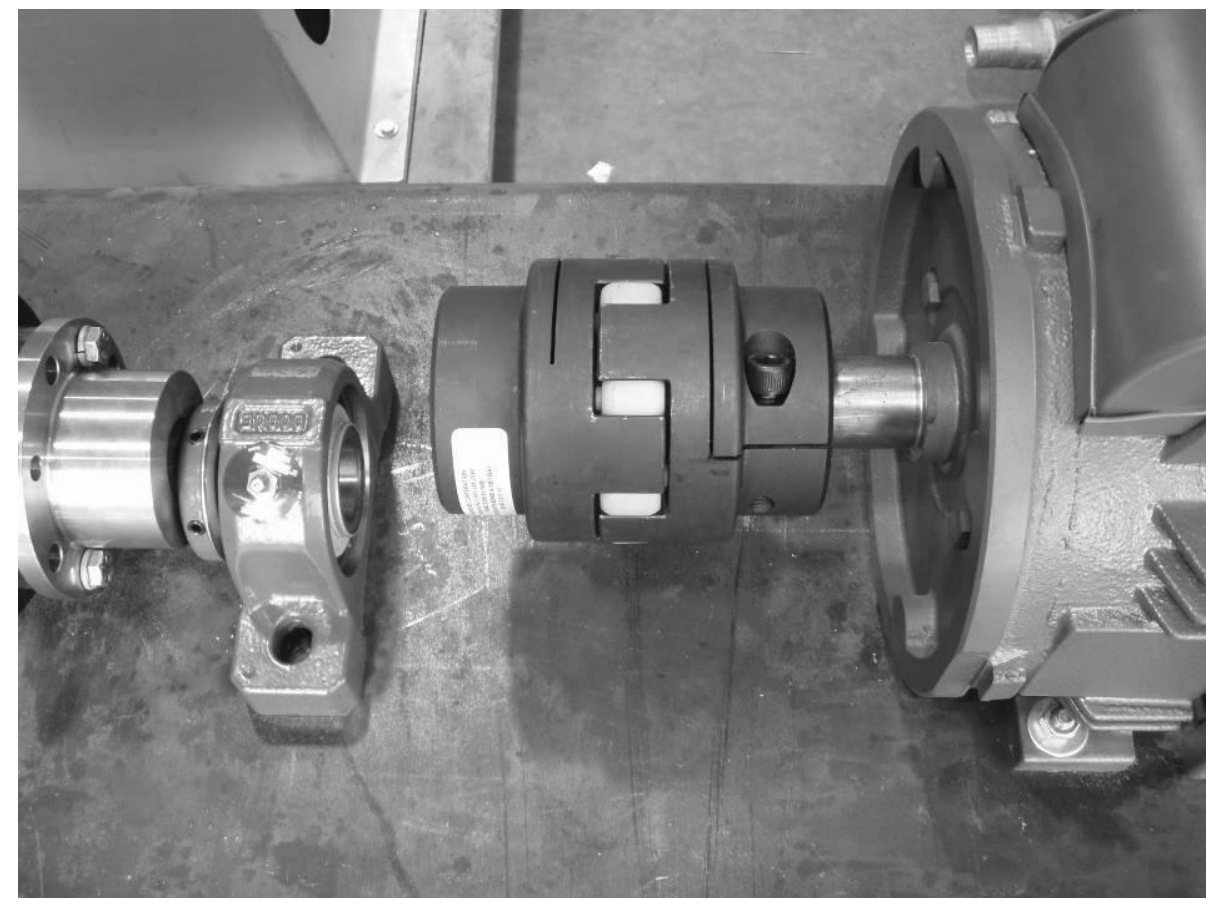

Figure 10 - Ringfeder Coupling

\subsection{Vulcan Coupling and Adapter Plate}

The second coupling used in the shaft system was the Vulcan torsional dampener. This coupling connected the flywheel of the engine to the universal joint of the shaft system via a 
custom adapter plate. This coupling provided vibration dampening which would relieve some of the stress on the shaft system introduced by the test engine, especially at low engine speeds.

The design of the flexible coupling made direct attachment to the flywheel of the Thermo King engine impossible. The coupling required a recessed section that did not exist on the flywheel. The flywheel surface was completely flat with six threaded bolt holes. It was necessary to design an adapter plate that would allow for the coupling to be mated to flywheel securely. The custom adapter plate included the proper bolt patterns for both the flywheel and the coupling. It also included recessed sections on both the front and back of the plate. The thickness of the adapter plate and other dimensions were machined accurately to ensure proper fitting of the coupling on the adapter and proper fitting of the adapter on the flywheel. The flywheel housing limited the outside diameter and the thickness of the adapter. The thickness of the plate was 0.8 inches with the outside diameter being 12 inches. The adapter plate was modeled in a computer aided design (CAD) program and machined by Wilson Works. The design of the adapter plate is shown in Figure 11. The installed Vulcan coupling and adapter plate are shown in Figure 12. 


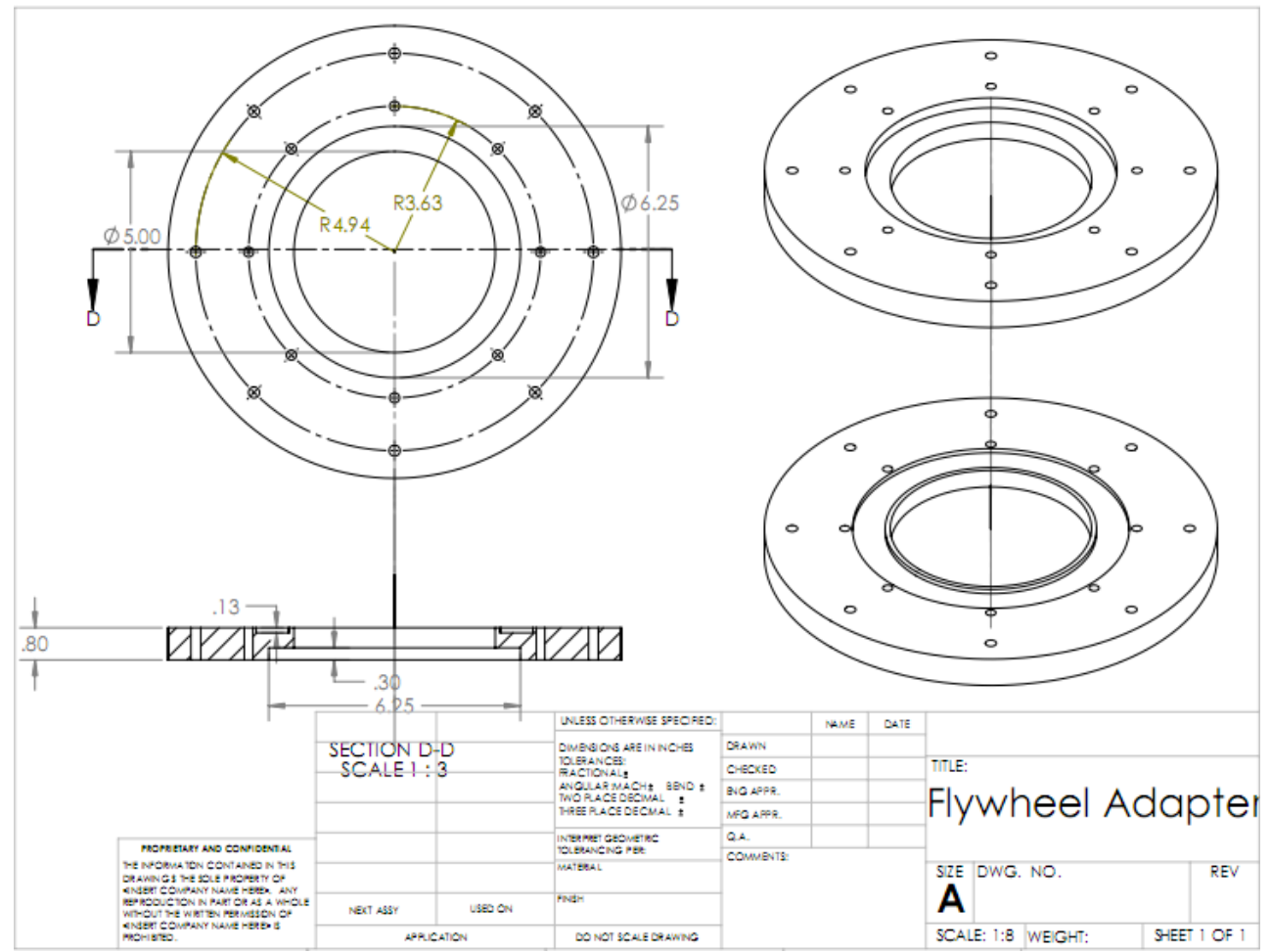

Figure 11 - Flywheel Adapter Plate Design

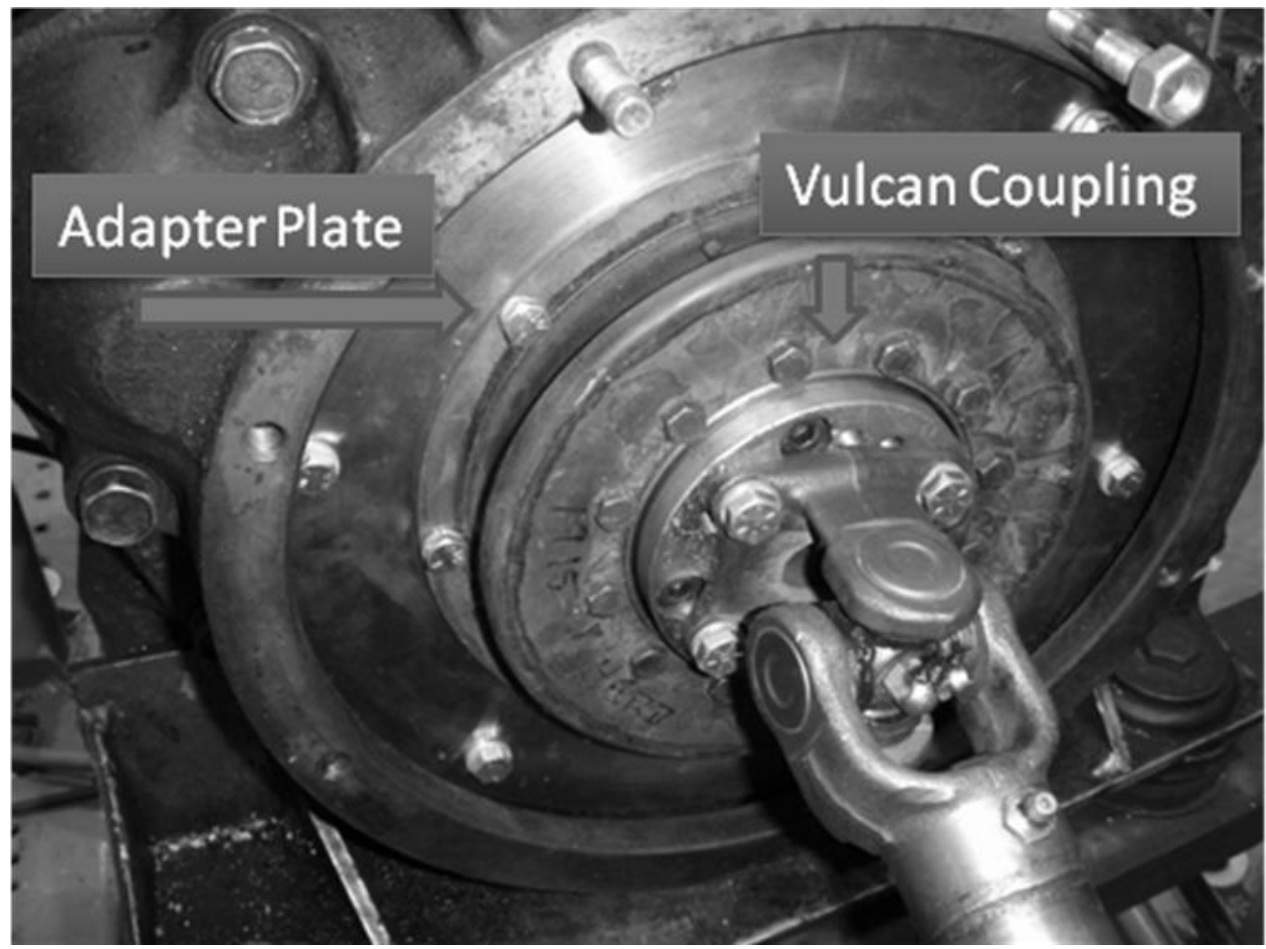

Figure 12 - Adapter Plate and Vulcan Coupling 


\subsection{Dynamometer Installation and Wiring}

At the heart of every emission testing laboratory is an engine dynamometer. The dynamometer measures the torque of the engine and also provides other necessary data about the engine as it runs. There are numerous types of dynamometers that can provide this torque, including an eddy current dynamometer and a water brake dynamometer.

For the SEEL, a variable speed alternating current dynamometer made by Reliance Electric was chosen. The size of the dynamometer determines the size of the engines that can be tested. Therefore, it must be large enough to handle the power and torques produced by the biggest engine that is anticipated to be tested on the dynamometer. Also, it can't be too big to the point where the dynamometer is too big for the smallest engines and causes the data collected by the electric motor to not have sufficient resolution. With these considerations in mind, it was determined that the largest engine that the dynamometer would be designed to handle was a 40 hp engine. A $40 \mathrm{hp} \mathrm{AC} \mathrm{motor} \mathrm{from} \mathrm{reliance} \mathrm{electric} \mathrm{was} \mathrm{purchased.} \mathrm{Included} \mathrm{with} \mathrm{this} \mathrm{motor}$ was a dedicated $1 / 3 \mathrm{hp}$ blower to provide cooling. The blower was mounted to the top of the motor and forced air around the fins of the motor casing. Specifications for the motor are shown in Table 14. The blower and motor are shown in Figure 13.

Table 14 - Reliance Dynamometer Specifications

\begin{tabular}{|l|c|}
\hline Manufacturer & Reliance Electric \\
\hline Model & P18T314 \\
\hline Rated Power & $40 \mathrm{hp}$ \\
\hline Rated Torque & $59 \mathrm{ft}-\mathrm{lb}$ \\
\hline Rated Speed & $3550 \mathrm{rpm}$ \\
\hline Max Speed & $5323 \mathrm{rpm}$ \\
\hline Voltage & $460 \mathrm{volts}$ \\
\hline Max Amperage & $53 \mathrm{amps}$ \\
\hline
\end{tabular}




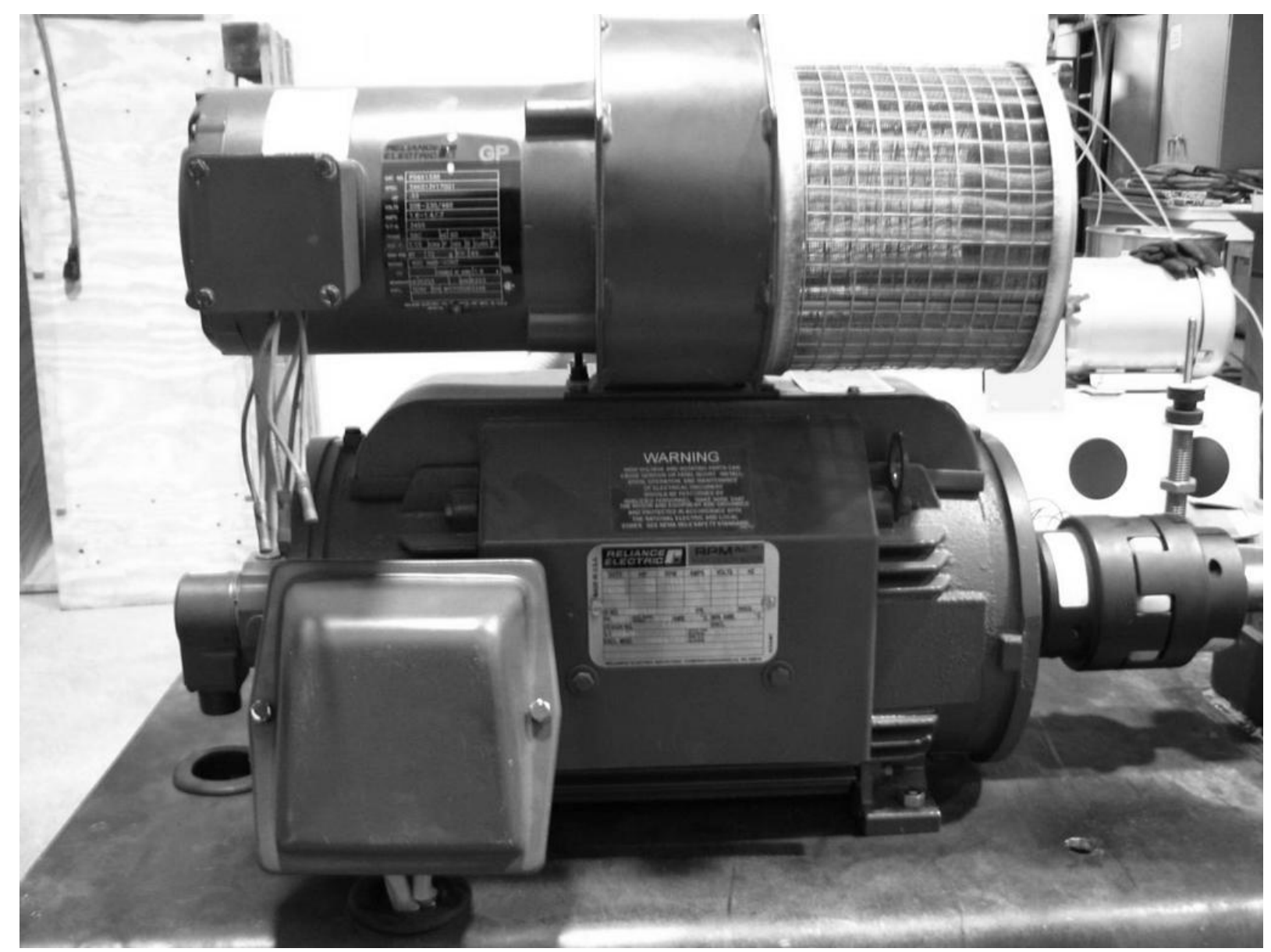

Figure 13 - Reliance Dynamometer Motor and Blower

The motor was powered by three-phase AC power and was supplied by a dedicated transformer mounted on the wall next to the motor. The blower was also wired for high voltage three-phase AC power. The blower had the capability of being used with low voltage power as shown in Figure 14. On the backside of the motor, was a 7 pin Amphenol connector for an included speed transducer. This speed transducer provided readings of the speed of the shaft which was also the speed of the engine. This connector was wired to the control system with the wiring pin-out shown in Table 15. 


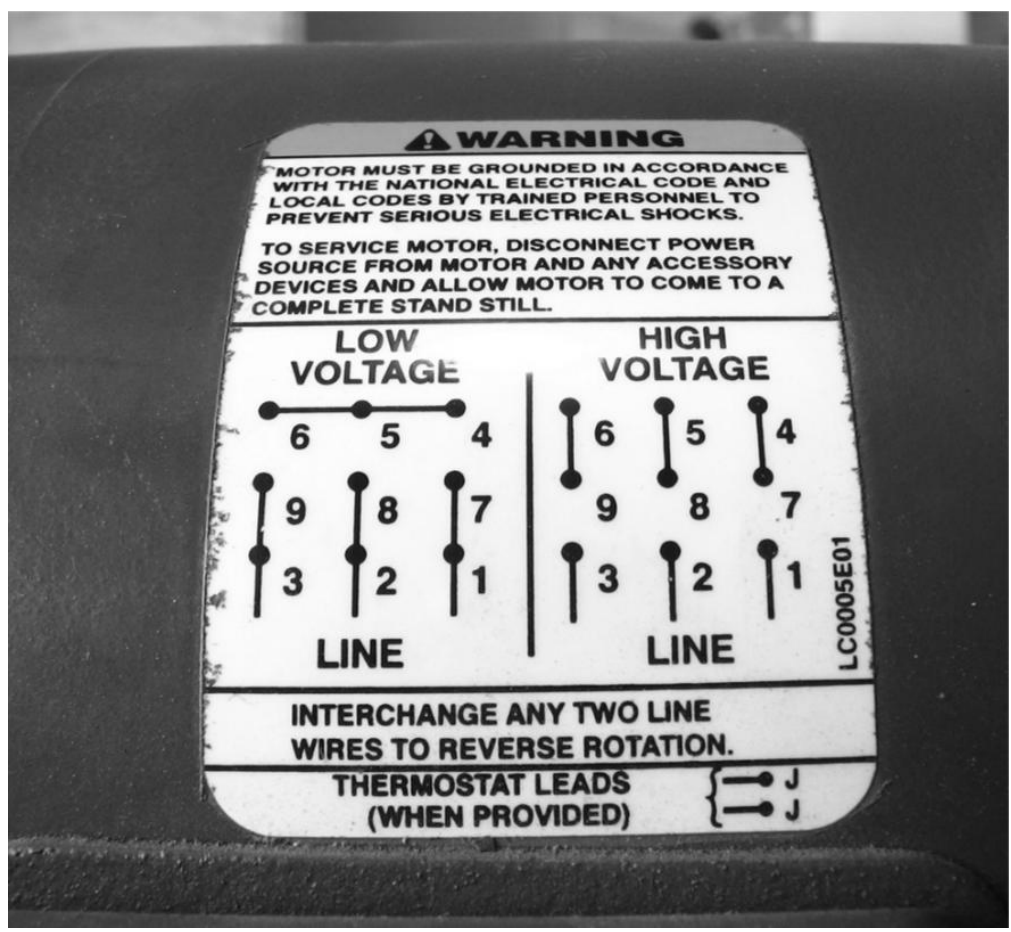

Figure 14 - Dynamometer Blower Wiring Diagram

Table 15 - Speed Transducer Wiring

\begin{tabular}{|c|c|c|}
\hline Connector Pin & Function & Color \\
\hline A & A & White \\
\hline B & B & Green \\
\hline D & Supply Voltage & Red \\
\hline F & Ground Circuit & Red/Black \\
\hline H & a & White/Black \\
\hline I & b & Green/Black \\
\hline G & Case Ground & Unshielded \\
\hline
\end{tabular}

\subsection{Laboratory Control}

The three major components of the control system included: the Invertek Opti-Drive Plus motor controller, a digital throttle controller (DTC) made by DyneSystems, and a data acquisition (DAQ) computer on which custom software would run. In conjunction with the motor controller was a Smarty controller also made by Bardac. The Smarty controller was a rail 
mounted programmable controller for motor drive systems. It was networked via Ethernet to the dynamometer controller and the DAQ computer. The DTC and dynamometer controller are shown in Figure 15 and Figure 16.

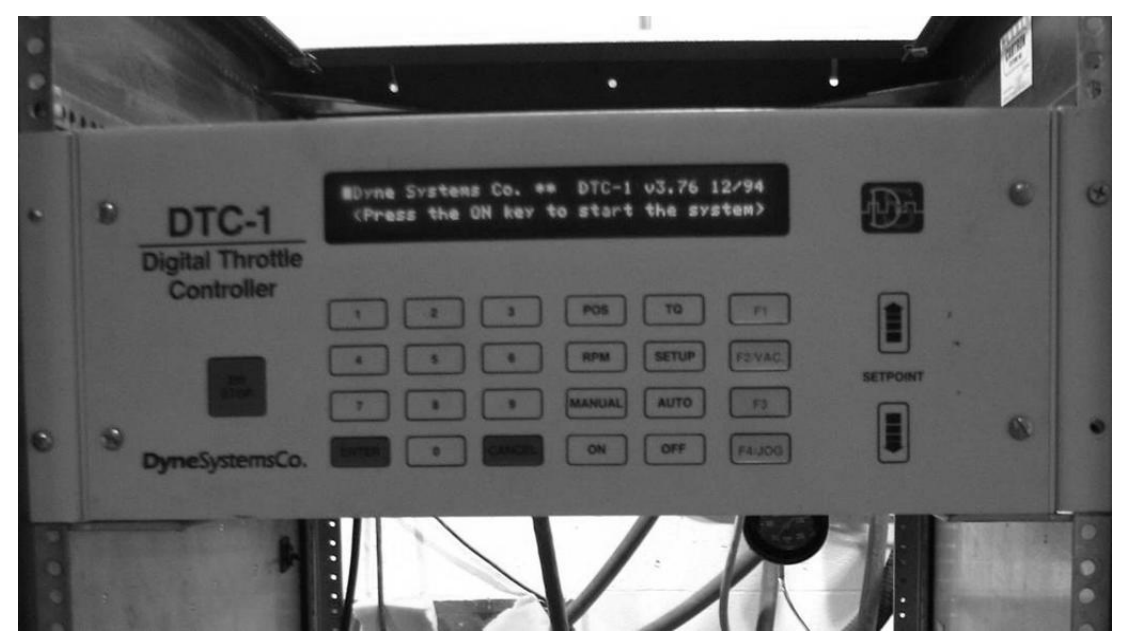

Figure 15 - Digital Throttle Controller

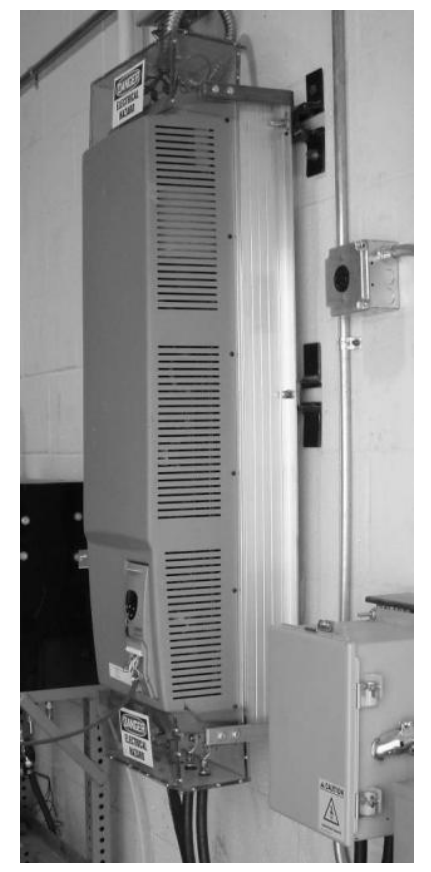

Figure 16 - Invertek Optidrive Plus Dynamometer Controller 
Software for the SEEL was written by Richard Atkinson with help from fellow graduate student Jacob Brown [2]. This software was written in Microsoft Visual Basic 6 and provided complete control of the engine and dynamometer systems. This software communicated directly with the DTC and with the dynamometer controller via the Smarty. The signals from thermocouples and other sensors were recorded in the computer via a National Instruments DAQ card.

Although the SEEL control software was new, the control strategy implemented in the software was similar to the existing systems at CAFEE's EERL facility. To perform an emissions test, the user would defined the test cycle via a simple text file. This file included details including the number of modes, the speed and torque set points for each mode. The length of the modes and duration of data collection were also included. The software then controlled the engine and dynamometer according to this set point file. The control software adjusted the throttle of the engine to adjust and control the engine load. An example of a set point file is shown in Table 16.

Table 16 - Set Point File Example

\begin{tabular}{|c|c|c|c|c|c|}
\hline Mode & Speed (rpm) & Torque (Nm) & $\begin{array}{c}\text { Switch } \\
\text { Length (sec) }\end{array}$ & $\begin{array}{c}\text { Mode } \\
\text { Length (sec) }\end{array}$ & $\begin{array}{c}\text { Sample } \\
\text { Time (sec) }\end{array}$ \\
\hline 1 (idle) & 600 & 0 & 15 & 240 & 75 \\
\hline 2 & 1212 & 1750 & 15 & 120 & 75 \\
\hline 3 & 1431 & 820 & 15 & 120 & 75 \\
\hline 4 & 1431 & 1230 & 15 & 120 & 75 \\
\hline 5 & 1212 & 870 & 15 & 120 & 75 \\
\hline 6 & 1212 & 1310 & 15 & 120 & 75 \\
\hline 7 & 1212 & 440 & 15 & 120 & 75 \\
\hline 8 & 1431 & 1640 & 15 & 120 & 75 \\
\hline 9 & 1431 & 410 & 15 & 120 & 75 \\
\hline 10 & 1650 & 1495 & 15 & 120 & 75 \\
\hline 11 & 1650 & 370 & 15 & 120 & 75 \\
\hline 12 & 1650 & 1130 & 15 & 120 & 75 \\
\hline 13 & 1650 & 760 & 15 & 120 & 75 \\
\hline
\end{tabular}




\subsection{Lebow Torque Sensor}

The torque sensor selected for the SEEL was a Lebow torque sensor model 1248 made by Eaton, now owned by Honeywell. It was a flange drive slip ring torque sensor and is shown in Figure 17. This was an important component to the SEEL and was one of the key components for engine control. It allowed for important parameters to be determined including torque, power and work produced by the engine. The sensor provided torque readings through a strain gauge. This strain gauge was mounted on the rotating part of the shaft and was measured with a Wheatstone bridge configuration. When torque was applied to the shaft, the strain gauge deformed and changed resistance. This change in resistance was then measured by the Wheatstone bridge and allowed the amount of torque to be inferred. Figure 18 shows the wiring diagram for the Wheatstone bridge on the Lebow. The specifications for the sensor are shown in Table 17 and Table 18.

This type of torque sensor works on the principle of slip rings. Slip rings allowed for electrical connections to the rotating shaft. This worked by having metal bands around the shaft, connected to electrical components on the shaft which in this case were a strain gauge and Wheatstone bridge. Metal contacts called brushes slid along the bands as the shaft rotated while maintaining an electrical connection. This allowed for power to be transferred to the device and signals to be received.

The torque sensor was mounted to the shafts via Spicer flanges. Originally, the flanges had a bolt pattern that did not match the bolt pattern of the Lebow. This required a new set of holes to be drilled on the flanges. The bolt circle diameter for the new holes was retrieved from the mounting dimensions provided by Lebow. 


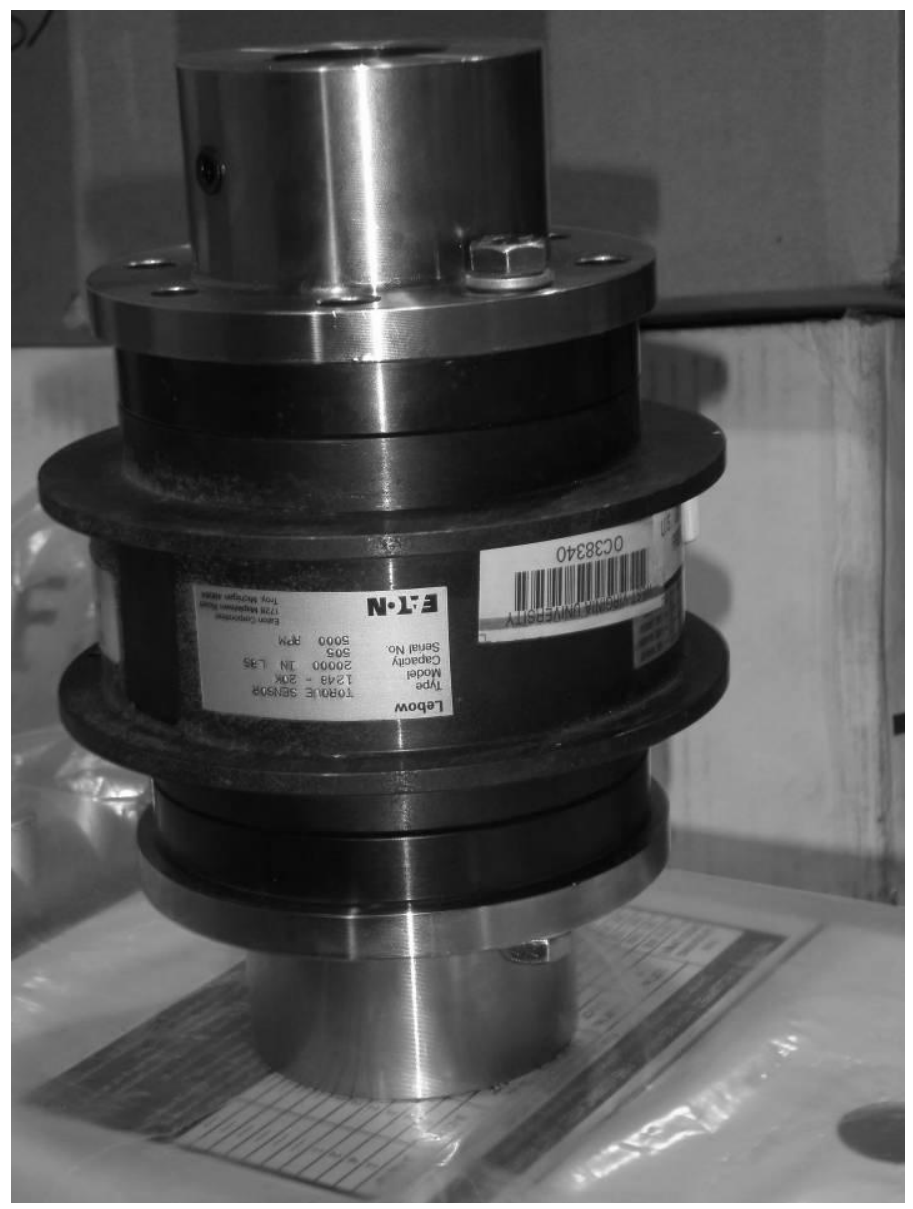

Figure 17 - Lebow Torque Sensor with Flanges

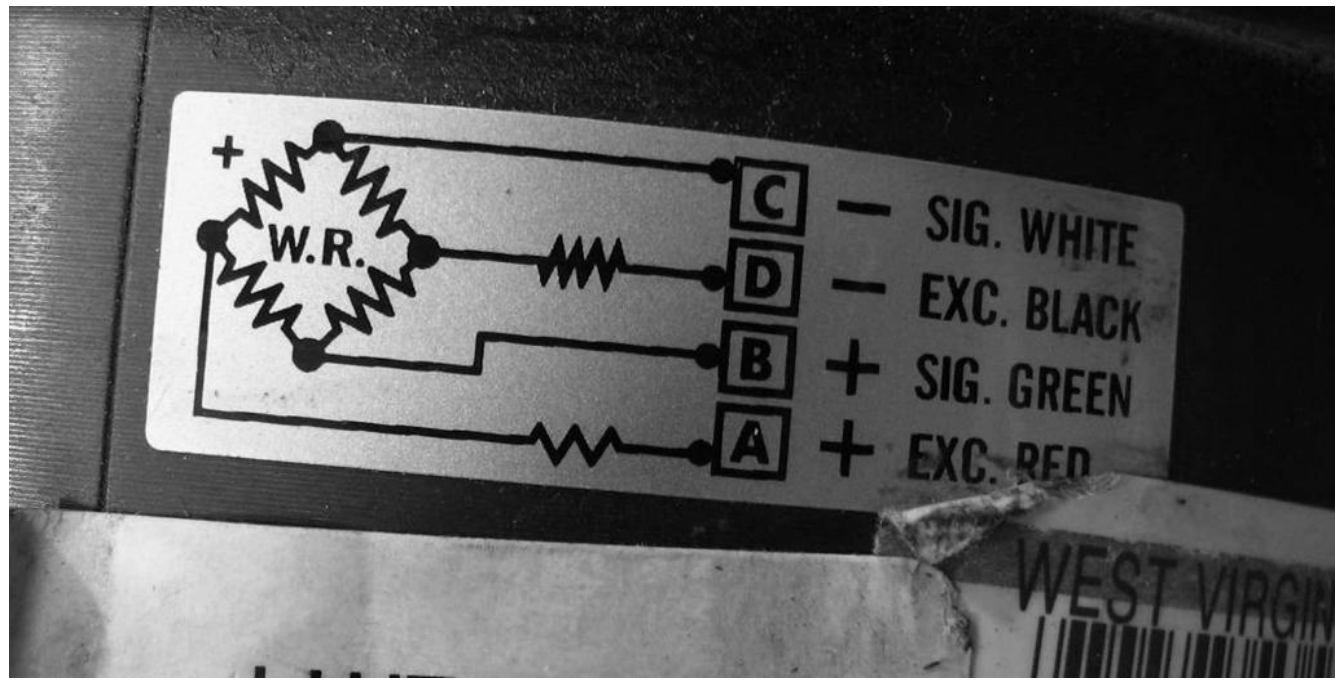

Figure 18 - Torque Sensor Strain Gauge Wiring Diagram 
Table 17 - Lebow Torque Sensor Specifications

\begin{tabular}{|l|c|}
\hline Model Number & 1248 \\
\hline Max Torque (lb-in) & 20000 \\
\hline Max Torque (N-m) & 2250 \\
\hline Max speed (rpm) & 5000 \\
\hline Overload Capacity (\% of nominal capacity) & 150 \\
\hline Torsional Stiffness (lb-in/rad) & 4657000 \\
\hline Rotating Inertia (lb-in/sec2) & $4.02 \times 10-2$ \\
\hline Operating Temperature & $-29^{\circ} \mathrm{C}$ to $90^{\circ} \mathrm{C}\left[-20^{\circ} \mathrm{F}\right.$ to $\left.200^{\circ} \mathrm{F}\right]$ \\
\hline Weight $(\mathrm{lb})$ & 17 \\
\hline
\end{tabular}

Table 18 - Physical Dimensions of the Lebow Torque Sensor

\begin{tabular}{|c|c|c|c|c|}
\hline Model & $\mathbf{C}$ (in) & $\mathbf{N}$ (in) & $\mathbf{U}$ (in) & $\mathbf{H}$ (in) \\
\hline 1248 & 4.31 & 0.56 & 4.25 & 0.31 \\
\hline &
\end{tabular}

\subsubsection{Safety Wiring}

The safety of the torque sensor was of great concern when designing and assembling the shaft system. Vibrations from the high rotational speed of the shaft could easily loosen bolts and cause parts to disassemble. The Lebow torque sensor was a valuable piece of equipment and extra effort was made to ensure its safety. The sensor was connected to each flange by 8 bolts. Each bolt was fastened with lock washers with additional safety wiring.

The installation of safety wiring involved physically connecting the bolts on each flange 
with sections of twisted safety wire. Each of the bolts had a hole drilled in the head of the bolt perpendicular to the main axis of the bolt. A safety wire tool was then used to twist the wire while running it between the bolts. Specific guidelines received with the wiring tool indicated the amount of twists that the wire should have based upon the thickness of the wire. The diameter of the wire that was used was .032 inches. With this wire size, it was determined that 8 turns per inch of wire were needed. Using the safety wire tool, the bolts were connected with the proper wiring procedure. The principle behind the safety wiring is that if one bolt starts to loosen itself, the twisting of the bolt will tighten the safety wire, which is connected to an adjacent bolt. With the proper setup, the adjacent bolt will already be tight, and will prevent the first bolt from loosening. Figure 19 shows an example of three bolts correctly installed with one piece of safety wire. Figure 20 shows the installation of the safety wires on the flange bolts for the Lebow.

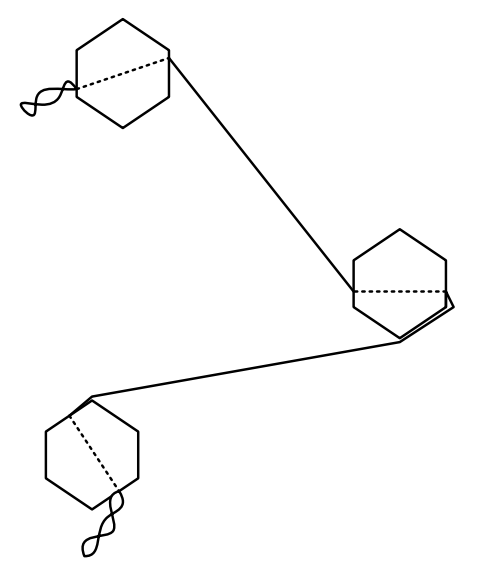

Figure 19 - Safety Wiring Example 


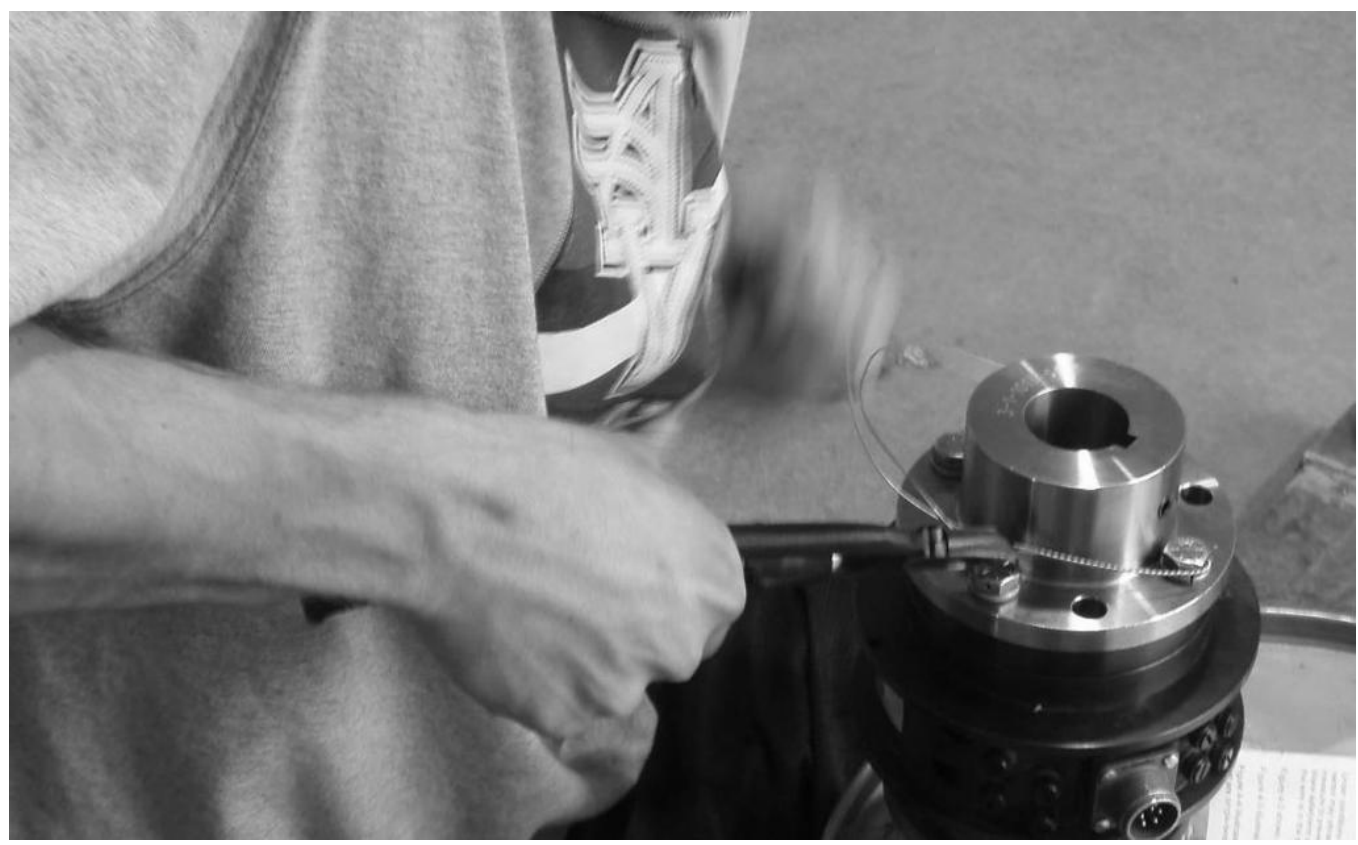

Figure 20 - Lebow Safety Wiring Installation

\subsubsection{Calibration}

Once the Lebow was installed and wired to the DAQ system, it was important to make sure that it was calibrated correctly. The calibration process involved attaching weights to a lever arm which generated a known torque on the Lebow. The distance of the lever arm and other important dimensions and weights were carefully measured in order to calculate the anticipated torque that the sensor should be reading. This calculated torque was then compared to the measured torque coming from the Lebow.

The first step in the calibration process was to weigh all the components being used. The lever arm and bolt were weighted using the same scale being used for fuel weighing during the engine tests. The weights used in the calibration process were official weights used for dynamometer calibrations. These weights had engraved identifying numbers on them which allowed us to relate them to a certain official weight values. These weights were regularly shipped to a certified weighing facility which provided certified accurate weight values for the 
weights. The weights of each of the calibration components are shown in Table 19.

Table 19 - Weight of Calibration Components

\begin{tabular}{|l|c|c|}
\hline Component & Serial Number & Weight (lbs) \\
\hline Lever Arm & N/A & 2.2 \\
\hline Bolt & N/A & 0.07 \\
\hline Basket & N/A & 1.0 \\
\hline Weight \#6 & WCAL 0406 & 11.43 \\
\hline Weight \#7 & WCAL 0407 & 11.43 \\
\hline Weight \#8 & WCAL 0408 & 11.37 \\
\hline Weight \#9 & WCAL 0409 & 11.37 \\
\hline Weight \#10 & WCAL 0410 & 11.40 \\
\hline
\end{tabular}

It was very important that these weights are accurate because torque measurement is such an important part of the emissions measurement process. An incorrect calibration would cause the dynamometer to apply a consistently incorrect load onto the engine. The engine would then produce more or less power than it should and would directly affect the emissions being produced by the engine.

To perform the calibration, the Lebow was isolated from the engine and dynamometer. The Ringfeder coupling was disconnected by separating the two hubs of the coupling and removing the elastic element. This freed the Lebow from the dynamometer. The opposite size of the Lebow needed to be fixed in place. To do this, a metal rod was placed through the u-joint on the other side of the Lebow which then contacted the frame of the skid and prevented rotational movement. This allowed torque to be applied to the other end of the shaft. The lever arm was then attached to the open hub. Great care was taken to make sure that the lever arm was kept level and did not move horizontally. This was very important as any slip would change the lever arm length. The setup for the calibration is shown in Figure 21. 


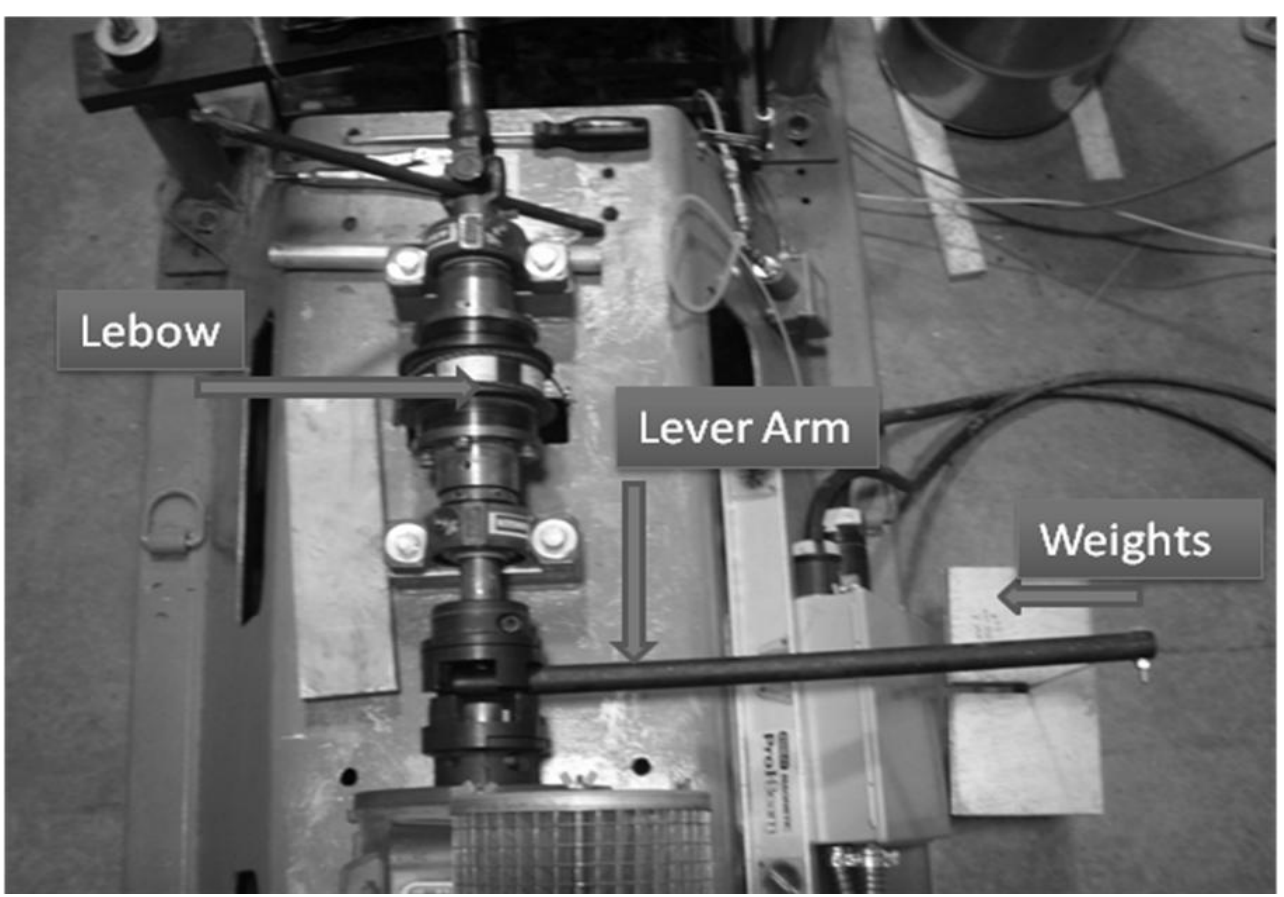

Figure 21 - Overhead View of Torque Calibration Setup

There are some improvements to this calibration method that could be made. The connection between the lever arm and shaft could be replaced by a dedicated device which could be officially weighed with the calibration weights. This device could simply be a lever arm welded to a flange or a solid beam that could be clamped to the shaft. Another area that could use improvement was where the weight basket was attached to the lever arm. The original design included the hook from the basket hanging on a bolt fastened to the lever arm. This bolt could be replaced by pointed edge that would change the contact area to a smaller point. These design changes would reduce measurement errors and would give greater confidence in the calibrations.

In addition to these changes, it was also recommended that a negative torque calibration be performed if the dynamometer were ever be used to motor the engine. This AC dynamometer had the capabilities to not only absorb torque from the engine, but could also produce torque in 
order to start the engine or simulate engine braking. This was not completed during the commissioning of the laboratory because the steady state tests performed did not require negative torque readings. Such a calibration could be performed in the same manner as the positive torque calibration, only hanging the weights from the opposite side of the shaft. The positive torque calibration setup is shown in Figure 21.

A seven point calibration was performed. The first point was at zero torque. The second calibration point consisted of only the lever arm and weight basket. From then, the weights were individually added to the basket, to create 5 more calibration points. Initially, default parameters in the controller caused large errors between the measured and actual torques. These errors initially varied from $2 \%$ to $15 \%$ but eventually became close to zero through adjustment of parameters within the Smarty controller. These parameters were a torque offset value and the zero and span values of the Lebow. After multiple calibration sequences were performed, the error between the measured and calculated torques agreed within $1 \%$ of each other with the exception of the second calibration point. The results from the calibration are shown in Figure 22.

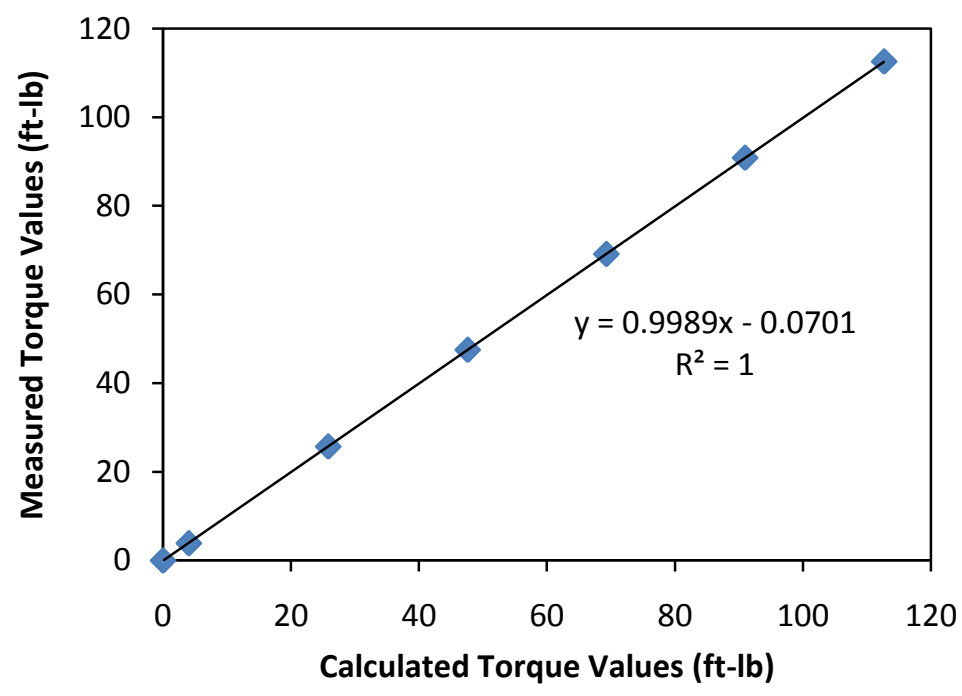

Figure 22 - Lebow Torque Sensor Calibration Results 
The requirements for this calibration process according to EPA CFR part 1065 [28] required that the error between the calculated and measured torque values be within $0.5 \%$ of each other. Six of the seven calibration points met these requirements. The calibration point that did not meet this requirement was a torque value that is so low it would not affect the torque measurements of most engines anticipated for this lab. The $4.03 \mathrm{ft}-1 \mathrm{~b}$ of anticipated torque for the second calibration point is within one half of a percent of the $1667 \mathrm{ft}-\mathrm{lb}$ range of the Lebow. If an engine was to be tested that produced torque within this low range, a new torque sensor would be needed to eliminate this error. In conclusion, this calibration showed that the Lebow torque sensor was capable of measuring torque values while meeting the requirements with the exception of torque values that are less than one percent of the full range of the sensor.

\subsection{Shaft Guard}

It was necessary to have a shaft guard in the SEEL for safety reasons. A rugged shaft guard was designed and built to cover the entire shaft assembly from the dynamometer to the engine. The guard consisted of two separate pieces. The first piece covered the flexible coupling, shaft bearings, and torque sensor. The second piece covered the Vulcan coupling and the universal joint connection. Precautions were taken to ensure that there was sufficient clearance between the guard and the engine and dynamometer. Fittings were incorporated into the shaft guard to accommodate for the Teflon safety lines which run inside the guard. Figure 23 shows the completed shaft guard. 


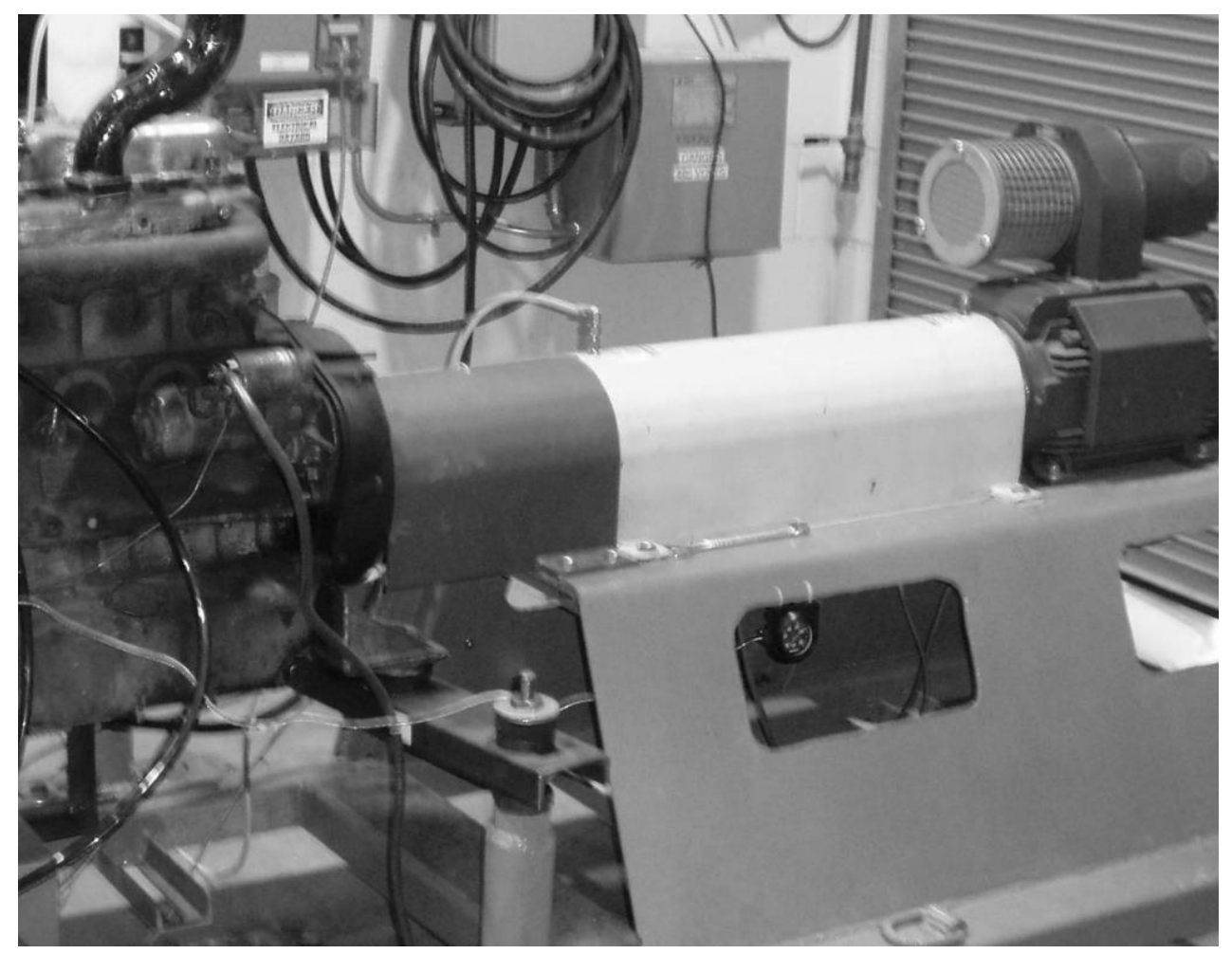

Figure 23 - Shaft Guard

\subsection{Safety Systems}

An automatic safety system was designed and incorporated into the SEEL. This system would shut down the engine and dynamometer in the event that the connecting shaft was to fail. This safety system consisted of a pressure switch connected to a Teflon hose running inside the shaft guard. If any component of the shaft assembly failed, the Teflon hose would rupture causing the pressure in the hose to drop, causing the pressure switch to close. This immediately turned off the engine, cut off its fuel supply and disabled the dynamometer.

In order to make the system work, it was necessary to make sure that the supply air did not provide enough pressure to hold the switch open even in the event of the line getting ruptured. If the puncture is small enough, it is possible to have shaft failure and Teflon line rupture, but still not have the switch close and turn off the engine. The solution to this problem was to introduce a fitting that restricted the volume of air that can flow into the system at any 
time. This included a restricting diaphragm through which only a small volume of air was allowed to flow through. This restriction was placed where the main air supply met the safety system. Figure 24 shows the safety switch and restricting diaphragm. In addition to the pressure switch safety system, the SEEL also included an emergency shut of switch, located near the DAQ computer. This switch would shut off power to the dynamometer and halt fueling of the engine by closing a solenoid valve.

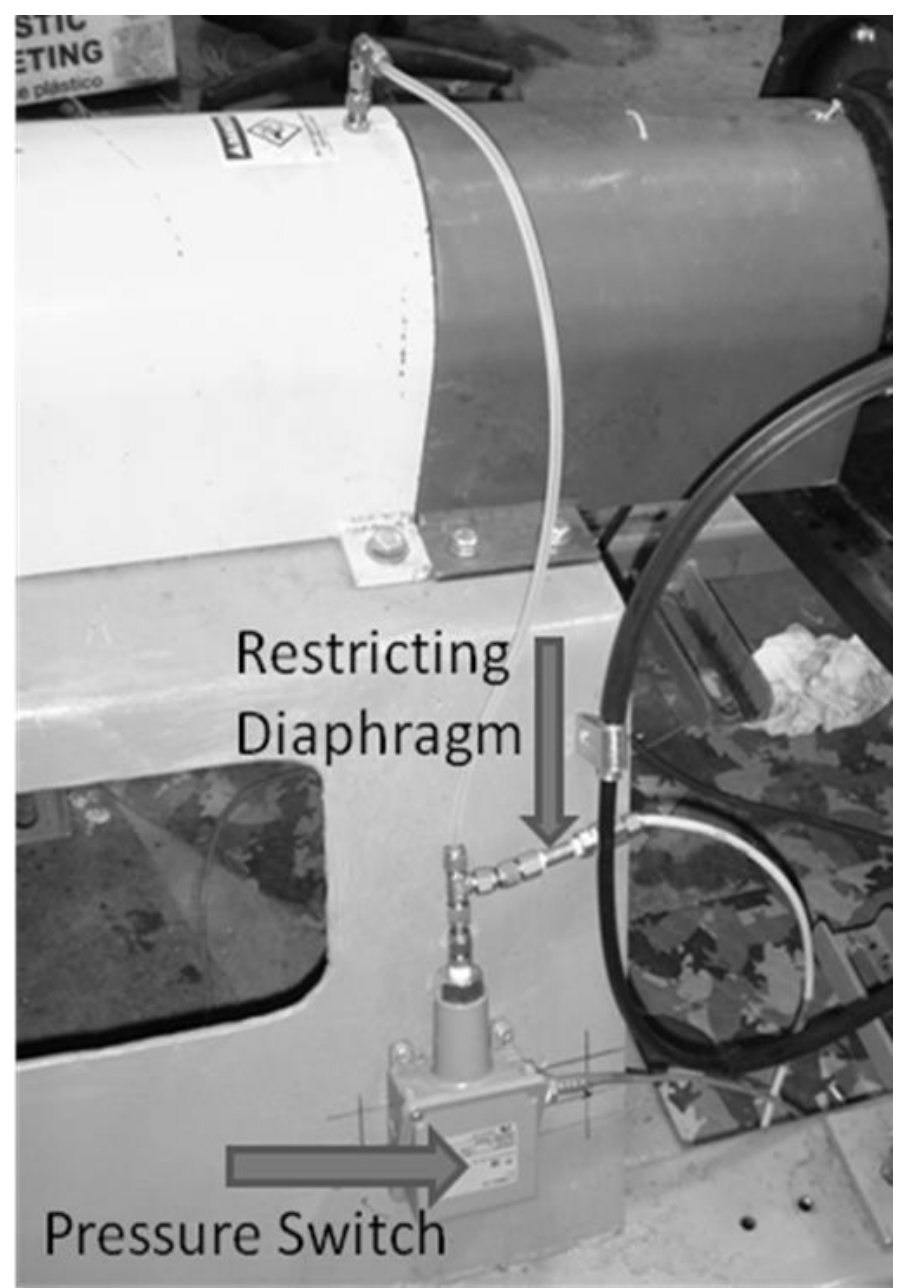

Figure 24 - Pressure Switch for Automatic Shut Off System 


\subsection{Fuel Conditioning}

A fuel conditioning system was built for the SEEL by fellow students Bryan Dickenson, Sier Zia, and Chad Crosby, with guidance from Dr. Ben Shade. This system was designed to heat or cool the fuel prior to delivery to the engine to make sure it meets a required temperature. In addition, the system included a weighing scale to measure fuel consumption. The system used heat exchangers with hot and cold water sources. Because of the lack of hot water at CAFEE's Westover facility, a small electric hot water heater was used. The fuel conditioning system was ready for use but it was determined that the electrical requirements of the hot water heater were beyond what was available and so the system was not used. A separate fuel weighing scale was used and it was determined that the temperature of the fuel at the time of the verification tests was satisfactory.

\subsection{Test Engine}

\subsubsection{TRU Basics}

The SEEL was commissioned using a four cylinder diesel engine from a transportable refrigeration unit (TRU). A TRU is a dedicated refrigeration system that provides cooling independently of the vehicles air conditioning unit. It allows for the transport of frozen and perishable goods over long distances. The TRU is usually mounted to the front of the storage container and runs off of a dedicated engine. A TRU unit is shown in Figure 25. 


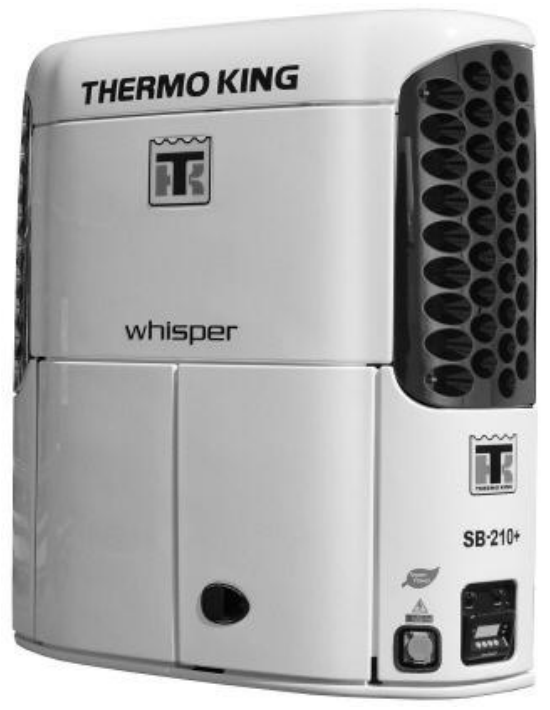

Figure 25 - Thermo King Transportable Refrigeration Unit [29]

\subsubsection{Thermo King C201}

The commissioning of the SEEL was done with a Thermo King engine which was removed from a TRU. Thermo King is a manufacturer of TRU equipment with the engines produced by Isuzu. The engine was an in-line 4 cylinder diesel engine utilizing direct injection. Additional specifications can be found in Table 20 .

Table 20 - Isuzu Engine Specifications

\begin{tabular}{|l|c|}
\hline Manufacturer & Isuzu \\
\hline Model & C201 \\
\hline Year & 1986 \\
\hline Number of Cylinders & 4 \\
\hline Bore & $83 \mathrm{~mm}$ \\
\hline Stroke & $92 \mathrm{~mm}$ \\
\hline Displacement & $1991 \mathrm{~cm}^{3}$ \\
\hline Power & $27 \mathrm{hp}$ \\
\hline Rated Speed & $2200 \mathrm{rpm}$ \\
\hline
\end{tabular}

This engine was donated by Belt Transfer Inc. The engine was stripped from a TRU and needed much work before being operational again. The engine was first cleaned and the oil and coolant was changed. A new intake air filter was installed along with new exhaust piping, 
coolant lines and oil filters. The throttle linkage was modified to work with the digital throttle controller actuator. The fuel system required bleeding to remove air from the fuel lines. Oil and coolant temperature sensors were installed and wired to the DAQ system. Figure 26 shows the engine upon its arrival to the lab, before being installed.

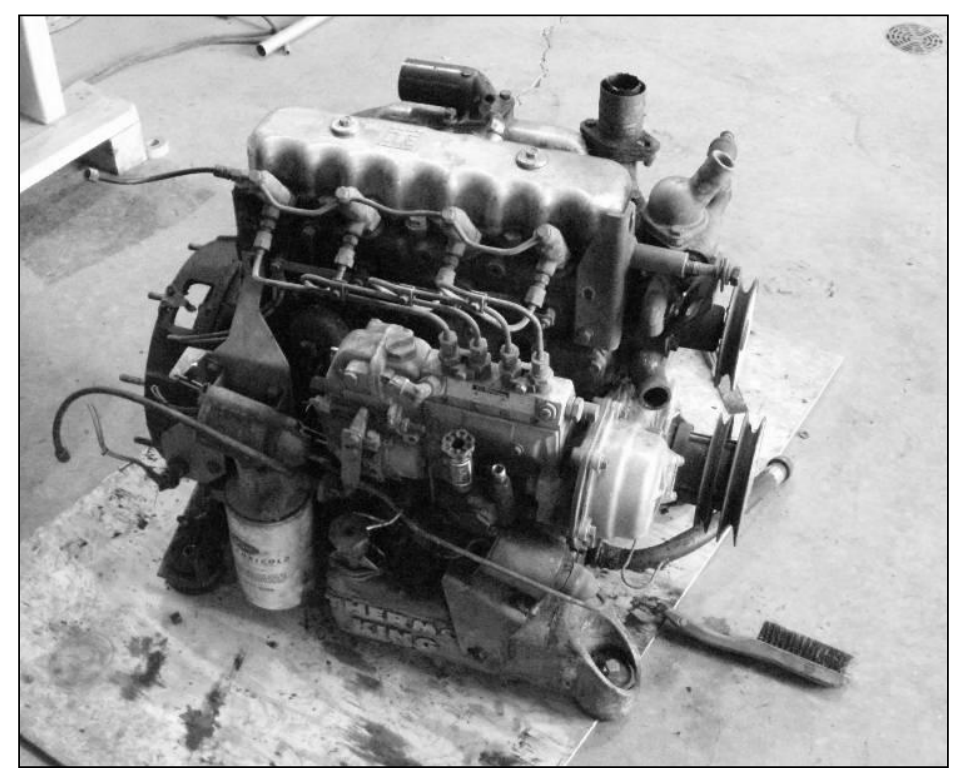

Figure 26 -1986 Isuzu C201 Engine

\subsection{Cooling System}

The cooling system for the SEEL was based upon the cooling system used at CAFEE's EERL facility and was constructed by Jacob Brown [2]. This system provided cooling for both the engine coolant and the dynamometer immersion water heater. This immersion water heater absorbed the energy that was generated by the dynamometer and dissipates it to water in a holding tank. This hot water was then cooled by passing it through a heat exchanger with cool water from a reservoir tank. The water in this reservoir tank was then cooled by a radiator. A similar system was used for the engine cooling.

The engine coolant was passed through another heat exchanger with cool water from the 
same reservoir tank. The engine coolant was also passed through an expansion tank which allowed the coolant to expand when heated. The heat exchangers, pumps and expansion tank were located inside the test cell. The radiator, reservoir and immersion heater were located outside due to space constraints. A diagram of the cooling system is shown in Figure 27. The heat exchangers, expansion tank and pumps are shown in Figure 28.

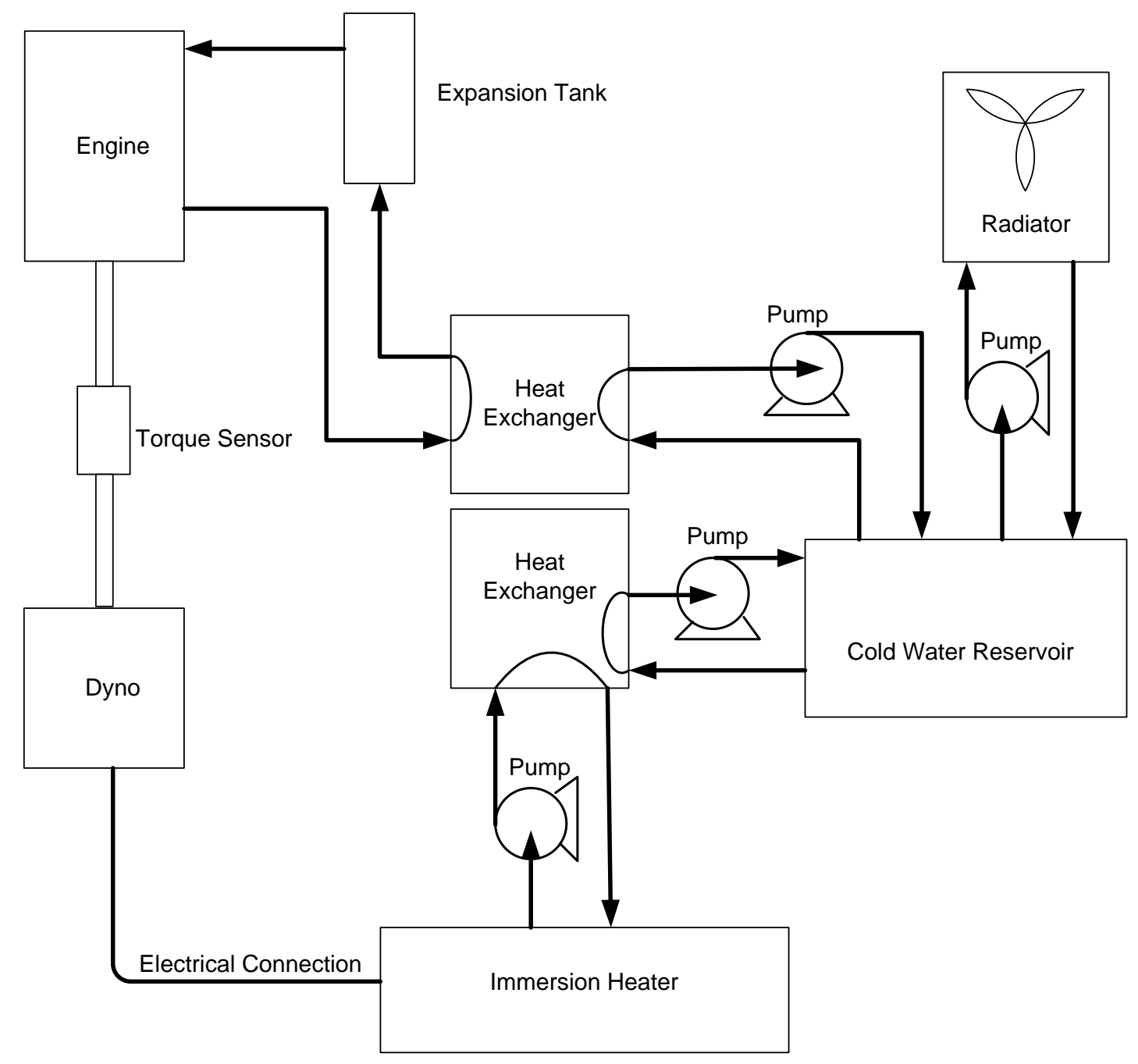

Figure 27 - Overview of Cooling System 


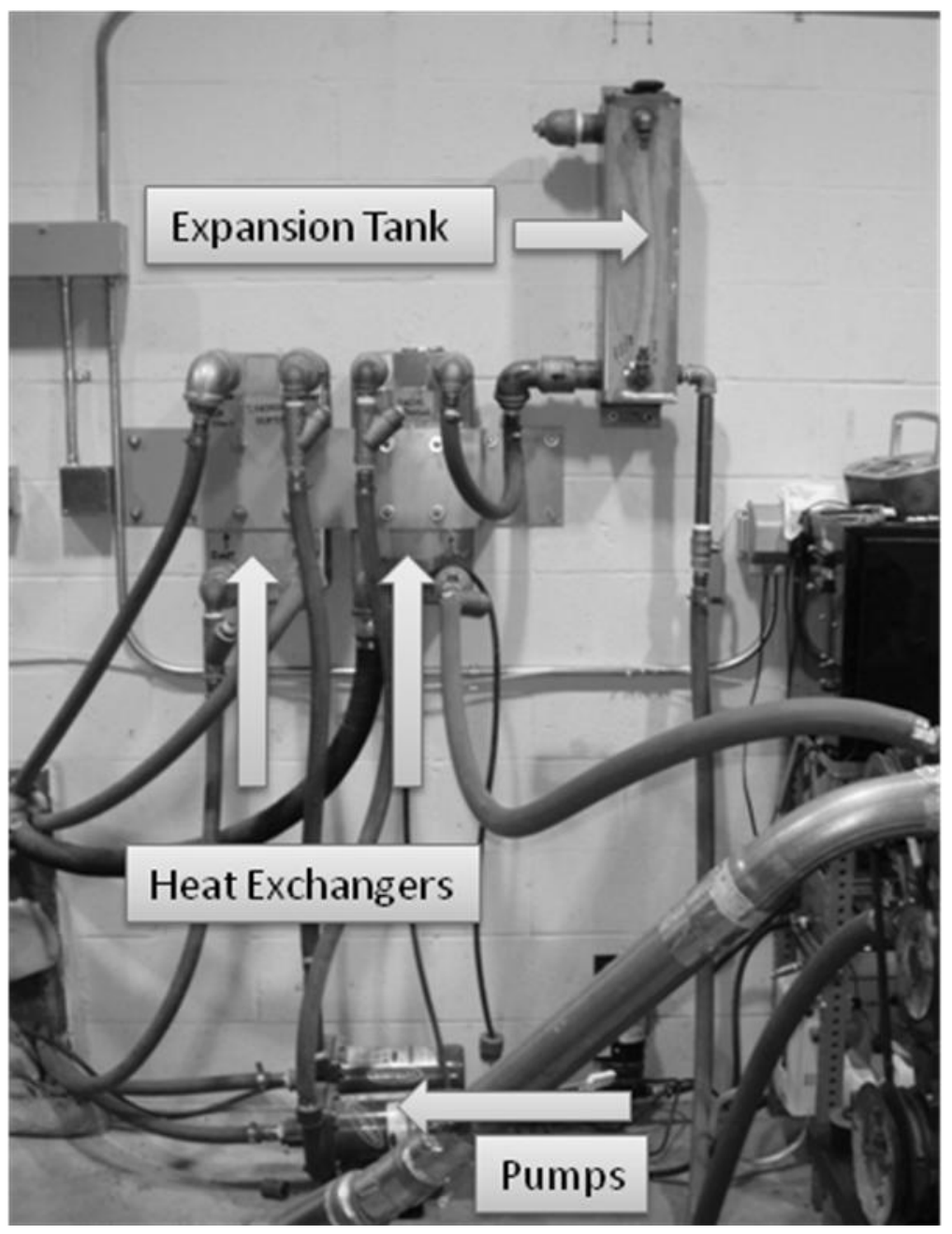

Figure 28 - Heat Exchangers and Expansion Tank 


\section{EXPERIMENTAL EQUIPMENT AND PROCEDURES FOR RAW LAB VERIFICATION}

\subsection{Introduction}

The SEEL was designed to be used with multiple emissions sampling systems including the 2007 Transportable Emissions Laboratory Container, the Transportable Analytical Trailer, the EERL Full-Scale Dilution Tunnel and the Raw Emissions Sampling System. Fellow graduate student Jacob Brown successfully used CAFEE's Transportable Analytical Trailer to test the SEEL and was able to show repeatable results [2]. It was desired that the raw emissions sampling system was to be used to test the SEEL. However, the raw emissions sampling system was not prepared for the commissioning process and needed to be verified against a separate dilute emissions measurement system in order to ensure its working capabilities and to provide confidence in the sampling system. It was deemed satisfactory to demonstrate the feasibility of using the raw emissions sampling system together with the SEEL by performing a set of verification tests at CAFEE's EERL facility

The verification tests for the raw sampling system were performed using a 1992 DDC S60 12.7 liter diesel engine. Simultaneous sampling of both the raw and dilute emissions sampling systems allowed for a direct comparison of the two data sets. These tests would confirm whether or not the raw sampling system was in working order and if they would be ready for testing with the SEEL. It was determined that steady state tests were best suited for the verification process, as a majority of certification procedures for off-road diesel engines are steady state emissions tests.

Three European Stationary Cycle (ESC) tests were performed for the purpose of gaseous emissions verification. All of the required pre-test checks and quality assurance procedures were 
performed prior to these tests. These include but are not limited to: leak checks, $\mathrm{NO}_{\mathrm{x}}$ efficiency checks, and water interference checks. For the three tests performed, both the raw emissions sampling system and the dilute sampling system simultaneously sampled exhaust from the same test engine. The raw sampling system results were compared to the results from a dilute sampling system which had previously been verified according to the EPA CFR Title 40 Part 86 [30]. CAFEE engineers set verification criteria that the raw emissions sampling system was required to meet in order to be verified as a working system. This criteria was based upon experience with previous comparisons that had been performed, as the US EPA CFR does not define verification standards for comparing raw and dilute sampling systems.

\subsection{DDC S60 Test Engine}

The engine used for the raw lab verification was a heavy-duty diesel engine made by the Detroit Diesel Corporation (DDC). It was a $12.7 \mathrm{~L}$ in-line 6 cylinder turbocharged diesel engine. It used a direct-injection fuel system with a turbocharged and intercooled intake system. This engine was designed for use in heavy-duty truck applications and has been used by CAFEE for numerous emissions related projects. This engine was chosen for these tests because it was a reliable engine with a well documented history of performance and emissions data. The engine was well maintained and because it has gone through sufficient aging over its lifetime, the emissions it produced were stable and repeatable. The engine specifications can be found in Table 21. The engine map is shown in Figure 29. 
Table 21 - DDC S60 Test Engine Information

\begin{tabular}{|l|c|}
\hline Manufacturer & Detroit Diesel \\
\hline Serial Number & 06R0105610 \\
\hline Year & DDC S60 \\
\hline Model Number & 12.7 liters \\
\hline Displacement & Inline-6 \\
\hline Configuration & 130mm X 160mm \\
\hline Bore X Stroke & 4 \\
\hline Strokes per Cycle & 1925 \\
\hline Induction & 365 \\
\hline Idle (rpm) & 1800 \\
\hline High Idle (rpm) & 1450 \\
\hline Rated Power (hp) & 1200 \\
\hline Rated Power Speed (rpm) & \\
\hline Rated Torque (ft-lb) & Turbocharged and Intercooled \\
\hline Rated Torque Speed (rpm) & 600 \\
\hline
\end{tabular}

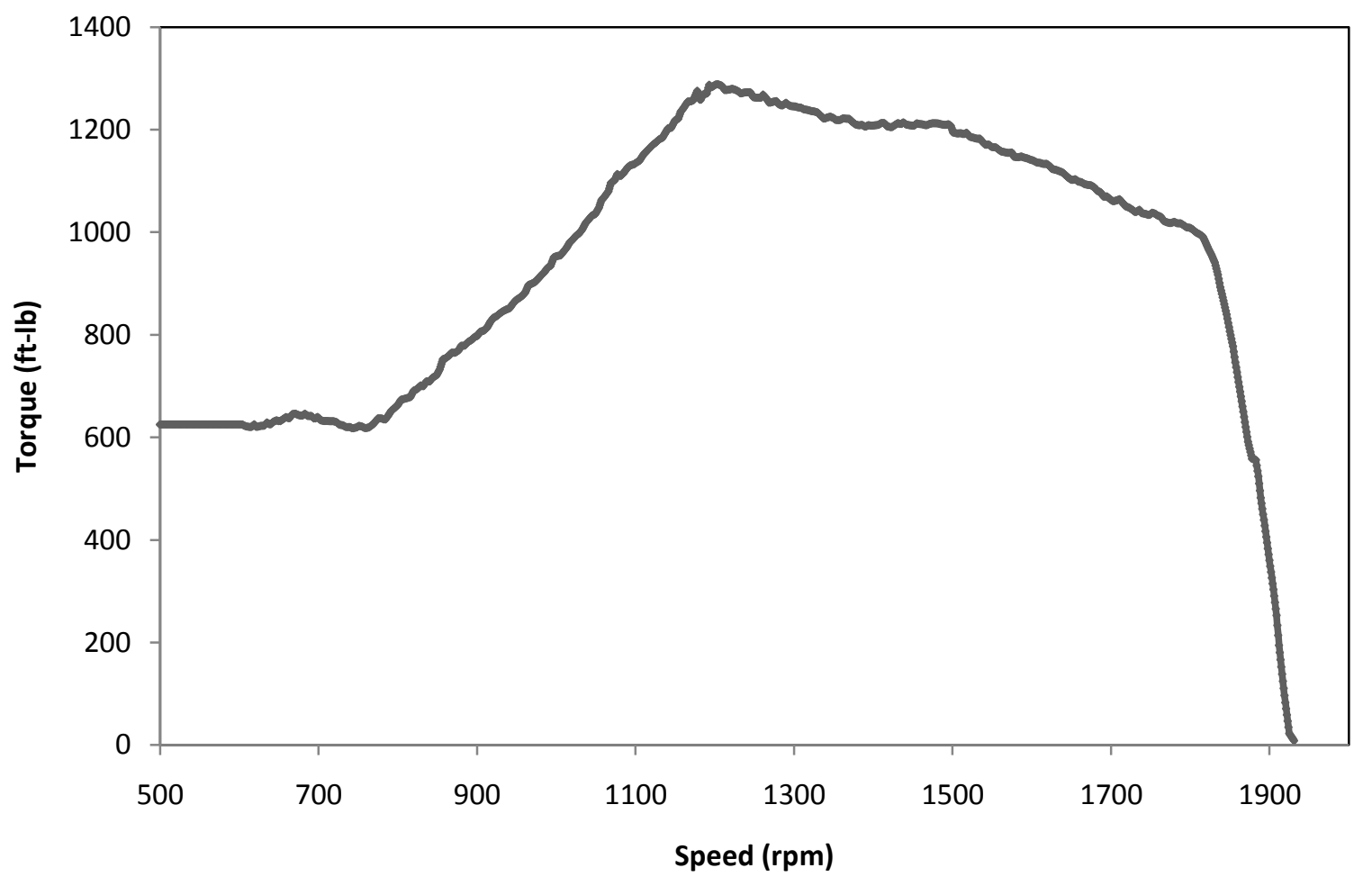

Figure 29 - Engine Map for DDC S60 


\subsection{Dynamometer}

The dynamometer used to test the DDC S60 engine was a direct current (DC) dynamometer made by General Electric model number DYC 243. It was capable of absorbing a maximum of $550 \mathrm{hp}$, and continuously able to absorb $500 \mathrm{hp}$. Additional specifications for this dynamometer are shown in Table 22.

Table 22 - G.E. Dynamometer Specifications

\begin{tabular}{|l|c|}
\hline Manufacturer & General Electric \\
\hline Serial Number & ZG-2-44-2G \\
\hline Model Number & DYC 243 \\
\hline Type & Direct Current \\
\hline Absorbing Capacity & $550 \mathrm{hp} @ 474$ volts, $812 \mathrm{amps}$ \\
\hline Motoring Capacity & $500 \mathrm{hp} @ 507$ volts, $812 \mathrm{amps}$ \\
\hline
\end{tabular}

\subsection{Raw Emissions Sampling System}

\subsubsection{Introduction}

The raw emissions sampling system was a measurement system that sampled gaseous emissions from raw engine exhaust with no dilution air. Typical emissions systems mix raw engine exhaust with dilution air in order to simulate the conditions that exist when engine exhaust mixes with the ambient air. This is especially important for PM measurement because of the formation processes that depend on conditions of the ambient air. The other exhaust constituents are less affected by dilution air and therefore can be measured with a raw sampling system. The raw sampling system had an independent PM measurement system but it was not working at the time of this testing, and therefore it will not be discussed.

The raw lab was primarily composed of three gaseous analyzers, their associated flow control systems and a DAQ system. Each analyzer and its accompanying hardware were housed 
in robust stainless steel boxes. The configuration of this system allowed for each analyzer to be individually moved during the transportation of the lab. The same is true for the DAQ computer. Without the use of dilution air and therefore no need for a dilution tunnel, the raw lab had the ability to be easily transported for in-field testing of off-road engines, locomotives and marine vessels. Although this system had been primarily used to test heavy duty diesel engines, it could test a large range of engine sizes including small engine. Information for the analyzers is shown in Table 23.

Table 23 - Analyzer Information for the Raw Sampling System

\begin{tabular}{|c|c|c|c|}
\hline Gas & Manufacturer & Measurement Method & Model \\
\hline $\mathrm{CO} / \mathrm{CO}_{2}$ & Horiba & NDIR & AIA220 \\
\hline $\mathrm{HC}$ & Horiba & HFID & FIA236 \\
\hline $\mathrm{NO}_{\mathrm{x}}$ & EcoPhysics & Chemiluminescence & CLD822CMH \\
\hline
\end{tabular}

The raw sampling system analyzers described in this section were all required to meet specifications described by CFR Title 40, Part 1065 [28]. These included the ability to meet certain response, precision, and drift requirements. The analyzers were required to have a response time of $95 \%$ of a step value within 6 seconds or less. The zero drift for each analyzer must have been less than $2 \%$ of full scale. The precision of the analyzers must have been $\pm 1 \%$ of full scale concentration for ranges above $155 \mathrm{ppm}$, and $\pm 2 \%$ of full scale concentration for ranges below $155 \mathrm{ppm}$. Additional specifications including exemptions and detailed requirements can be found in the US EPA CFR Title 40 Part 1065 [28].

\subsection{2 $\mathrm{CO} / \mathrm{CO}_{2}$ Analyzer}

A single analyzer was used to measure both $\mathrm{CO}$ and $\mathrm{CO}_{2}$. This analyzer was a Horiba model AIA220 analyzer. This analyzer worked on the principle of non-dispersive infrared (NDIR) sensors. This type of sensor had four main components, an infrared source, a sample chamber or light tube, a wavelength filter, and an infrared detector [31]. The sample gas was 
pumped into the sample chamber which was then exposed to the IR light. On the other end of the sample chamber the IR light was filtered and absorbed by the detector. The operating principle behind this sensor was the fact that a certain concentration of gas will absorb a certain wavelength of IR light. The remaining wavelengths will transmit through the gas. The analyzer included a sample cell and reference cell filled with non-absorbing gas. The analyzers IR detectors measured the difference between these cells which enabled the analyzer to determine the concentration of $\mathrm{CO}$ and $\mathrm{CO}_{2}$ gas in the sample stream. The amount of IR light that reached the detector was inversely related to the concentration of target gas in the sample chamber [31].

A flow control system accompanied the $\mathrm{CO} / \mathrm{CO}_{2}$ analyzer which included heated pumps, filters, and a chiller which removed water from the sample stream. From the exhaust sample probe, the sample stream first traveled through heated stainless steel lines to a filter which removed any particles which may cause damage to the analyzer. It then traveled through a heated pump to a chiller and then to a pressure regulator. The chiller removed water from the sample stream because if water was introduced into the NDIR sensor it would cause false readings and could cause damage. A bypass valve before the chiller and heated pump allowed for the correct flow to be controlled through the analyzer. The heated pumps and filters were held at a temperature of $235^{\circ} \mathrm{F}$ in accordance with US EPA CFR Part 1065 [28]. The $\mathrm{CO} / \mathrm{CO}_{2}$ analyzer is shown in Figure 30. 


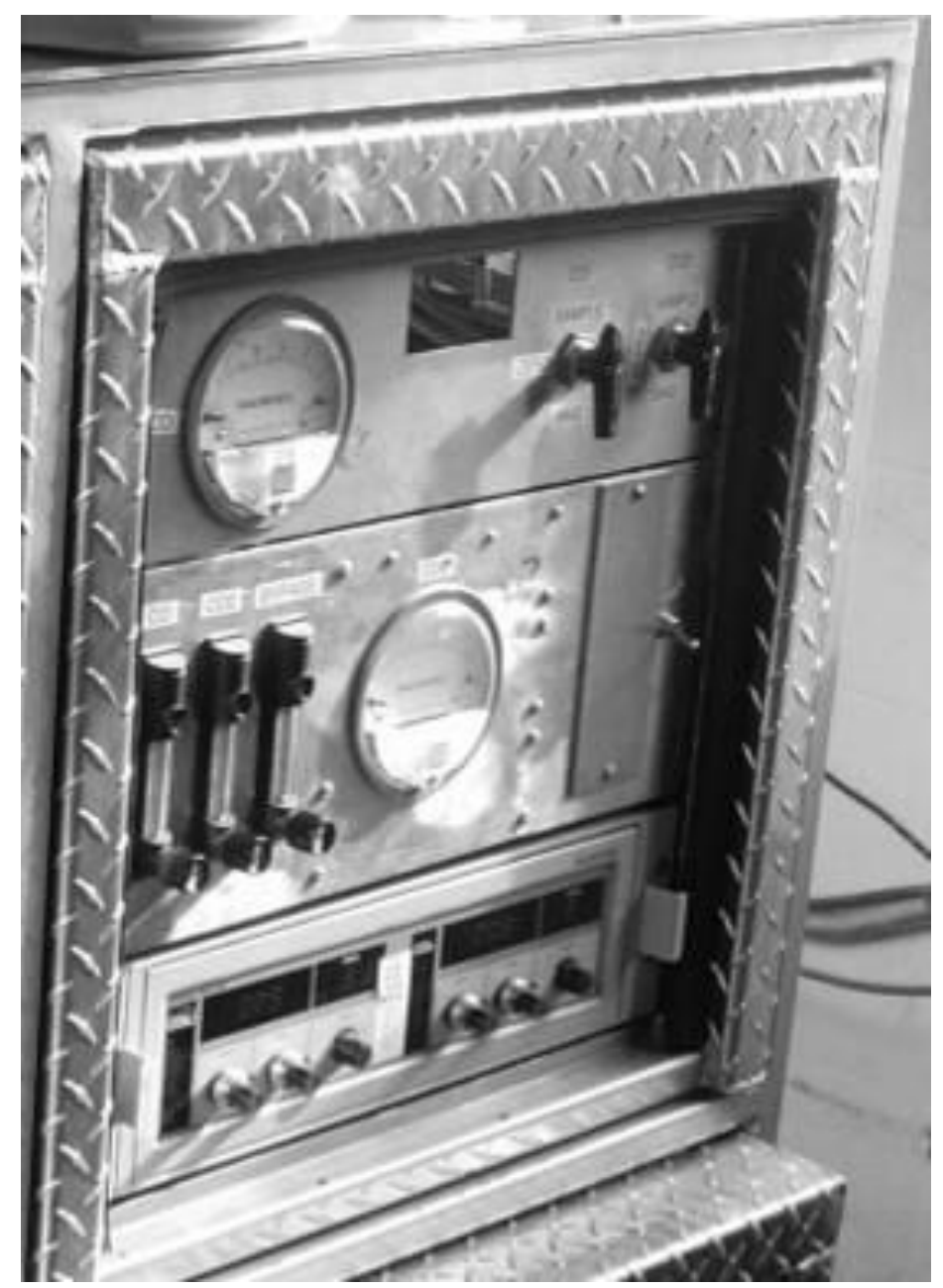

Figure 30 - $\mathrm{CO} / \mathrm{CO}_{2}$ Analyzer and Flow Control

\subsection{3 $\mathrm{NO}_{\mathrm{x}}$ Analyzer}

For the purpose of measuring $\mathrm{NO}_{\mathrm{x}}$, the raw emissions sampling system used an EcoPhysics analyzer based on chemiluminescent detection technology. The principle behind this technology was that when an NO molecule reacts with ozone, it is oxidized to $\mathrm{NO}_{2}$ in an excited state [32]. A small portion of these molecules decay by emitting a photon (giving off light) in the infrared portion of the spectrum. Therefore, if one mixes a gas sample with ozone and measures the amount of light emitted, the concentration of NO in the sample may be determined. Since we would also like to measure $\mathrm{NO}_{2}$ as well as $\mathrm{NO}$, and collectively report it as $\mathrm{NO}_{\mathrm{x}}$, the sample stream passed through an external $\mathrm{NO}_{\mathrm{x}}$ converter before reaching the analyzer. This device 
efficiently converted all $\mathrm{NO}_{2}$ molecules to $\mathrm{NO}$ molecules, which were then detected by the analyzer. The exact efficiency of this device was regularly checked as part of quality assurance procedures, and is discussed in Section 5.8. There was also an internal converter in the analyzer but it was not capable of handling the $\mathrm{NO}_{2}$ concentrations in a raw sample and therefore the external $\mathrm{NO}_{\mathrm{x}}$ converter was needed.

Accompanying the $\mathrm{NO}_{\mathrm{x}}$ analyzer and external converter, there was also a flow control system similar to that of the $\mathrm{CO} / \mathrm{CO}_{2}$ analyzer. This included heated lines and pumps, filters, bypass valves, and a flooded probe with distribution box. It was also important that there was no condensation in this analyzer and flow control system. $\mathrm{NO}_{2}$ is soluble in water and therefore any condensation would absorb $\mathrm{NO}_{2}$ and would result in poor analyzer readings [33]. A chiller, downstream of the external converter, removed any water in the sample line before it reached the analyzer. Also, heated lines were run from the sample probe to the inlet of the $\mathrm{NO}_{\mathrm{x}}$ measurement box. The plumbing inside the $\mathrm{NO}_{\mathrm{x}}$ box was also heated and insulated to prevent any part of the system from forming condensation. The temperature of the heated sample lines and pump was held at $235^{\circ} \mathrm{F}$ in accordance with the US EPA CFR Title 40 Part 1065 [28]. The $\mathrm{NO}_{\mathrm{x}}$ analyzer is shown in Figure 31. 


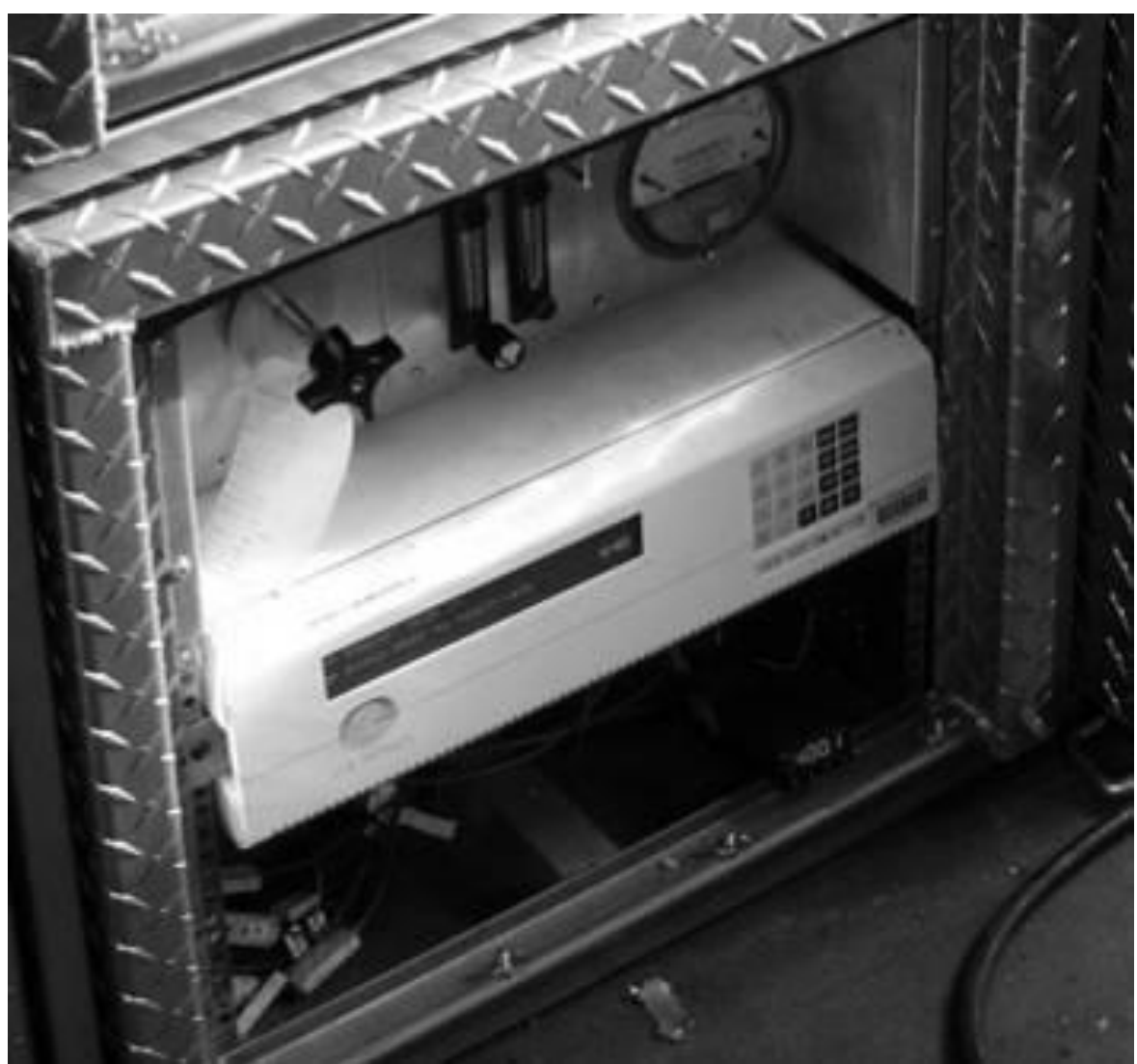

Figure 31 - NO/ $\mathrm{NO}_{x}$ Analyzer, Filter and Flow Control

\subsubsection{HC Analyzer}

The raw emissions sampling system used a Horiba model number FIA 236 analyzer to measure HC. This analyzer worked on the principle of heated flame ionization detection (HFID). HFID was a type of gas chromatography first developed by James and Martin in 1952 [34]. This method of measuring $\mathrm{HC}$ involved the detection of ions which are produced when the sample is burned in a small flame of hydrogen and air. This flame is at a temperature which burns most organic compounds and produces an electric current which can be measured and recorded.

The $\mathrm{HC}$ analyzer was part of a system which included heated lines, pumps, bypass valves, and a flooded probe with distribution box similar to that of the $\mathrm{NO}_{\mathrm{x}}$ analyzer systems. This analyzer did not include a chiller because the analyzer is capable of reporting $\mathrm{HC}$ 
measurements with water vapor in the sample. Heated lines were still used to prevent condensation. The temperature of the heated lines and pump was held at $375^{\circ} \mathrm{F}$ in accordance with the US EPA CFR Title 40 Part 1065 [28]. The analyzer is shown in Figure 32.

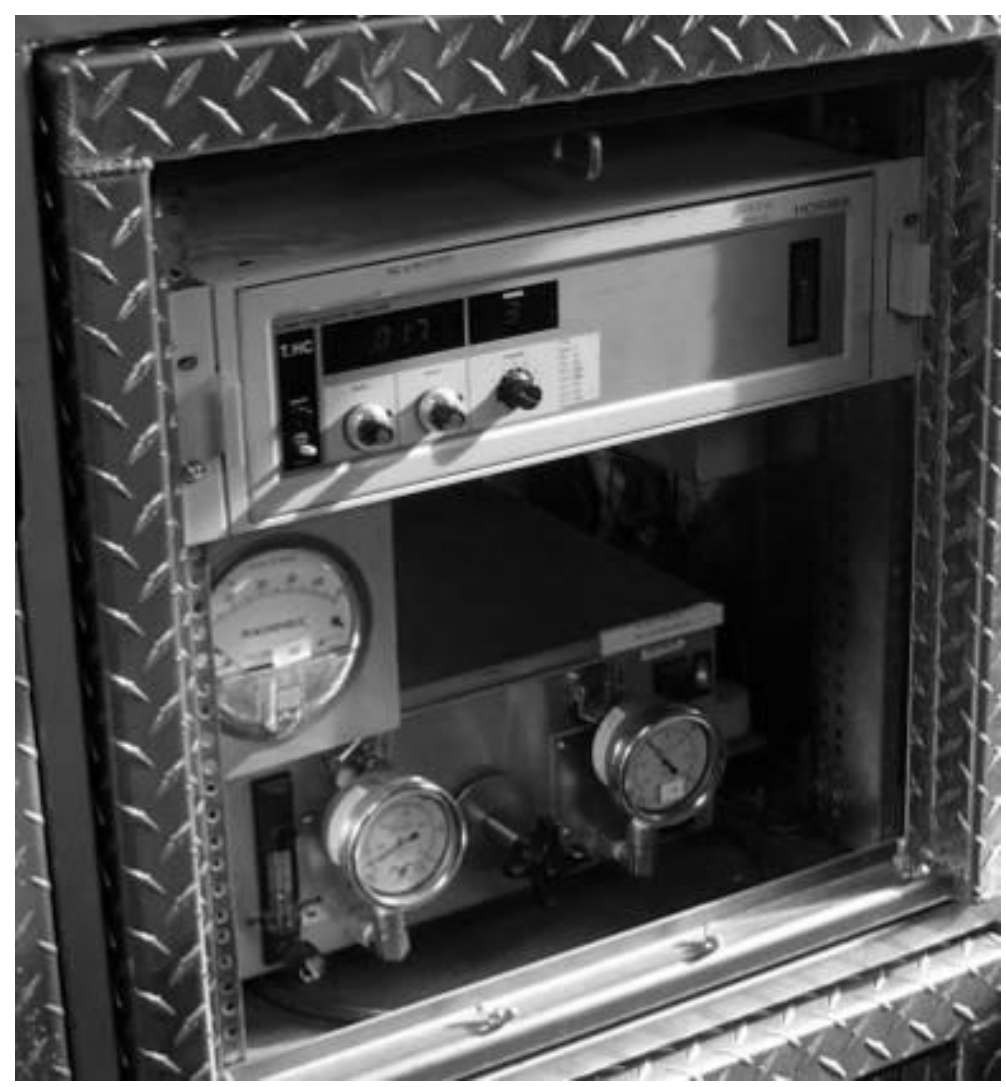

Figure 32 - HC Analyzer

\subsubsection{Data Acquisition}

A dedicated computer system for the raw lab was housed in a stainless box similar to that of the analyzers. This computer was responsible for recording all data coming from the analyzers during testing. It was used to perform the calibrations of each analyzer and stored the results to be used during the emissions tests. Each analyzer communicated with the DAQ computer via an Ethernet connection. The details of the calibration process are discussed in Section 5.4.6. 


\subsubsection{Calibration of Analyzers}

The calibration process for each analyzer system was essentially the same with the differences being the type and concentration of the gases used for each analyzer. The process involved calibrating each individual analyzer using zero and span gases and a gas divider. The gas divider was a device that controlled the amount of the two gases flowing through it. The gas divider position represents the amount of span gas being sent to the analyzer. At gas divider position $100 \%$, the analyzer is receiving $100 \%$ span gas with no zero gas. At gas divider position $0 \%$, the analyzer is receiving no span gas, and only the zero gas. The gases then flowed to the analyzers which provided a voltage response to the DAQ system. Ample time was given to ensure a steady state response was reached. The response was then related to concentration of the gas according to the gas divider position. A polynomial equation was generated which defined the relationship between the output voltage from the analyzer, and the concentration of gas flowing through the analyzer. Using this equation, the concentration of the gas was then predicted and compared to the actual concentration, which allow for an error between the calibrated and fit values to be determined. The coefficients from this polynomial equation were then stored in a calibration file which were then used for the emissions tests. The $\mathrm{R}^{2}$ value for each calibration represents how well the equation fits the data points. An $\mathrm{R}^{2}$ value of one represents a perfect fit, with a less perfect fit being anything lower than that. It can be seen from the calibration results below, that each calibration equation fit the data very well, with $\mathrm{R}^{2}$ values being very close to one.

The $\mathrm{NO}_{\mathrm{x}}$ and $\mathrm{HC}$ analyzers both provide a linear voltage response to the changes in concentrations, while the $\mathrm{CO}$ and $\mathrm{CO}_{2}$ analyzers provide non-linear response. A strict labeling procedure ensured that the concentrations of the calibration gases are accurate. Table 24 shows 
the zero and span gases for the analyzers for both the raw and dilute sampling systems.

Table 25 through Table 28 shows the calibration results for the four analyzers.

Table 24 - Zero and Span Gases

\begin{tabular}{|c|c|c|}
\hline Analyzer & Zero Gas & Span Gas \\
\hline $\mathrm{CO}_{2}$ & $\mathrm{~N}_{2}$ & $\mathrm{CO}_{2}$ \\
\hline $\mathrm{CO}$ & $\mathrm{N}_{2}$ & $\mathrm{CO}$ \\
\hline $\mathrm{NO}_{\mathrm{x}}$ & $\mathrm{N}_{2}$ & $\mathrm{NO}^{*}$ \\
\hline $\mathrm{HC}$ & Zero Grade Air & $\mathrm{C}_{3} \mathrm{H}_{8}$ \\
\hline \multirow{2}{*}{$\begin{array}{c}\text { single blends of NO named as NO } \mathrm{NO}_{\mathrm{x}} \text { with a maximum } \mathrm{NO}_{2} \\
\text { concentration of 5 percent of the nominal value [28] }\end{array}$} \\
\hline
\end{tabular}

Table $25-\mathrm{CO}_{2}$ Analyzer Calibration Results

\begin{tabular}{|c|c|c|c|c|}
\hline $\begin{array}{c}\text { Gas Divider } \\
\text { Position }\end{array}$ & $\begin{array}{c}\text { Voltage } \\
\text { Response }(\mathbf{V})\end{array}$ & $\begin{array}{c}\text { Calibrated Value } \\
(\%)\end{array}$ & $\begin{array}{c}\text { Fit Value } \\
(\%)\end{array}$ & $\begin{array}{c}\text { Error (\% } \\
\text { of Point) }\end{array}$ \\
\hline $100 \%$ & 5.0055 & 12.110 & 12.088 & $-0.2 \%$ \\
\hline $90 \%$ & 4.7149 & 10.899 & 10.906 & $0.1 \%$ \\
\hline $80 \%$ & 4.3982 & 9.688 & 9.712 & $0.2 \%$ \\
\hline $70 \%$ & 4.0414 & 8.477 & 8.479 & $0.0 \%$ \\
\hline $60 \%$ & 3.6602 & 7.266 & 7.283 & $0.2 \%$ \\
\hline $50 \%$ & 3.2204 & 6.055 & 6.043 & $-0.2 \%$ \\
\hline $40 \%$ & 2.732 & 4.844 & 4.824 & $-0.4 \%$ \\
\hline $30 \%$ & 2.1783 & 3.633 & 3.614 & $-0.5 \%$ \\
\hline $20 \%$ & 1.5538 & 2.422 & 2.427 & $0.2 \%$ \\
\hline $10 \%$ & 0.8397 & 1.211 & 1.243 & $2.7 \%$ \\
\hline $0 \%$ & -0.0057 & 0 & -0.015 & $\mathrm{n} / \mathrm{a}$ \\
\hline $\mathbf{P}^{\mathbf{P}} \%$ & $0.0329687 \mathrm{x}^{3}+0.0299377 \mathrm{x}^{2}+1.44035 \mathrm{x}-0.00671397$ \\
\hline $\mathbf{R}^{\mathbf{2}}$ Value: & 0.999978 & \multicolumn{5}{l}{} \\
\hline
\end{tabular}


Table 26 - CO Analyzer Calibration Results

\begin{tabular}{|c|c|c|c|c|}
\hline $\begin{array}{c}\text { Gas Divider } \\
\text { Position } \\
\end{array}$ & $\begin{array}{c}\text { Voltage } \\
\text { Response (V) }\end{array}$ & $\begin{array}{c}\text { Calibrated } \\
\text { Value (ppm) }\end{array}$ & $\begin{array}{c}\text { Fit Value } \\
(\mathrm{ppm})\end{array}$ & $\begin{array}{c}\text { Error (\% } \\
\text { of Point) }\end{array}$ \\
\hline $100 \%$ & 5.015 & 987.0 & 985.19 & $-0.2 \%$ \\
\hline $90 \%$ & 4.6186 & 888.3 & 889.03 & $0.1 \%$ \\
\hline $80 \%$ & 4.1988 & 789.6 & 790.63 & $0.1 \%$ \\
\hline $70 \%$ & 3.7597 & 690.9 & 691.55 & $0.1 \%$ \\
\hline $60 \%$ & 3.3033 & 592.2 & 592.66 & $0.1 \%$ \\
\hline $50 \%$ & 2.8261 & 493.5 & 493.78 & $0.1 \%$ \\
\hline $40 \%$ & 2.3248 & 394.8 & 394.84 & $0.0 \%$ \\
\hline $30 \%$ & 1.7924 & 296.1 & 295.31 & $-0.3 \%$ \\
\hline $20 \%$ & 1.2288 & 197.4 & 196.17 & $-0.6 \%$ \\
\hline $10 \%$ & 0.6305 & 98.7 & 97.94 & $-0.8 \%$ \\
\hline $0 \%$ & -0.0056 & 0 & 1.42 & $\mathrm{n} / \mathrm{a}$ \\
\hline Polynomial: & \multicolumn{4}{|c|}{$10.0843 x^{2}+145.426 x+2.24029$} \\
\hline $\mathbf{R}^{2}$ Value: & 0.99999 & & & \\
\hline
\end{tabular}

Table 27 - HC Analyzer Calibration Results

\begin{tabular}{|c|c|c|c|c|}
\hline $\begin{array}{c}\text { Gas Divider } \\
\text { Position }\end{array}$ & $\begin{array}{c}\text { Voltage } \\
\text { Response (V) }\end{array}$ & $\begin{array}{c}\text { Calibrated } \\
\text { Value (ppm) }\end{array}$ & $\begin{array}{c}\text { Fit Value } \\
(\mathrm{ppm})\end{array}$ & $\begin{array}{l}\text { Error (\% } \\
\text { of Point) }\end{array}$ \\
\hline $100 \%$ & 4.9954 & 302.70 & 302.94 & $0.1 \%$ \\
\hline $90 \%$ & 4.4924 & 272.43 & 272.46 & $0.0 \%$ \\
\hline $80 \%$ & 3.9922 & 242.16 & 242.15 & $-0.0 \%$ \\
\hline $70 \%$ & 3.4874 & 211.89 & 211.56 & $-0.2 \%$ \\
\hline $60 \%$ & 2.9907 & 181.62 & 181.47 & $-0.1 \%$ \\
\hline $50 \%$ & 2.4933 & 151.35 & 151.33 & $-0.0 \%$ \\
\hline $40 \%$ & 1.9941 & 121.08 & 121.08 & $0.0 \%$ \\
\hline $30 \%$ & 1.4953 & 90.81 & 90.86 & $0.1 \%$ \\
\hline $20 \%$ & 0.9984 & 60.54 & 60.75 & $0.3 \%$ \\
\hline $10 \%$ & 0.4985 & 30.27 & 30.46 & $0.6 \%$ \\
\hline $0 \%$ & -0.0075 & 0 & -0.2 & $\mathrm{n} / \mathrm{a}$ \\
\hline Polynomial: & \multicolumn{4}{|c|}{$60.5919 x+0.25513$} \\
\hline $\mathbf{R}^{2}$ Value: & 0.999997 & & & \\
\hline
\end{tabular}


Table $28-\mathrm{NO}_{x}$ Analyzer Calibration Results

\begin{tabular}{|c|c|c|c|c|}
\hline $\begin{array}{l}\text { Gas Divider } \\
\text { Position }\end{array}$ & $\begin{array}{c}\text { Voltage } \\
\text { Response }(\mathbf{V})\end{array}$ & $\begin{array}{c}\text { Calibrated } \\
\text { Value (ppm) }\end{array}$ & $\begin{array}{c}\text { Fit Value } \\
\text { (ppm) }\end{array}$ & $\begin{array}{l}\text { Error (\% } \\
\text { of Point) }\end{array}$ \\
\hline $100 \%$ & 9.4945 & 1477.0 & 1475.70 & $-0.1 \%$ \\
\hline $90 \%$ & 8.5465 & 1329.3 & 1327.62 & $-0.1 \%$ \\
\hline $80 \%$ & 7.6033 & 1181.6 & 1180.29 & $-0.1 \%$ \\
\hline $70 \%$ & 6.6606 & 1033.9 & 1033.04 & $-0.1 \%$ \\
\hline $60 \%$ & 5.7240 & 886.2 & 886.72 & $0.1 \%$ \\
\hline $50 \%$ & 4.7992 & 738.5 & 742.27 & $0.5 \%$ \\
\hline $40 \%$ & 3.8507 & 590.8 & 594.10 & $0.6 \%$ \\
\hline $30 \%$ & 2.8998 & 443.1 & 445.57 & $0.6 \%$ \\
\hline $20 \%$ & 1.9464 & 295.4 & 296.65 & $0.4 \%$ \\
\hline $10 \%$ & 0.9865 & 147.7 & 146.70 & $-0.7 \%$ \\
\hline $0 \%$ & 0.0143 & 0 & -5.17 & $\mathrm{n} / \mathrm{a}$ \\
\hline Polynomial: & \multicolumn{4}{|c|}{$156.206 x-7.39659$} \\
\hline $\mathbf{R}^{2}$ Value: & 0.999972 & & & \\
\hline
\end{tabular}

\subsection{EERL Dilute Emissions Sampling System}

Results from the raw sampling system were compared to the data from the dilute measurement system at CAFEE's Engine and Emissions Research Laboratory (EERL). This dilute system was built according to CFR Title 40, Chapter 1, Subchapter C, Part 86, Subpart N [30] which provides specifications for laboratories performing emissions tests on heavy-duty diesel engines. The dilution system allowed for simulation of real world conditions of the engine exhaust mixing with ambient air. Many of the chemical components of the exhaust are affected by the conditions of the ambient air with which they mix. Having control of these conditions is very important specifically for PM measurement. The details of the dilute sampling system can be quite intricate, and so a brief overview is provided here. 


\subsubsection{Dilution Tunnel and Critical Flow Venturi}

The EERL facility used a full scale critical flow venturi - constant volume sampler (CFV-CVS) system. This CFV-CVS system was used to ensure a constant flow rate through the dilution tunnel. There were four different venturis that could be used to achieve different flow rates. The dilution tunnel used was a stainless steel tunnel $40 \mathrm{ft}$ long and 18 inches in diameter. The exhaust gas was introduced into the center of the tunnel cross section where the ambient air was flowing. Soon after, the gases encountered a mixing orifice which created a homogeneous mixture. The temperature and humidity of the dilution air were controlled. The sample probes were placed downstream at a sufficient distance to ensure proper mixing before sampling. Three different probes were used to extract samples for the $\mathrm{HC}, \mathrm{CO} / \mathrm{CO}_{2}$, and $\mathrm{NO}_{\mathrm{x}}$ analyzers. The probes drew samples into heated lines where the temperature was controlled.

\subsubsection{Analyzers}

The manufacturer and model numbers of the gaseous analyzers used with this dilute system are shown in Table 29. These were the same model analyzers used in the raw sampling system with the exception of the $\mathrm{HC}$ analyzer. These analyzers underwent different calibration processes to compensate for the lower concentrations that were present in the diluted samples. Accompanying flow control systems and sample conditioning chillers were also used with these analyzers. As with the raw lab, the $\mathrm{HC}$ analyzer system did not include a chiller. The temperature of the heated lines and pumps for each analyzer system was controlled.

Table 29 - Analyzer Information for EERL Dilute Measurement System

\begin{tabular}{|c|c|c|c|}
\hline Gas & Manufacturer & Measurement Method & Model \\
\hline $\mathrm{CO} / \mathrm{CO}_{2}$ & Horiba & NDIR & AIA220 \\
\hline $\mathrm{HC}$ & $\begin{array}{c}\text { California Analytical } \\
\text { Instruments }\end{array}$ & FID & $600 \mathrm{M}$ HFID \\
\hline $\mathrm{NO}_{\mathrm{x}}$ & EcoPhysics & Chemiluminescence & CLD822CMH \\
\hline
\end{tabular}




\subsubsection{Data Acquisition}

The data from the gas analyzers was recorded on the data acquisition systems of the EERL. This system included equipment for signal conditioning and analog to digital conversions. The DAQ computer used software developed for the EERL lab to retrieve inputs from the analyzers as well as numerous other sensors in the lab.

\subsubsection{Calibration of Analyzers}

Similar to the calibration process of the raw lab analyzers, a gas divider was used to send zero and span gases to each analyzer in order to review its response and generate a calibration curve which was then used during the emissions tests. The results from the calibration of the analyzers for the EERL dilute measurement system include the coefficients of the polynomial equation, while the actual voltages and errors corresponding to the gas divider positions are not given. Table 30 shows the calibration results for the four analyzers. Note how the calibration equations for $\mathrm{NO}_{\mathrm{x}}$ and $\mathrm{HC}$ are linear while $\mathrm{CO}_{2}$ and $\mathrm{CO}$ are higher order polynomials.

Table 30 - Calibration Results for the EERL Analyzers

\begin{tabular}{|c|c|c|}
\hline Analyzer & Polynomial Equation & $\mathbf{R}^{2}$ Value \\
\hline $\mathrm{CO}_{2}$ & $1.250 \mathrm{e}-7 \mathrm{x}^{3}+1.413 \mathrm{x}^{2}+13.984 \mathrm{x}-0.9947$ & 0.99999 \\
\hline $\mathrm{CO}$ & $7.869 \mathrm{x}^{3}-5.389 \mathrm{x}^{2}+0.3604 \mathrm{x}+0.11379$ & 0.99999 \\
\hline $\mathrm{NO}_{\mathrm{x}}$ & $0.2493 \mathrm{x}+0.3124$ & 0.99999 \\
\hline $\mathrm{HC}$ & $0.01486 \mathrm{x}-1.5182$ & 0.99999 \\
\hline
\end{tabular}

\subsection{ESC Test Cycle}

The European Stationary Cycle (ESC) is a 13 mode steady state emissions test cycle developed for the certification of heavy duty diesel engines [35]. The cycle was developed in Europe in the year 2000. The ESC cycle describes the speed and load set points and other 
requirements that the engine must meet during the test. The engine must complete the load and speed changes between modes within the first 20 seconds of each mode. During each mode, the engine must be held at the specified speed within $\pm 50 \mathrm{rpm}$. The torque must be held within $\pm 2 \%$ of the maximum torque at that speed. Each mode is assigned a weighting factor which defines its weight in the final weighted average for the entire test. Incorporating these weighting factors, the emissions are averaged over the cycle and results are then expressed in units of $\mathrm{g} / \mathrm{bkW}$-hr or g/bhp-hr. The duration, weighting factors and speed and load set points are shown for each mode in Table 31.

Table 31 - ESC Test Cycle Details [35]

\begin{tabular}{|c|c|c|c|c|}
\hline Mode & Engine Speed & \% Load & Weight Factor (\%) & Duration \\
\hline 1 & Low Idle & 0 & 15 & 4 minutes \\
\hline 2 & A & 100 & 8 & 2 minutes \\
\hline 3 & B & 50 & 10 & 2 minutes \\
\hline 4 & B & 75 & 10 & 2 minutes \\
\hline 5 & A & 50 & 5 & 2 minutes \\
\hline 6 & A & 75 & 5 & 2 minutes \\
\hline 7 & A & 25 & 5 & 2 minutes \\
\hline 8 & B & 100 & 9 & 2 minutes \\
\hline 9 & B & 25 & 10 & 2 minutes \\
\hline 10 & C & 100 & 8 & 2 minutes \\
\hline 11 & C & 25 & 5 & 2 minutes \\
\hline 12 & C & 75 & 5 & 2 minutes \\
\hline 13 & C & 50 & 5 & 2 minutes \\
\hline
\end{tabular}

The A, B and C values for the engine speed set points were determined from equations based upon engine speeds at $70 \%$ and $50 \%$ of the maximum power of the engine [35]. The percent load values were based upon the maximum torque produced by the engine. For the DDC S60 test engine, the values of the engine speeds A, B, and C are $1212 \mathrm{rpm}, 1431 \mathrm{rpm}$, and $1650 \mathrm{rpm}$, respectively. Figure 33 shows the engine speed and torque during this test cycle. 


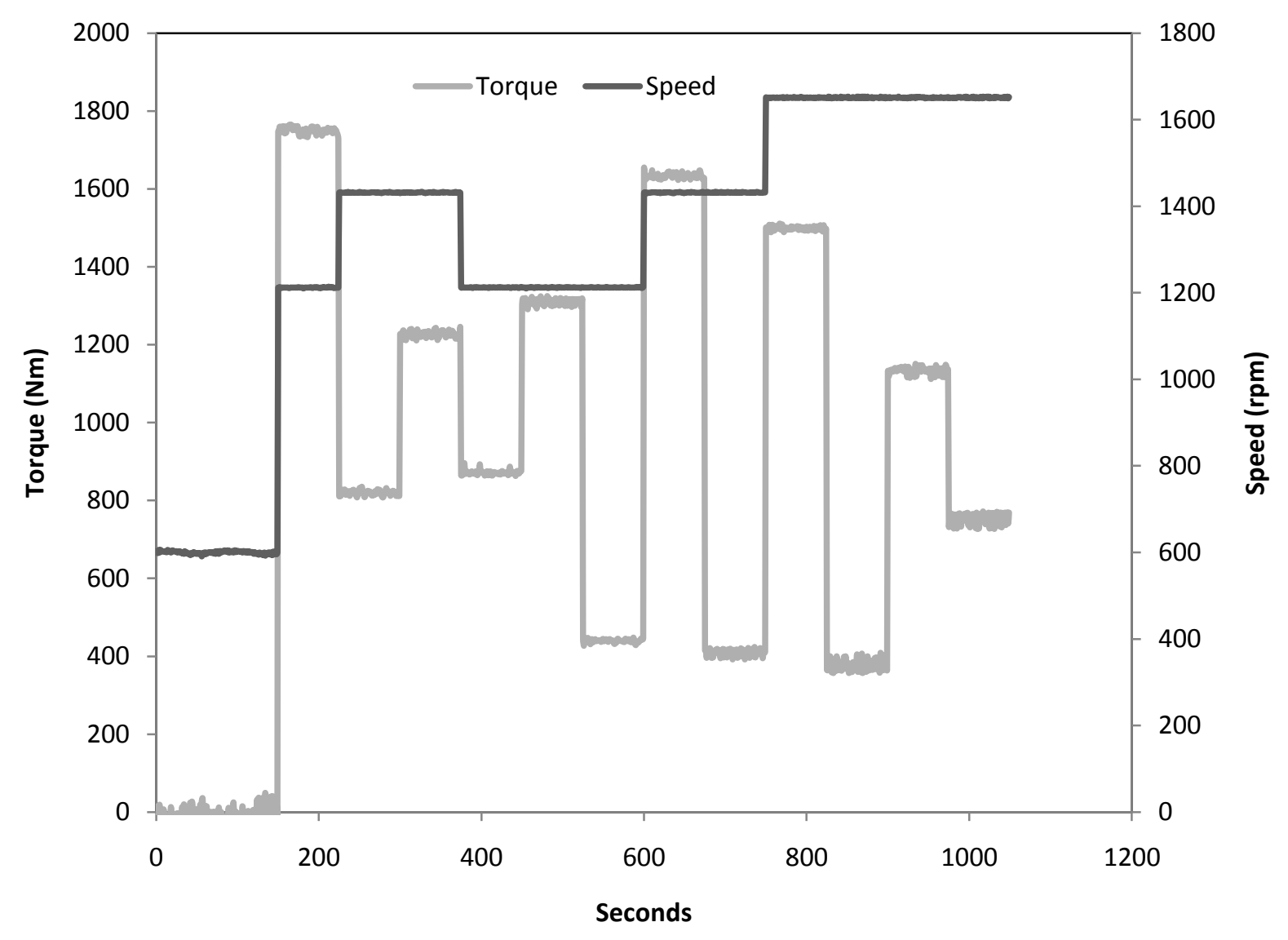

Figure 33 - Load and Speed during the ESC Test Cycle for the DDC S60 Engine

\subsection{Pre-Test Checks}

Prior to performing the emissions tests discussed here, both the raw and dilute sampling systems underwent quality assurance (QA) checks. These checks are outlined in the US EPA CFR Title 40 Part 1065 Subpart D [28]. These checks include but are not limited to; analyzer calibrations, drift checks, $\mathrm{NO}_{\mathrm{x}}$ conversion efficiency checks, water interference checks for $\mathrm{CO}$ analyzers, dynamometer calibrations, critical flow venturi (CFV) system verifications, and leak checks for flow systems. The dynamometer calibration, CFV verifications as well as the rest of the required tests were all performed within the required time frame prior to the emissions tests. Only the results from the $\mathrm{NO}_{\mathrm{x}}$ conversion efficiency test and $\mathrm{CO}$ water interference tests will be shown. 
The frequency at which each check should be performed is different for each type. A majority of the QA checks are only required after initial installation and after major maintenance. The exception to this includes the $\mathrm{NO}_{\mathrm{x}}$ converter efficiency test which is required to be performed within 35 days of the emissions test [28]. This test shows how efficient the $\mathrm{NO}_{\mathrm{x}}$ converter is at converting $\mathrm{NO}_{2}$ to NO. Table 32 and Table 33 show the results from $\mathrm{NO}_{\mathrm{x}}$ efficiency tests for both sampling systems. The efficiency tests were run three times for each analyzer, with the important data shown for the corresponding steps in the test process. All data sets passed the criteria set by the EPA CFR Title 40 Part 1065.378 that the converter must be at least $95 \%$ efficient [28].

Table $32-N O_{x}$ Efficiency Test Results for Raw Lab NO Analyzer

\begin{tabular}{|c|c|c|c|}
\hline Step & Data Set 1 & Data Set 2 & Data Set 3 \\
\hline A & 223.0 & 224.5 & 227.0 \\
\hline B & 49.0 & 50.0 & 55.5 \\
\hline C & 222.0 & 224.0 & 226.5 \\
\hline D & 225.0 & 226.5 & 229.0 \\
\hline Final OO $_{\mathrm{x}}$ Efficiency & $98.2 \%$ & $98.5 \%$ & $98.5 \%$ \\
\hline Pass/Fail & Pass & Pass & Pass \\
\hline
\end{tabular}

Table 33 - NO $O_{x}$ Efficiency Test Results for Dilute Lab NO ${ }_{x}$ Analyzer

\begin{tabular}{|c|c|c|c|}
\hline Step & Data Set 1 & Data Set 2 & Data Set 3 \\
\hline A & 225.4 & 224.3 & 226.8 \\
\hline B & 53.3 & 48.95 & 56.45 \\
\hline C & 225.7 & 225.4 & 227.9 \\
\hline D & 226.6 & 226.7 & 228.9 \\
\hline Final NO $_{x}$ Efficiency & $99.4 \%$ & $99.3 \%$ & $99.4 \%$ \\
\hline Pass/Fail & Pass & Pass & Pass \\
\hline
\end{tabular}

The process for performing the water interference checks involves introducing water vapor into the $\mathrm{CO}$ sample stream and measuring the response. The exact process for this 
interference check is described in the US EPA CFR Title 40 Part 1065 [28]. The pass/fail criteria for these checks require that the interference response of the analyzer be less than a maximum allowable response (MAR). For the dilute sampling system CO analyzer, the MAR values were $1.2 \%, 1 \%, 1 \%$, and $0.52 \%$, with corresponding interference response values of $-0.1 \%, 0.0 \%, 0.0 \%$, and $0.0 \%$. From these values it can be seen that the dilute $\mathrm{CO}$ analyzer interference response values were all less than the MAR values and so passed the interference check. For the raw sampling system $\mathrm{CO}$ analyzer, the MAR values were $1.2 \%, 1.0 \%, 1.0 \%$, and $0.52 \%$, with corresponding interference response values of $0.6 \%, 0.3 \%, 0.1 \%$, and $0.0 \%$. From these values it can be seen that the raw $\mathrm{CO}$ analyzer interference response values were all less than the MAR values and so passed the interference check.

\subsection{Experimental Uncertainty}

It was necessary to quantify the error propagation through calculations involving data from multiple sources, each with its own associated error. The calculations performed on the data during the conversion of concentration values over time, to mass of emissions will have a level of uncertainty due to each measured quantity having a certain level of inaccuracy. The combined effects of these errors on the final results are calculated according to Equation 2. Where $\mathrm{x}_{\mathrm{n}}$ represents the independent variables, $\mathrm{u}_{\mathrm{n}}$ represents the relative uncertainty for each measured quantity $(n), u_{f}$ represents the relative uncertainty caused by the combined effects of $u_{n}$, and $\mathrm{f}$ represents the function of $\mathrm{n}$ independent variables.

Equation 2 - Experiment Error from the Combined Effects of Relative Uncertainties [36]

$$
u_{f}= \pm\left[\left(\left(\frac{\partial f}{\partial x_{1}}\right) u_{1}\right)^{2}+\left(\left(\frac{\partial f}{\partial x_{2}}\right) u_{2}\right)^{2}+\ldots+\left(\left(\frac{\partial f}{\partial x_{n}}\right) u_{n}\right)^{2}\right]^{1 / 2}
$$


While reducing the emissions data from a concentration basis, to mass flow emissions, it is evident that the uncertainty in the temperature, pressure and gas concentrations may have an effect on the final outcome of the emissions data reduction. Equations 3, 4, 5, and 6 were used in the data reduction and include the relationships between the temperature, pressure and concentrations on the final emissions outcome. An error analysis was performed on the calculation of the mass flow of $\mathrm{CO}_{2}$ based upon equation 2 shown above. $\mathrm{CO}, \mathrm{NO}_{\mathrm{x}}$, and $\mathrm{HC}$ are calculated using similar equations. In these equations, the relative uncertainties for the independent variables were defined as follows; the uncertainty for each analyzer concentration was $2 \%$ of the measured values, the uncertainty for the temperature measurement was $0.1^{\circ} \mathrm{C}$ and the uncertainty for the pressure measurement was $0.2 \%$ of full scale.

\section{Equation 3 - Calculation of the Diluted Exhaust Volumetric Flow Rate}

$$
V_{\text {mix }}=\frac{K_{v} * P_{v}}{\sqrt{\left(T_{v}\right)}}
$$

Equation 4 - Calculation of the Dilution Factor

$$
D F=\frac{13.4}{\left(C O_{2, e}+C O_{e}+H C_{e}\right) / 10^{4}}
$$

\section{Equation5 - Calculation of the $\mathrm{CO}_{2}$ Mass Flow Rate}

$$
\mathrm{CO}_{2, \text { mass flow }}=\frac{K_{w}}{10^{6}} *\left[\mathrm{CO}_{2, e}-\mathrm{CO}_{2, b} *\left(1-\frac{1}{D F}\right)\right] * V_{\text {mix }} * \text { Density } \mathrm{CO}_{2}
$$

The variables in equations $3,4,5$, and 6 are defined in the following way. $\mathrm{V}_{\text {mix }}$ represents the diluted exhaust volumetric flow rate at standard conditions of $20^{\circ} \mathrm{C}$ and $101.3 \mathrm{kPa} . \mathrm{Kv}$ is the venturi calibration coefficient. $P_{v}$ is the absolute inlet pressure of the venturi. $T_{v}$ is the absolute inlet temperature of the venturi. $\mathrm{K}_{\mathrm{w}}$ is the dry to wet correction factor. The density of $\mathrm{CO}_{2}$ at 
standard conditions is $1.803 \mathrm{~kg} / \mathrm{m}^{3} . \mathrm{CO}_{2, \mathrm{e}}$ is the $\mathrm{CO}_{2}$ concentration in ppm. $\mathrm{CO}_{2, \mathrm{~b}}$ is the background $\mathrm{CO}_{2}$ concentration in ppm. $\mathrm{CO}_{2}$, mass flow is the mass $\mathrm{CO}_{2}$ flow rate in grams per second. $\alpha$ is the atomic hydrogen-to-carbon ratio in the fuel which is 1.8 for the diesel fuel used in the tests. The results from the analysis of the experimental uncertainty using these equations showed that the uncertainty of the independent variables resulted in a $2.17 \%$ error in the final $\mathrm{CO}_{2}$ mass flow. This corresponds to $\mathrm{a} \pm 0.51 \mathrm{~g} / \mathrm{s}$ error in the final reported value of $23.68 \mathrm{~g} / \mathrm{s}$ of $\mathrm{CO}_{2}$.

This analysis demonstrates how initial uncertainties in measurement will propagate through calculations. The combined effects of multiple uncertainties will propagate through the calculations in different ways depending upon the equations and the relationship between the variables in the equations. This example shows how errors in temperature, pressure, and gas concentration measurements will propagate to the final mass flow of emissions. 


\section{EXPERIMENTAL RESULTS AND DISCUSSION}

\subsection{Introduction}

The objective of these tests was to verify the capabilities of the raw emissions measurement system in preparation for future testing with the SEEL. Since a majority of offroad engine certifications are steady state tests, it was decide that the verification tests would be steady state tests, as opposed to transient tests. Three 13 mode steady state tests following the ESC test cycle were performed to validate each analyzer system. During these tests, the DDC S60 test engine followed the ESC test cycle while both the raw and dilute emissions measurement systems collected data. This simultaneous testing allowed for a direct comparison between the two systems. The data from the dilute sampling system were used as the reference values to which the raw data were compared to and verified against. The dilute sampling system had previously undergone verification according to US EPA CFR Title 40 Part 86 [30] and was a trusted source of emissions data.

$\mathrm{HC}, \mathrm{CO}, \mathrm{CO}_{2}$, and $\mathrm{NO}_{\mathrm{x}}$ gaseous emissions data were collected. For each test, emissions were compared on a mode-to-mode basis as well as overall weighted brake-specific emissions. For the CO measurement system, data was recorded and analyzed for 12 of the 13 test modes. The data reduction for the raw sampling system analyzers was performed according to the US EPA CFR Title 40 Part 1065 [28] by a computer program written by Dr. John Nuszkowski. The data from the dilute sampling system analyzers was performed according to the US EPA CFR Title 40 Part 86 [30] by a computer program written by Richard Atkinson and Zac Luzader of CAFEE. It should be noted that process of comparing two sampling systems can be very involved. There are numerous statistical methods that could be applied to show the correlations and patterns between the data sets. In this analysis, only the percent difference between the 
individual modes as well as for the overall weighted brake-specific emissions will be discussed. The primary goal of these results was to show how each measurement system has met the verification criteria set by CAFEE engineers and to discuss any abnormalities. The verification criteria is set in Section 6.2 and is defined in terms of percent difference between the final weighted brake-specific emissions for each test.

\subsection{Verification criteria}

In order to assess the relationship between the two sets of data, it was necessary to establish verification criteria for each exhaust constituent. The criteria presented here was established by CAFEE engineers based upon past experiences with each analyzer system. Inherent differences between the raw and dilute sampling systems may cause slight differences between the data sets of each analyzer system and was expected. These differences are caused by the innate differences between the sampling systems and also by the errors associated with the calculations in each system. The verification criteria takes these differences into account but still sets strict limits as to how different from each other they may be. The US EPA CFR does not define verification criteria for such a comparison between these types of systems. Therefore, CAFEE engineers had to use their best judgment to set the allowable differences. There have been limited studies in the past which have studied such a comparison. One of these studies is discussed in Section 6.4.5.

For each analyzer system, verification would be confirmed if the weighted brakespecific results from the raw emission measurement system were within a certain value of the results from the dilute emissions measurement system. The same criteria may be applied to individual modes, but is not required. For research purposes it is not important that individual modes satisfy the verification criteria. Individual modes may have larger fluctuations and may 
not pass the verification criteria even though the overall results do. Because of this, it was only required that the overall weighted brake-specific emissions of the two systems meet the criteria defined here.

For the $\mathrm{CO}$ and $\mathrm{CO}_{2}$ system verification would be confirmed if the results from the raw emissions sampling system were within $2 \%$ of the dilute emission sampling systems results. For the $\mathrm{NO}_{\mathrm{x}}$ analyzer systems, verification would be confirmed if the results from the raw emissions sampling system were within 5\% of the dilute emissions sampling system results. For the HC

analyzer systems, previous experiences show that results typically vary more than that of the CO, $\mathrm{CO}_{2}$ and $\mathrm{NO}_{\mathrm{x}}$ systems. Therefore, it was not expected that the $\mathrm{HC}$ systems would correlate well with each other and a loose verification criteria was established for HC. A difference of less than $10 \%$ between the systems would give confidence but was not expected. The error values shown throughout the results were calculated according to the following formula:

$$
\begin{gathered}
\text { Equation 6-Relative Error Calculation } \\
\% \text { Error }=\left(\frac{(\text { Measured Value })-(\text { Reference Value })}{\text { Reference Value }}\right) * 100
\end{gathered}
$$

\subsection{Results from 13 Mode ESC Tests}

The results from the three steady state tests are shown in the following sections. The comparisons of both weighted brake specific emissions, and individual mode emissions are shown. For each of the three tests, the comparisons between the raw and dilute sampling systems showed promising results for all of the analyzers with the exception of HC. The CO, $\mathrm{CO}_{2}$, and $\mathrm{NO}_{\mathrm{x}}$ systems all met the verification criteria set for them. Over all three tests, the weighted brake specific emissions from the raw lab $\mathrm{HC}$ analyzer were consistently greater than the values from the dilute system. There are numerous possible reasons for the discrepancies 
between the HC measurement systems. These possibilities are discussed in Section 6.4.4.

It was also beneficial to compare the individual modes of each test to determine how the different systems respond to the combinations of speed and load on an individual mode basis. From these mode to mode comparisons, it was observed that certain modes show a better correlation than other modes.

\subsubsection{Test 1}

The results from the first test are shown in this section. The comparisons of both the weighted brake-specific emissions, as well as mode to mode comparisons, are shown.

\subsubsection{Comparison of Weighted Brake-Specific Emissions}

The weighted brake-specific emissions for $\mathrm{HC}, \mathrm{CO}, \mathrm{CO}_{2}$, and $\mathrm{NO}_{\mathrm{x}}$ for Test 1 are shown in Table 34. It can be seen from these results that there is a good correlation between the raw and dilute systems for $\mathrm{CO}, \mathrm{CO}_{2}$, and $\mathrm{NO}_{\mathrm{x}}$. However, the $\mathrm{HC}$ measurements from the two systems were not consistent with each other. The differences between the $\mathrm{HC}$ results were not only evident in the weighted brake-specific emissions, but were also evident in the mode to mode comparisons. The possible causes for these discrepancies are discussed in Section 6.4.

Table 34 - Weighted Brake-Specific Emissions for Test 1

\begin{tabular}{|c|c|c|c|c|c|}
\hline $\begin{array}{c}\text { Exhaust } \\
\text { Constituent }\end{array}$ & $\begin{array}{c}\text { Raw } \\
\text { (g/bhp-hr) }\end{array}$ & $\begin{array}{c}\text { Dilute } \\
(\mathbf{g} / \mathbf{b h p} \text {-hr) }\end{array}$ & $\begin{array}{c}\text { Difference } \\
(\boldsymbol{\%})\end{array}$ & $\begin{array}{c}\text { Allowable } \\
\text { Difference (\%) }\end{array}$ & Pass/Fail \\
\hline $\mathrm{HC}$ & 0.0638 & 0.0466 & 36.9 & 10.0 & Fail \\
\hline $\mathrm{CO}$ & 1.46 & 1.48 & -1.35 & 2.0 & Pass \\
\hline $\mathrm{CO}_{2}$ & 459.7 & 458.8 & 0.20 & 2.0 & Pass \\
\hline $\mathrm{NO}_{\mathrm{x}}$ & 7.28 & 7.19 & 1.25 & 5.0 & Pass \\
\hline
\end{tabular}

\subsubsection{Comparison of Individual Modes}

The mode to mode comparisons of each exhaust constituent for test 1 are shown in Figure 
34 through Figure 37 with the error values shown in Table 35.

Table 35 - Errors for Individual Modes of Test 1

\begin{tabular}{|c|c|c|c|c|}
\cline { 2 - 5 } \multicolumn{1}{c|}{} & \multicolumn{4}{c|}{ Error (\%) } \\
\hline Mode & $\mathbf{C O}_{\mathbf{2}}$ & $\mathbf{C O}$ & $\mathbf{N O}_{\mathbf{x}}$ & $\mathbf{H C}$ \\
\hline 1 & $2.6 \%$ & $-7.6 \%$ & $-0.6 \%$ & $63.8 \%$ \\
\hline 2 & $0.7 \%$ & $-9.7 \%$ & $1.8 \%$ & $27.1 \%$ \\
\hline 3 & $0.1 \%$ & $0.6 \%$ & $-0.9 \%$ & $38.5 \%$ \\
\hline 4 & $0.1 \%$ & $-1.4 \%$ & $0.2 \%$ & $35.6 \%$ \\
\hline 5 & $0.1 \%$ & $-2.6 \%$ & $-1.6 \%$ & $45.2 \%$ \\
\hline 6 & $0.1 \%$ & $-6.2 \%$ & $-0.7 \%$ & $39.4 \%$ \\
\hline 7 & $0.2 \%$ & $-1.7 \%$ & $-0.4 \%$ & $51.8 \%$ \\
\hline 8 & $0.1 \%$ & $-3.9 \%$ & $-0.1 \%$ & $28.0 \%$ \\
\hline 9 & $0.2 \%$ & $-0.6 \%$ & $0.0 \%$ & $36.3 \%$ \\
\hline 10 & $0.0 \%$ & $1.2 \%$ & $0.7 \%$ & $27.2 \%$ \\
\hline 11 & $0.2 \%$ & $1.3 \%$ & $0.3 \%$ & $28.8 \%$ \\
\hline 12 & $0.1 \%$ & $2.1 \%$ & $0.0 \%$ & $33.6 \%$ \\
\hline 13 & $0.1 \%$ & N/A & $-1.2 \%$ & $32.5 \%$ \\
\hline
\end{tabular}

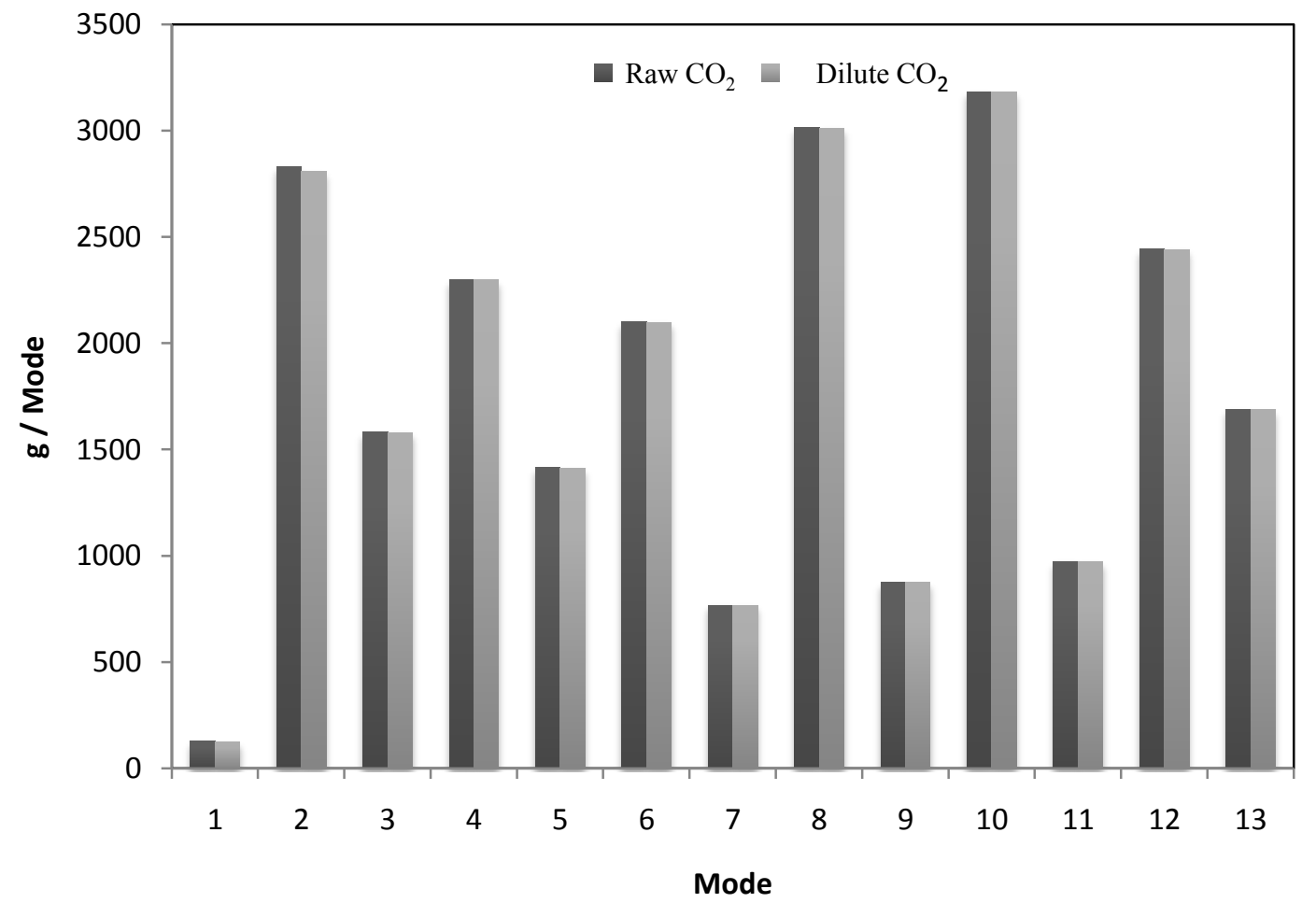

Figure 34 - Modal Comparison of $\mathrm{CO}_{2}$ for Test 1 


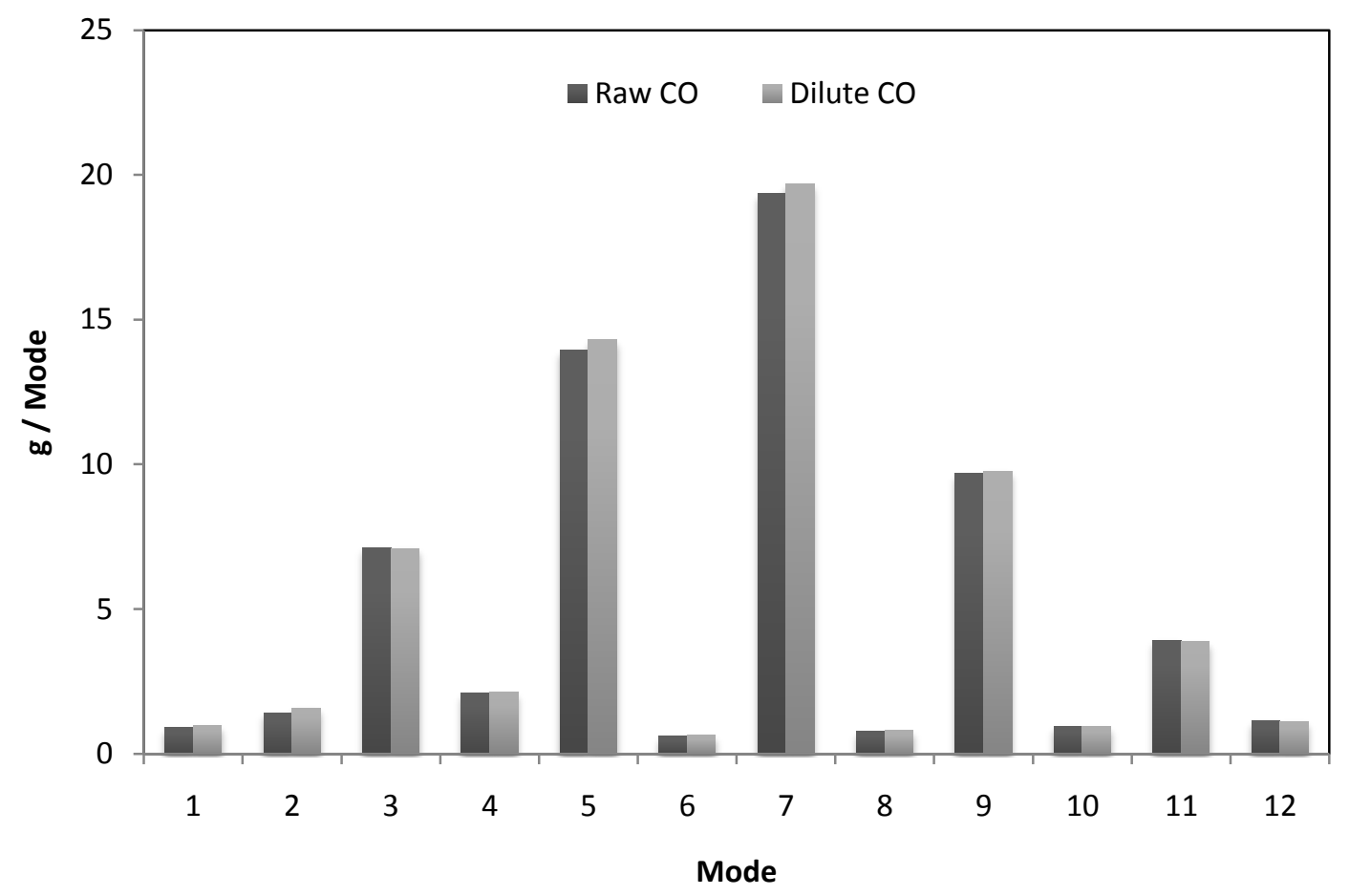

Figure 35 - Modal Comparison of CO for Test 1

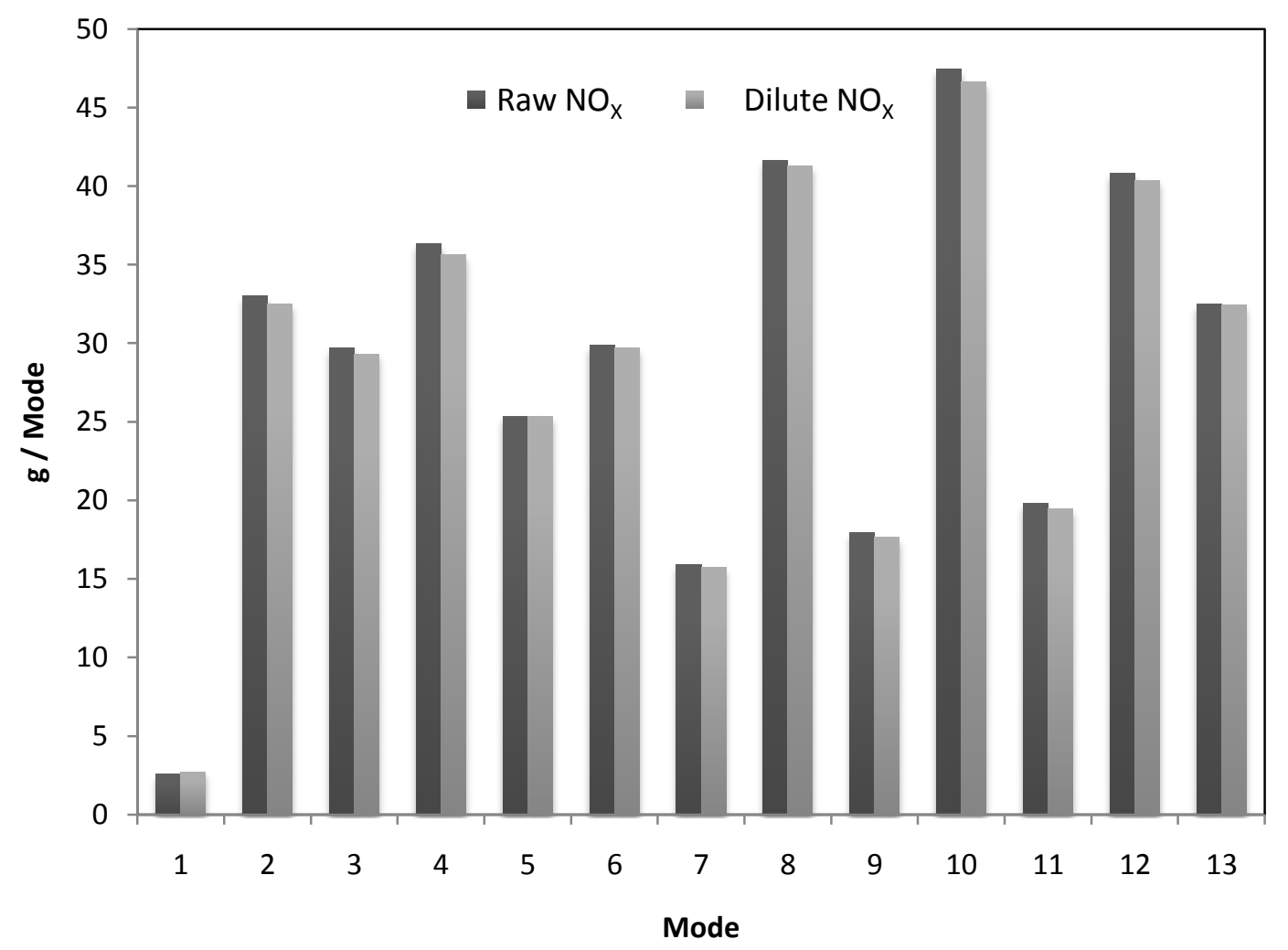

Figure 36 - Modal Comparison of $N O_{x}$ for Test 1 


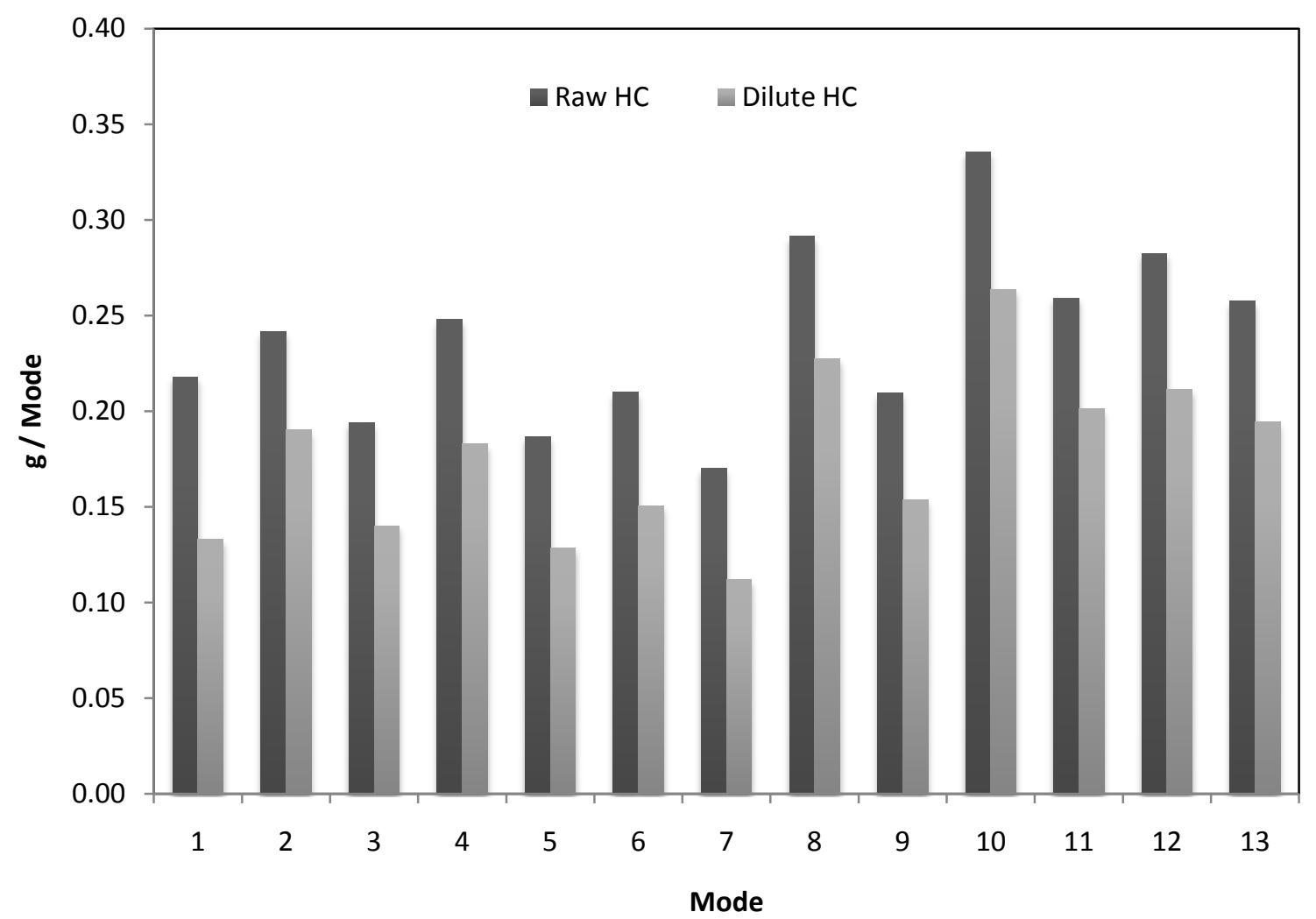

Figure 37 - Modal Comparison of HC for Test 1

\subsubsection{Test 2}

The results from the second test are shown in this section. The comparisons of both the weighted brake-specific emissions, as well as mode to mode comparisons, are shown.

\subsubsection{Comparison of Weighted Brake-Specific Emissions}

The weighted brake-specific emissions for $\mathrm{HC}, \mathrm{CO}, \mathrm{CO}_{2}$, and $\mathrm{NO}_{\mathrm{x}}$ for test 2 are shown in Table 36. It can be seen from these results that there is a good correlation between the raw and dilute systems for $\mathrm{CO}, \mathrm{CO}_{2}$, and $\mathrm{NO}_{\mathrm{x}}$. The differences between the $\mathrm{HC}$ results was not only evident in the weighted brake-specific emissions, but was also evident in the mode to mode comparisons. The possible causes for these discrepancies are discussed in Section 6.4. 
Table 36 - Weighted Brake-Specific Emissions for Test 2

\begin{tabular}{|c|c|c|c|c|c|}
\hline $\begin{array}{c}\text { Exhaust } \\
\text { Constituent }\end{array}$ & $\begin{array}{c}\text { Raw } \\
\text { (g/bhp-hr) }\end{array}$ & $\begin{array}{c}\text { Dilute } \\
\text { (g/bhp-hr) }\end{array}$ & $\begin{array}{c}\text { Difference } \\
(\mathbf{\%})\end{array}$ & $\begin{array}{c}\text { Allowable } \\
\text { Difference (\%) }\end{array}$ & Pass/Fail \\
\hline $\mathrm{HC}$ & 0.0602 & 0.0495 & 21.6 & 10.0 & Fail \\
\hline $\mathrm{CO}$ & 1.44 & 1.46 & -1.37 & 2.0 & Pass \\
\hline $\mathrm{CO}_{2}$ & 459.4 & 458.4 & 0.22 & 2.0 & Pass \\
\hline $\mathrm{NO}_{\mathrm{x}}$ & 7.30 & 7.24 & 0.83 & 5.0 & Pass \\
\hline
\end{tabular}

\subsubsection{Comparison of Individual Modes}

The mode to mode comparisons of each exhaust constituent for test 2 are shown in Figure 38 through Figure 41 with the error values shown in Table 37.

Table 37 - Errors for Individual Modes of Test 2

\begin{tabular}{|c|c|c|c|c|}
\cline { 2 - 5 } \multicolumn{1}{c|}{} & \multicolumn{4}{c|}{ Error (\%) } \\
\hline Mode & $\mathbf{C O}_{\mathbf{2}}$ & $\mathbf{C O}$ & $\mathbf{N O}_{\mathbf{x}}$ & $\mathbf{H C}$ \\
\hline 1 & $2.6 \%$ & $-1.4 \%$ & $1.6 \%$ & $37.9 \%$ \\
\hline 2 & $0.8 \%$ & $-8.1 \%$ & $0.1 \%$ & $12.4 \%$ \\
\hline 3 & $0.1 \%$ & $0.3 \%$ & $0.8 \%$ & $22.0 \%$ \\
\hline 4 & $0.1 \%$ & $-0.5 \%$ & $1.0 \%$ & $19.7 \%$ \\
\hline 5 & $0.1 \%$ & $-3.2 \%$ & $-0.3 \%$ & $29.2 \%$ \\
\hline 6 & $0.1 \%$ & $-2.7 \%$ & $-0.4 \%$ & $22.3 \%$ \\
\hline 7 & $0.2 \%$ & $-1.6 \%$ & $0.9 \%$ & $30.3 \%$ \\
\hline 8 & $0.1 \%$ & $-3.3 \%$ & $0.9 \%$ & $14.5 \%$ \\
\hline 9 & $0.2 \%$ & $-0.7 \%$ & $1.8 \%$ & $23.5 \%$ \\
\hline 10 & $0.1 \%$ & $2.2 \%$ & $1.5 \%$ & $17.6 \%$ \\
\hline 11 & $0.2 \%$ & $0.3 \%$ & $1.5 \%$ & $18.2 \%$ \\
\hline 12 & $0.1 \%$ & $2.3 \%$ & $0.2 \%$ & $20.5 \%$ \\
\hline 13 & $0.1 \%$ & $\mathrm{~N} / \mathrm{A}$ & $0.0 \%$ & $19.1 \%$ \\
\hline
\end{tabular}




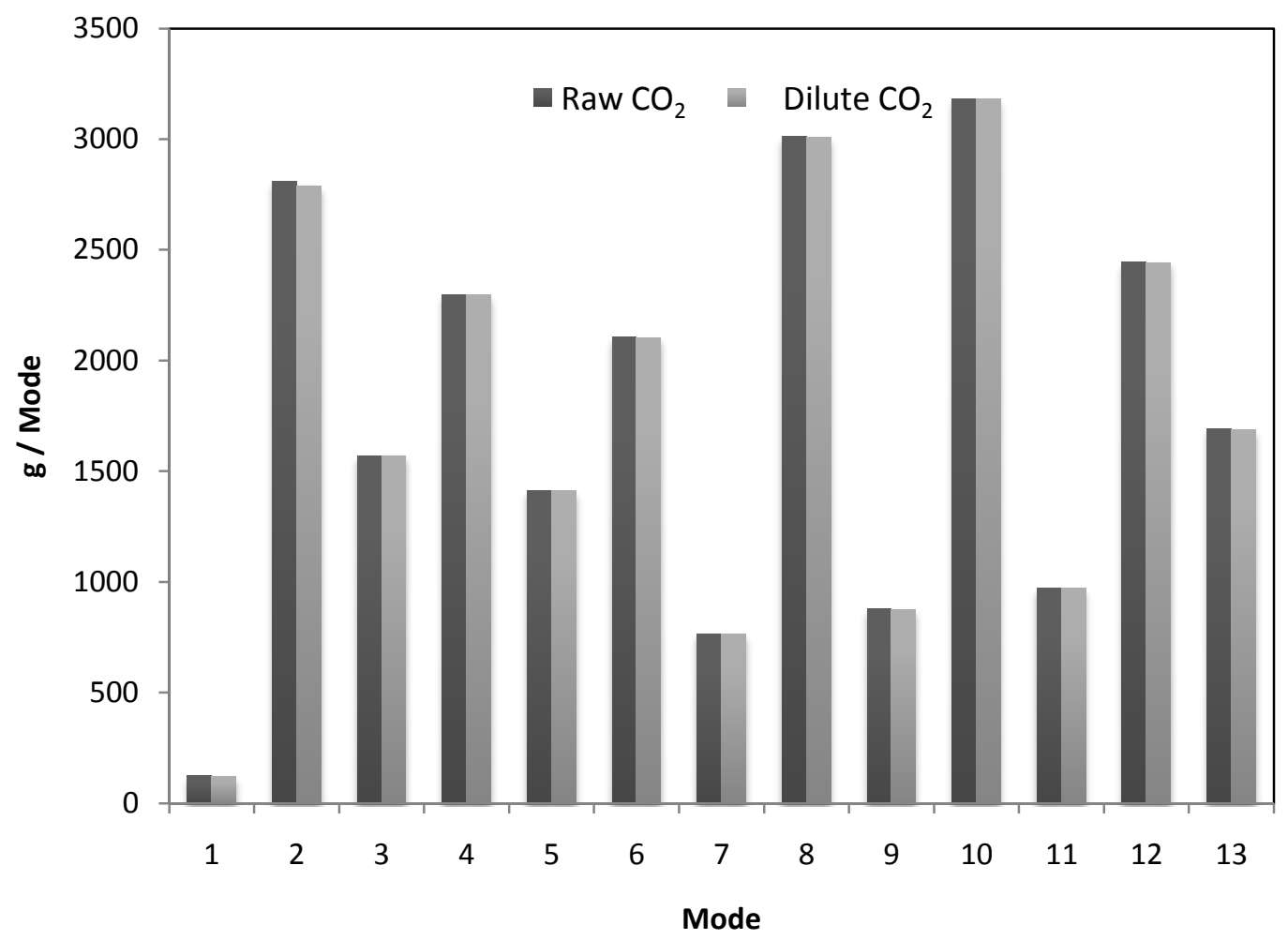

Figure 38-Modal Comparison of $\mathrm{CO}_{2}$ for Test 2

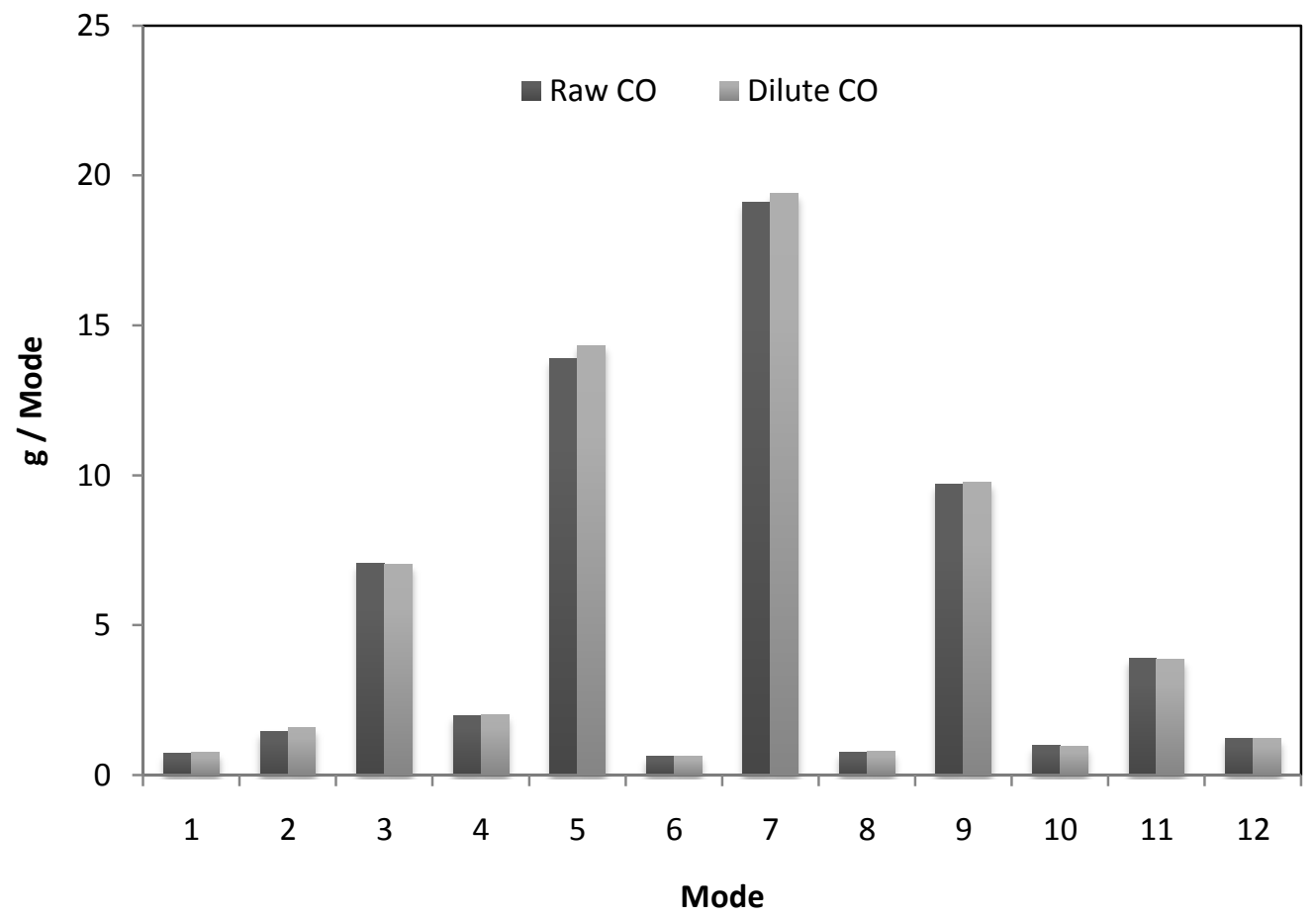

Figure 39-Modal Comparison of CO for Test 2 


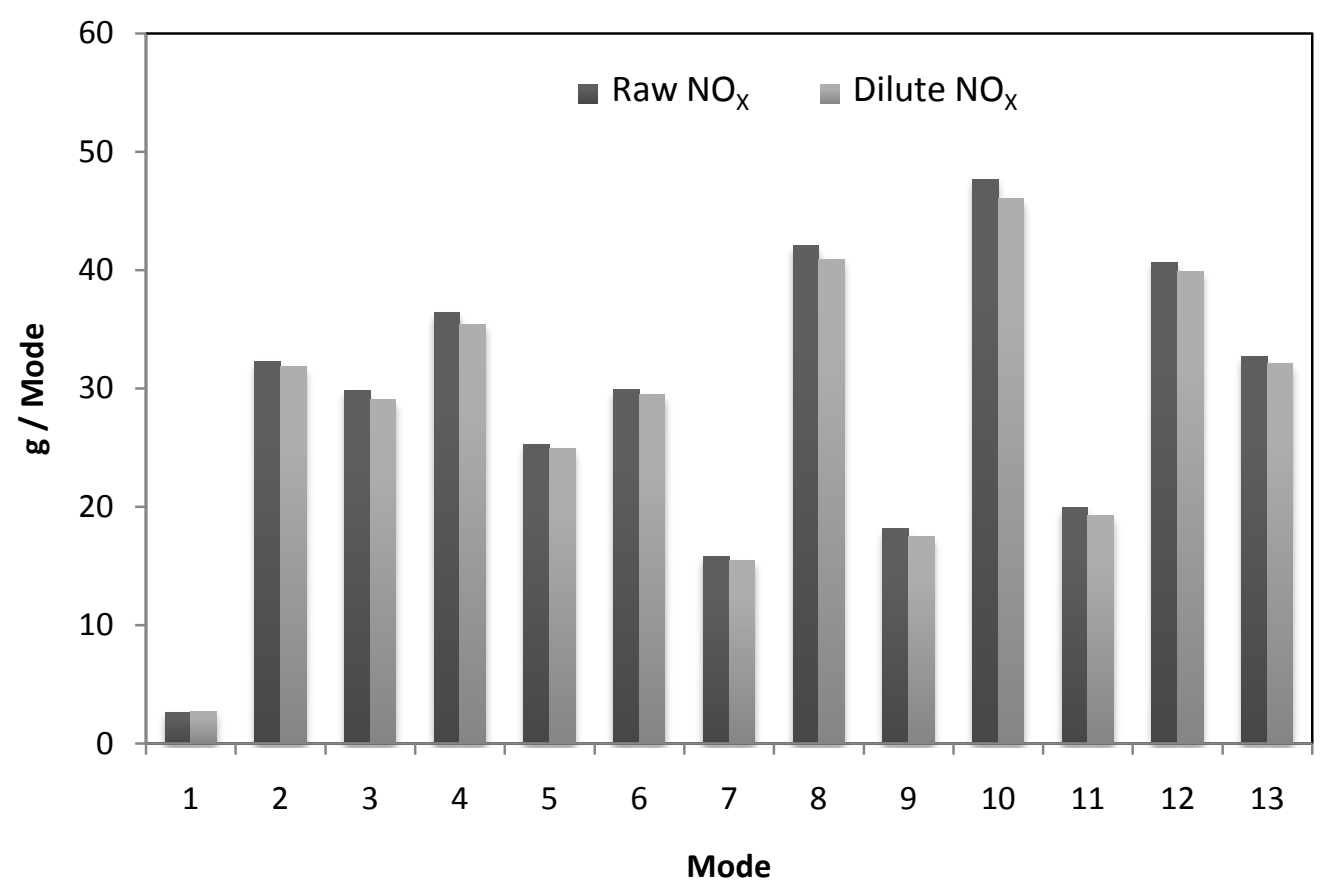

Figure 40-Modal Comparison of $\mathrm{NO}_{x}$ for Test 2

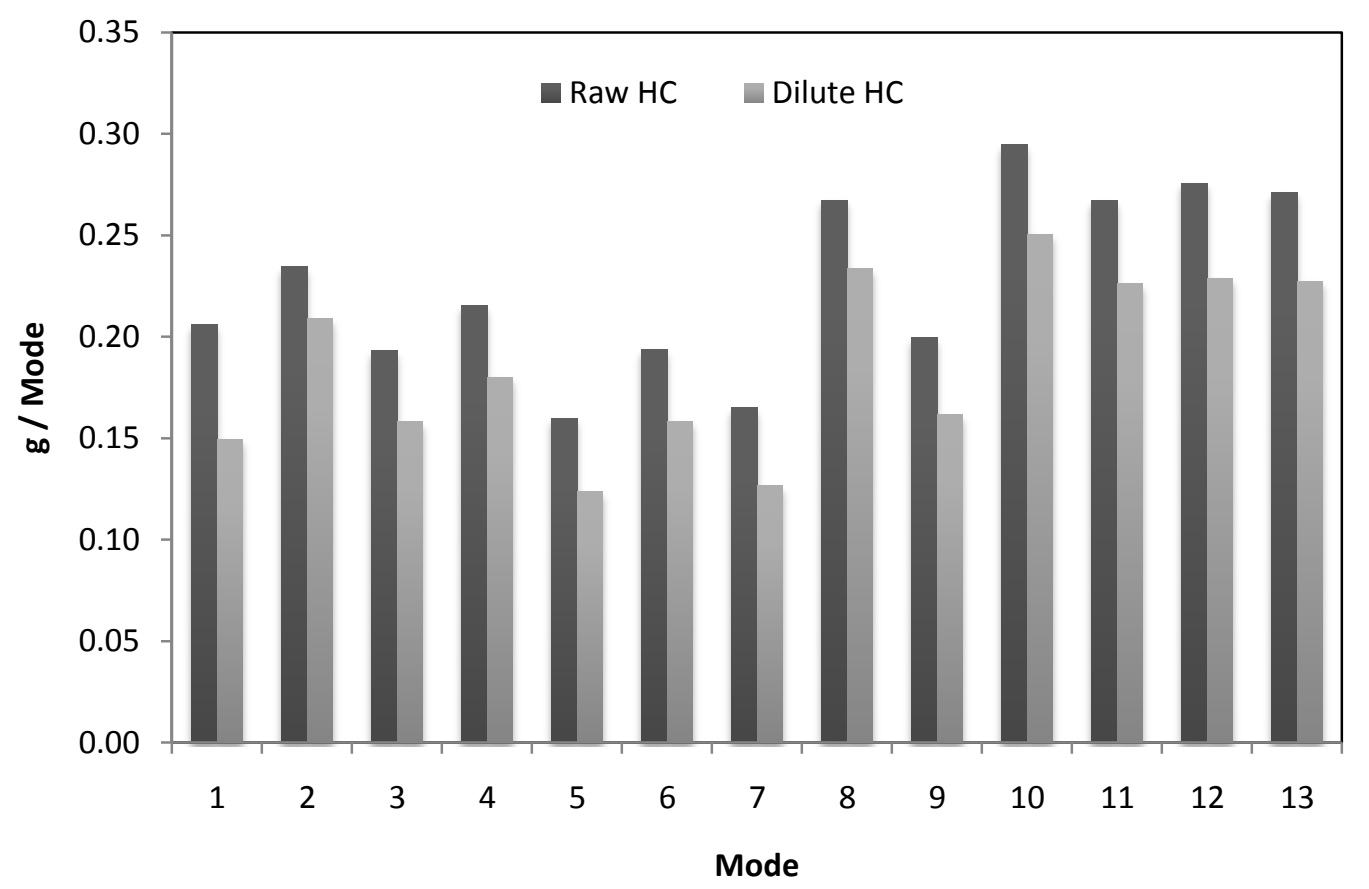

Figure 41 - Modal Comparison of HC for Test 2 


\subsubsection{Test 3}

The results from the third ESC test are shown in this section. The comparisons of both the weighted brake-specific emissions, as well as mode to mode comparisons, are shown.

\subsubsection{Comparison of Weighted Brake-Specific Emissions}

The weighted brake-specific emissions for $\mathrm{HC}, \mathrm{CO}, \mathrm{CO}_{2}$, and $\mathrm{NO}_{\mathrm{x}}$ for test 3 are shown in Table 38. As with the previous two tests, the results show that there is a good correlation between the raw and dilute systems for $\mathrm{CO}, \mathrm{CO}_{2}$, and $\mathrm{NO}_{\mathrm{x}}$. This is also not the case for $\mathrm{HC}$ however. The discrepancies for this test will be discussed in Section 6.4.

Table 38 - Weighted Brake-Specific Emissions for Test 3

\begin{tabular}{|c|c|c|c|c|c|}
\hline $\begin{array}{c}\text { Exhaust } \\
\text { Constituent }\end{array}$ & $\begin{array}{c}\text { Raw } \\
(\mathbf{g} / \mathbf{b h p}-\mathbf{h r})\end{array}$ & $\begin{array}{c}\text { Dilute } \\
(\mathbf{g} / \mathbf{b h p}-\mathbf{h r})\end{array}$ & $\begin{array}{c}\text { Difference } \\
(\boldsymbol{\%})\end{array}$ & $\begin{array}{c}\text { Allowable } \\
\text { Difference (\%) }\end{array}$ & Pass/Fail \\
\hline $\mathrm{HC}$ & 0.058 & 0.049 & 18.4 & 10.0 & Fail \\
\hline $\mathrm{CO}$ & 1.46 & 1.48 & -1.35 & 2.0 & Pass \\
\hline $\mathrm{CO}_{2}$ & 460.4 & 459.4 & 0.22 & 2.0 & Pass \\
\hline $\mathrm{NO}_{\mathrm{x}}$ & 7.41 & 7.29 & 1.69 & 5.0 & Pass \\
\hline
\end{tabular}

\subsubsection{Comparison of Individual Modes}

The mode to mode comparisons of each exhaust constituent for test 3 are shown in Figure 42 through Figure 45 with the error values shown in Table 39. 
Table 39 - Errors for Individual Modes of Test 1

\begin{tabular}{|c|c|c|c|c|}
\cline { 2 - 5 } \multicolumn{1}{c|}{} & \multicolumn{4}{c|}{ Error $(\%)$} \\
\hline Mode & $\mathbf{C O}_{\mathbf{2}}$ & $\mathbf{C O}$ & $\mathbf{N O}_{\mathbf{x}}$ & $\mathbf{H C}$ \\
\hline 1 & $2.7 \%$ & $1.1 \%$ & $-3.1 \%$ & $23.7 \%$ \\
\hline 2 & $0.8 \%$ & $-8.6 \%$ & $0.6 \%$ & $11.8 \%$ \\
\hline 3 & $0.1 \%$ & $0.3 \%$ & $1.0 \%$ & $18.6 \%$ \\
\hline 4 & $0.1 \%$ & $-0.9 \%$ & $1.6 \%$ & $17.6 \%$ \\
\hline 5 & $0.1 \%$ & $-2.4 \%$ & $0.7 \%$ & $25.0 \%$ \\
\hline 6 & $0.1 \%$ & $-3.9 \%$ & $1.3 \%$ & $20.0 \%$ \\
\hline 7 & $0.2 \%$ & $-1.1 \%$ & $2.2 \%$ & $26.9 \%$ \\
\hline 8 & $0.1 \%$ & $-4.2 \%$ & $1.8 \%$ & $13.7 \%$ \\
\hline 9 & $0.2 \%$ & $-0.1 \%$ & $2.9 \%$ & $19.7 \%$ \\
\hline 10 & $0.0 \%$ & $0.0 \%$ & $2.8 \%$ & $15.5 \%$ \\
\hline 11 & $0.2 \%$ & $1.2 \%$ & $2.8 \%$ & $14.7 \%$ \\
\hline 12 & $0.1 \%$ & $2.0 \%$ & $1.9 \%$ & $17.8 \%$ \\
\hline 13 & $0.1 \%$ & N/A & $2.0 \%$ & $17.4 \%$ \\
\hline
\end{tabular}

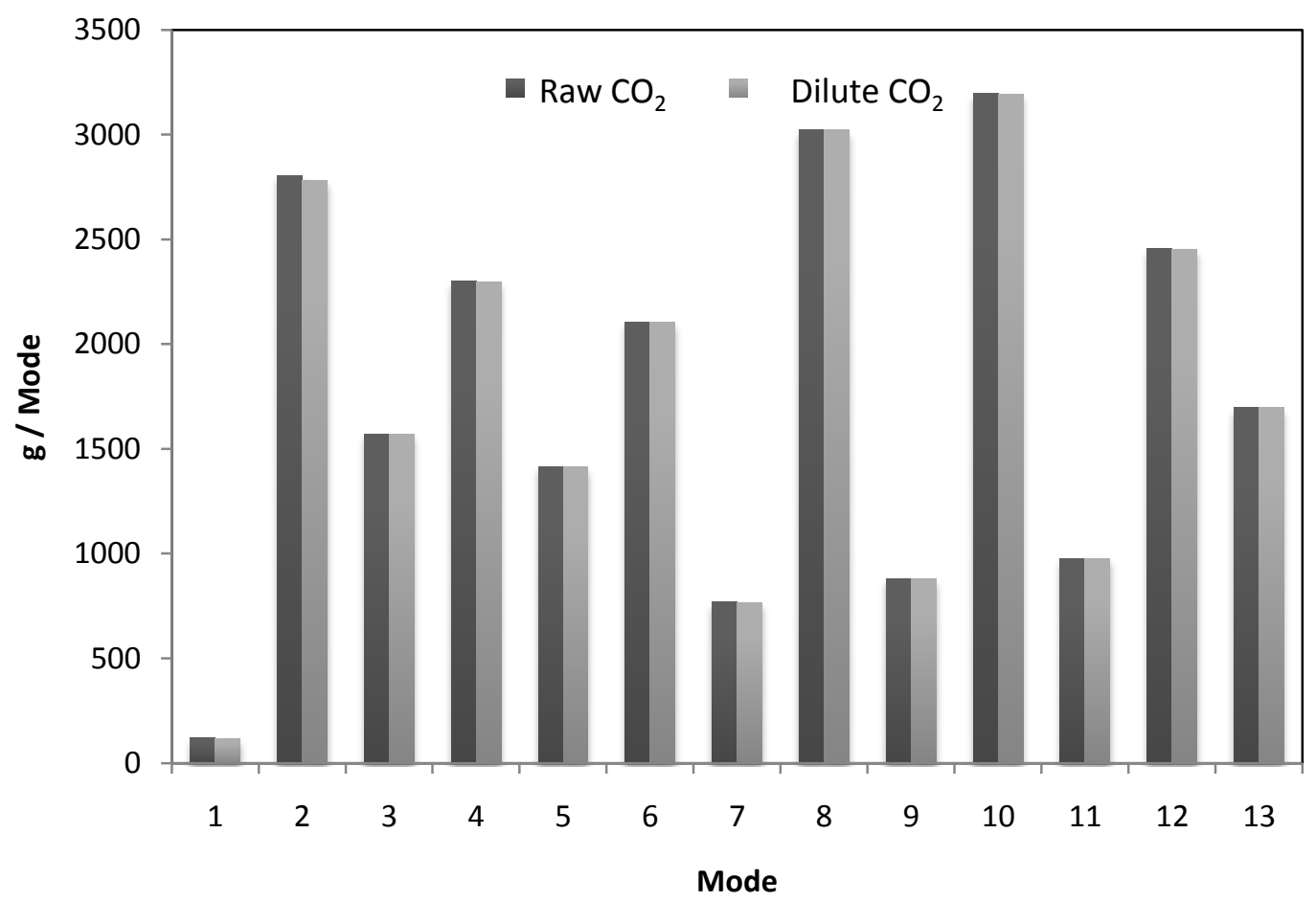

Figure 42 - Modal Comparison of $\mathrm{CO}_{2}$ for Test 3 


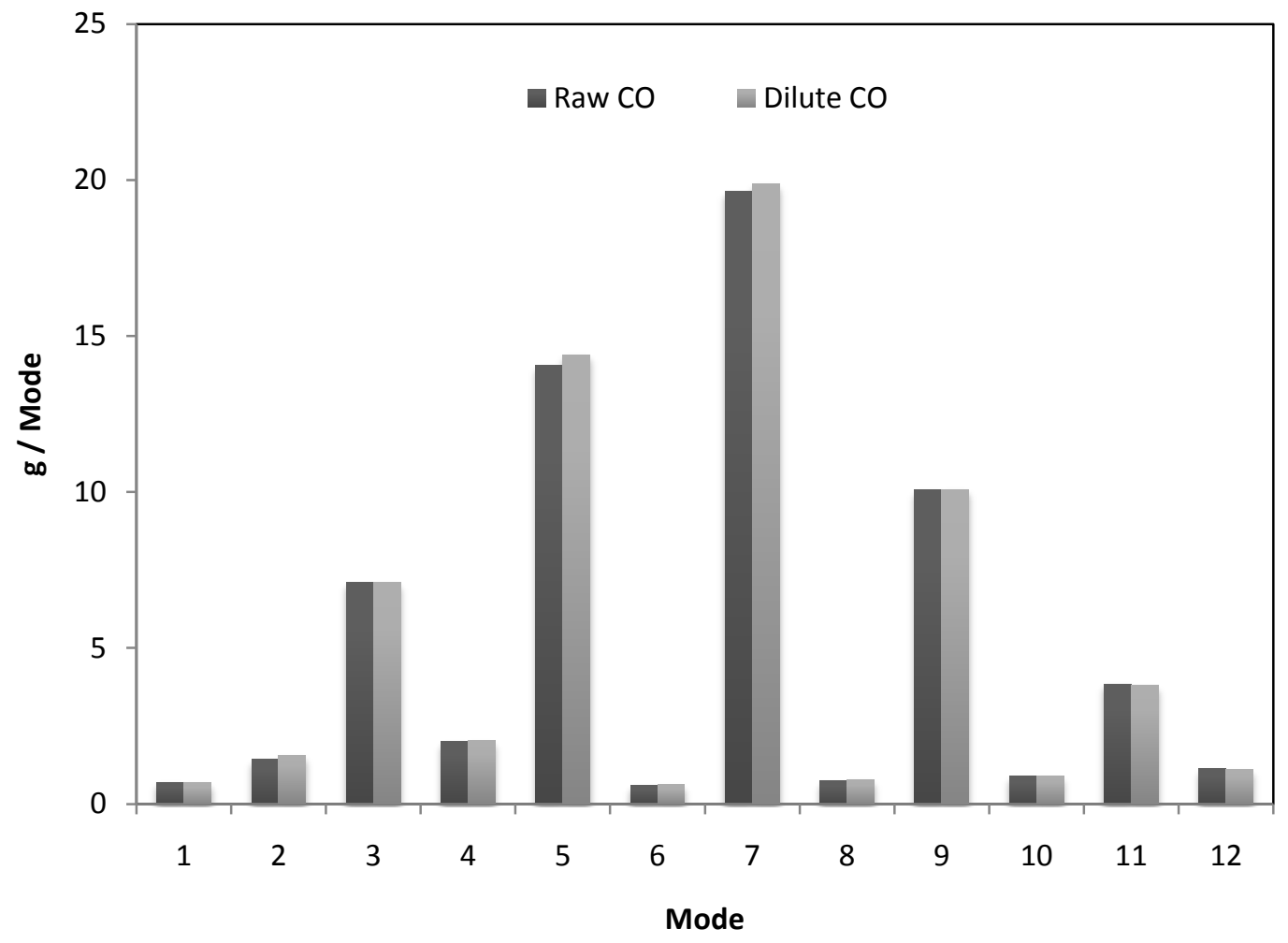

Figure 43 - Modal Comparison of CO for Test 3

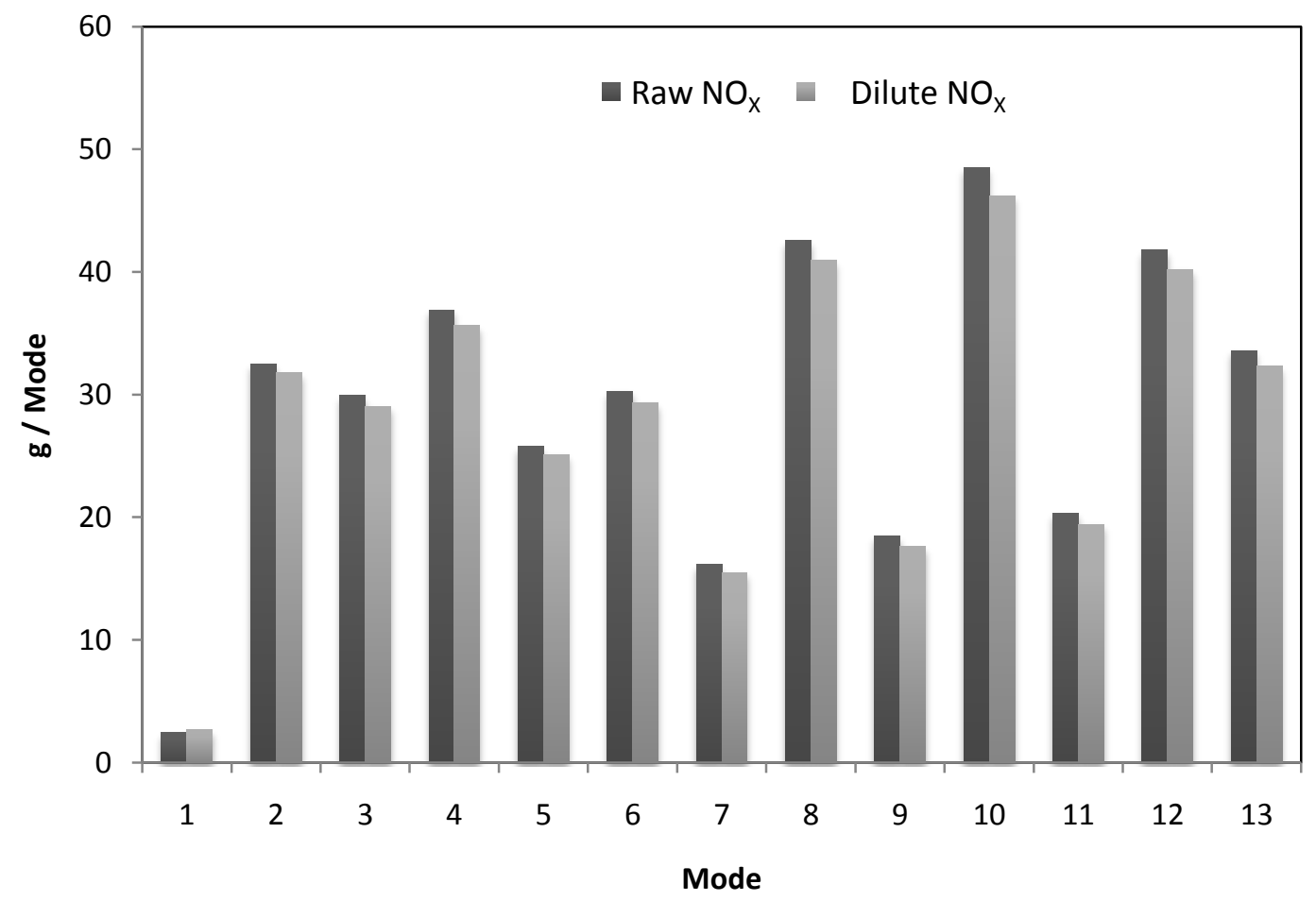

Figure 44 - Modal Comparison of $\mathrm{NO}_{x}$ for Test 3 


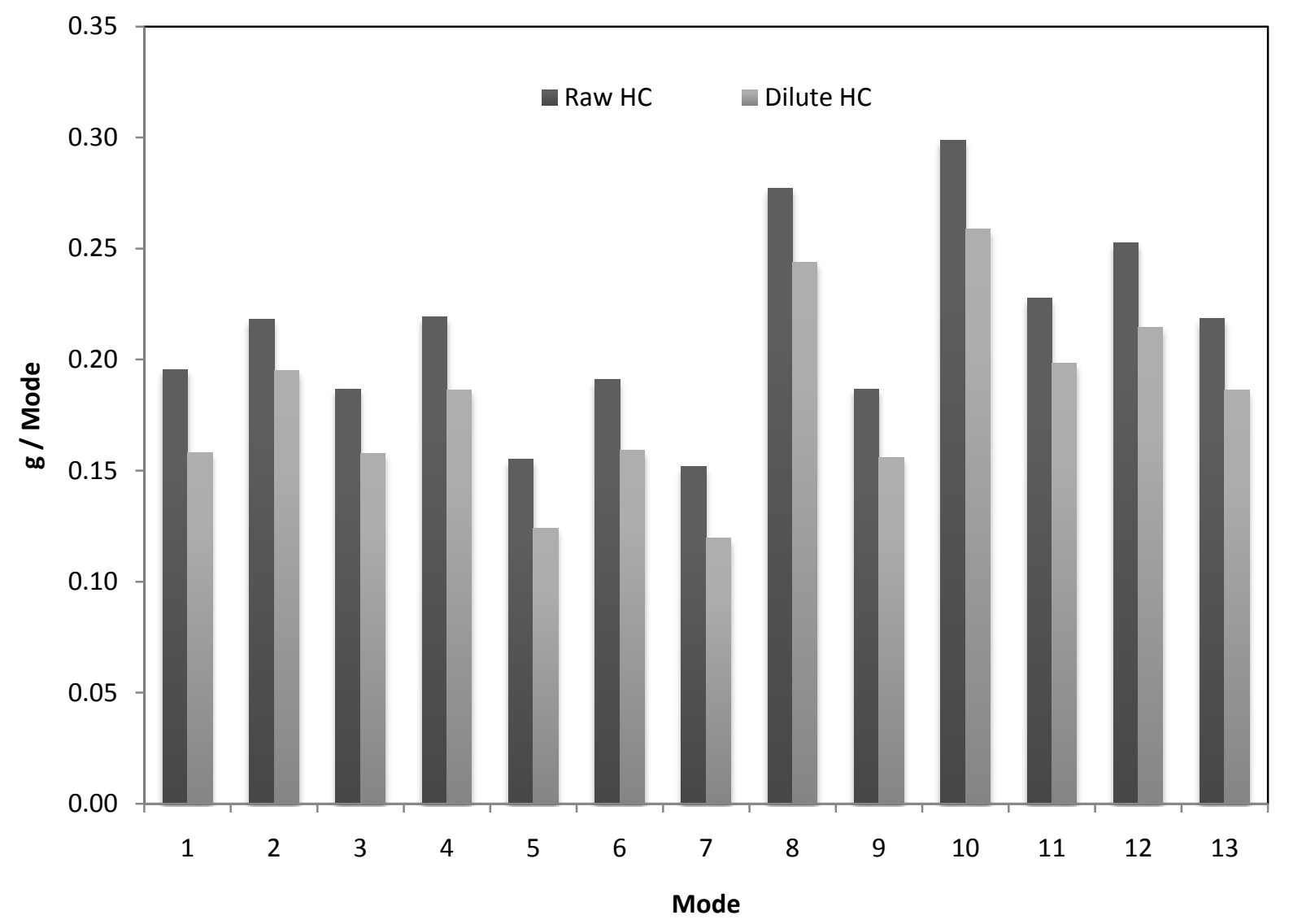

Figure 45 - Modal Comparison of HC for Test 3

\subsection{Discussion of Results}

\subsection{1 $\mathrm{CO}_{2}$ Results}

As shown in the tables above, the results from the raw sampling system $\mathrm{CO}_{2}$ analyzer were within $1 \%$ of the dilute sampling system $\mathrm{CO}_{2}$ analyzer for all three tests. This showed a very positive correlation between the systems and was expected. Previous experience comparing the systems had shown that the $\mathrm{CO}_{2}$ values correlated very well between the raw and dilute systems. With this information it was concluded that the raw $\mathrm{CO}_{2}$ measurement system was verified versus the dilute sampling system of the EERL according to the $2 \%$ verification criteria. This gives confidence in this analyzer system that it is ready to be used in testing with the SEEL. 


\subsubsection{NO $\mathrm{N}_{\mathrm{x}}$ Results}

From the results in Section 6.3, it can be concluded that the raw sampling system $\mathrm{NO}_{\mathrm{x}}$ analyzer was verified according to the verification criteria discussed in Section 6.2. For tests one and two, and three, the $\mathrm{NO}_{\mathrm{x}}$ measurements of the raw lab were within $2 \%$ of the dilute results. This is well within the acceptable level of 5\%. This gives confidence in this analyzer system that it is ready to be used with testing of the SEEL.

\subsubsection{CO Results}

From the results in Section 6.3, it can be concluded the raw CO sampling system was verified according to the certification criteria discussed in Section 6.2. For all three tests, the raw sampling system $\mathrm{CO}$ analyzer produced data that was within $2 \%$ of the dilute sampling system data. This gives confidence in this analyzer system that it is ready to be used with testing of the SEEL as it successfully met its $2 \%$ verification criteria.

\subsubsection{HC Results}

For each of the three tests, the difference in the weighted brake-specific HC emissions of the two sampling systems ranged from $18.4 \%$ to $36.9 \%$. Upon analysis of the data from the two systems, it can be seen that the raw sampling system consistently measured greater HC values than the dilute sampling system over all modes of all three tests. These results were not surprising, as it was expected for there to be a significant difference between the HC measurement systems. CAFEE engineers have previously performed $\mathrm{HC}$ verification tests that showed a poor correlation between two HC measurement systems. One such situation involved using two $\mathrm{HC}$ analyzers measuring the same diluted exhaust stream, and still the differences between the two exceeded 10\%. It was because of this kind of experience that the CAFEE engineer did not expect $\mathrm{HC}$ results to match between the raw and dilute sampling systems. The 
exact reason for these differences is unknown. It should be then recommended that there be further studies to look into the mechanics of $\mathrm{HC}$ measurements in engine exhaust. A deeper look into these discrepancies was beyond the scope of this study, but it would however make for a great topic for a detailed study.

\subsubsection{Results of Other Verification Studies}

A study by Stotler and Human sought to show the correlation between a raw and dilute sampling system. They measured $\mathrm{HC}, \mathrm{NO}_{\mathrm{x}}$, and $\mathrm{CO}$, with a full flow dilution tunnel as well as a raw sampling system. They found the error between $\mathrm{HC}, \mathrm{NO}_{\mathrm{x}}$, and $\mathrm{CO}$ to be $7.0 \%, 3.0 \%$, and $1.0 \%$ respectfully [37]. These results demonstrate how the $\mathrm{NO}_{\mathrm{x}}$ and $\mathrm{CO}$ results correlate very well between raw and dilute sampling systems, while the differences between the HC systems are slightly larger. These results do not exactly match the results found in these verification tests, but do show that $\mathrm{HC}$ measurements between two such systems to not correlate as well as $\mathrm{CO}$ or $\mathrm{NO}_{\mathrm{x}}$

\section{CONCLUSION AND RECOMMENDATIONS}

\subsection{Conclusion}

Over a two year period, the SEEL was constructed and commissioned. An engine mounting skid and A-frame for the dynamometer was constructed. A new dynamometer, controller, drive shaft, and cooling system were installed. A used engine from a Thermo King TRU was used to commission the lab. A DAQ and control system automatically managed the engine and dynamometer as tests were performed. Safety systems ensured the protection of the equipment and the engineers working in the lab. The lab had full engine and dynamometer cooling capabilities with fuel conditioning capabilities possible. The lab had capabilities to test 
engines up to $40 \mathrm{hp}$ in size. The emissions testing capabilities were demonstrated by fellow graduate student Jacob Brown with a dilute sampling system [2]. Transient test were not performed during the commissioning process however, steady state testing and engine mapping capabilities were demonstrated.

In preparation for future tests with the SEEL, the raw emissions sampling system was verified as a working emission testing system with the exception of the $\mathrm{HC}$ measurement system. Simultaneous testing of both the raw emissions sampling system and the dilute emissions sampling system at CAFEE's EERL facility allow for a comparison between the two systems. The results showed that the raw emission sampling system recorded $\mathrm{CO}, \mathrm{CO}_{2}$, and $\mathrm{NO}_{\mathrm{x}}$ emissions within $2 \%$ of the EERL dilute system. The HC measurement systems do not seem to be capable of providing comparable results. Further research was needed to determine the cause of these differences. Although it is unfortunate that the $\mathrm{HC}$ systems do not provide verifiable data, this would not prevent testing of the SEEL with the raw emissions sampling system. EPA regulations of $\mathrm{HC}$ emissions only exist for off-road engines larger than $75 \mathrm{hp}$ starting in 2012 [25]. At this time, the SEEL would only be used to test engines below $40 \mathrm{hp}$ and so this would not be a problem.

\subsection{Recommendations}

Upon completion the verification tests, it is recommended that the raw emissions sampling system be used to further verify the capabilities of the SEEL. These results could then be compared to data recorded by Jacob Brown during his verification of the SEEL [2]. This would not only show once again that the raw emissions sampling system can provide reliable results, but will also provide further confidence in the SEEL equipment and control software.

The calibration process for the Lebow torque cell would benefit if improvements were 
made to the lever arm setup that was used during calibration. Instead of using one half of the flexible coupling and a steel rod, a dedicated arm could be fabricated which could then be measured and weighed along with the other calibration weights. The current setup may allow for an error in the measurement of the lever arm distance which can cause poor calibration results. Ensuring accurate weight and distance measurements is a key part of the calibration process and so a new design of the calibration devices would provide further confidence in calibration results.

In addition to these changes, it was also recommended that a negative torque calibration be performed. During the commission of the SEEL, the dynamometer was not used to motor the engine and so the negative torque calibration was not needed. In the future, it may be required and so a negative torque calibration will be needed in addition to the positive torque calibration.

The fuel conditioning system for the SEEL still requires the installation of a hot water heater. A hot water source for the system is needed as there is no hot water in the facility. A dedicated hot water heater would work, but it would need to be sized correctly. An oversized hot water heater would draw too much power from the electrical system of the lab and could cause problems. An electric hot water heater was purchased for this purpose but it was decided that it was oversized and would draw too much power from the lab's electrical system.

It is also recommended that additional research be performed to determine the cause of the differences between raw and dilute sampling of HC. A successful verification of the HC measurement system would provide complete confidence in the raw emission sampling system as a whole. Emissions regulations will continue to restrict the levels of allowable $\mathrm{HC}$ emissions from small engine and so the verification of the $\mathrm{HC}$ measurement system will be a crucial step in the demonstration of the complete capabilities of the raw emission sampling system. 


\section{REFERENCES}

1. California Air Resources Board, www.arb.ca.gov, California Environmental Protection Agency, Accessed October 2009.

2. Brown, J., "Development and Commissioning of a Small Engine Test Cell," M.S. Thesis, Department of Mechanical and Aerospace Engineering, West Virginia University, Morgantown, WV, 2009.

3. Mayer, A., Czerwinski, J., Wyser, M., Stadler, E., Wolfensberger, U., Matter, U., Mattrel, P., Huthwohl, G. and Schindler, A., "Best Available Technology for Emission Reduction of Small 4S-SI-Engines,” SAE Technical Paper No. 1999-01-3338, 1999.

4. Swiss Environmental Protection Agency, www.bafu.admin.cu/luft/index.html?lang=eng, Federal Office for the Environment, Accessed October 2009.

5. Carroll, J. N., White, J. J. and Rowland, S., "Development of Low-Emissions Small OffRoad Engines," SAE Technical Paper No. 1999-01-3302, 1999.

6. White, J. J., Lela, C., Lourenco, J. and Salardino, D., "Durability of Low-Emissions Small Off-Road Engines," SAE Technical Paper No. 2004-32-0058, 2004.

7. Mallamo, F., Badami, M. and Millo, F., "Effect of Compression Ratio and Injection Pressure on Emissions and Fuel Consumption of a Small Displacement Common Rail Diesel Engine," SAE Technical Paper No. 2005-01-0379, 2005.

8. Montajir, R., Otsuki, Y., Inoue, K., Asano, I. and Kihara, N., "Solid and Volatile Particle Emission Behavior from a Small Non-Road Diesel Engine," SAE Technical Paper No. 200732-0059, 2007.

9. Onishi, T., Sasaki, H., Okuda, M., Naito, K. and Yoshida, K., "Techniques for Higher Power Density and Lower Exhaust Emissions on Non-Road In-Direct Injection Diesel Engines," SAE Technical Paper No. 2007-32-0021, 2007.

10. Heywood, J. B., Internal Combustion Engine Fundamentals, $1^{\text {st }}$ Edition, McGraw-Hill, New York City, New York, 1999.

11. Kittelson, D., Watts, W. and Arnold, M., "Review of Diesel Particulate Sampling Methods: Supplemental Report No. 2 Aerosol Dynamics, Laboratory and On-Road Studies," University of Minnesota, 1998.

12. Arnold, S., Balis, C., Jackel, D., Larcher, S., Uhl, P. and Shahed, S. M., "Advances in Turbocharging Technology and its Impact on Meeting Proposed California GHG Emission Regulations," SAE Technical Paper No. 2005-01-1852, 2005. 
13. Byers, R. J., "Measurement of Particulate Matter Size, Concentration and Mass Emissions from In-Use Heavy Duty Vehicles," M.S. Thesis, Department of Mechanical and Aerospace Engineering, West Virginia University, Morgantown, WV, 1999.

14. Ladommatos, N., Balian, R., Horrocks, R. and Cooper, L., "The Effect of Exhaust Gas Recirculation on Combustion and $\mathrm{NO}_{\mathrm{x}}$ Emissions in a High-Speed Direct-Injection Diesel Engine,” SAE Technical Paper No. 960840, 1996.

15. Ladommatos, N., Balian, R., Horrocks, R. and Cooper, L., "The Effect of Exhaust Gas Recirculation on Soot Formation in a High-Speed Direct-Injection Diesel Engine," SAE Technical Paper No. 960841, 1996.

16. Carder, D. K., Gautam, M., Thompson, G. J. and Barnet, R. A., "Determination of In-Use Brake Specific Emissions from Off-Road Equipment Powered by Mechanically Controlled Diesel Engines," SAE Technical Paper No. 2002-01-1756, 2002.

17. Lippmann, M., Gurman, J. and Schlesinger, R., "Role of Particle Deposition in Occupational Lung Disease," Aerosols in the Mining and Industrial Work Environment Volume 1:

Fundamentals and Status, Ann Arbor Science Publishers, Ann Arbor, Michigan, Vol 1, 1983.

18. Wolfson, R., Energy, Environment and Climate, 1st Edition, W.W. Norton and CO, New York City, New York, 2008.

19. Goldstein, M., “Carbon Monoxide Poisoning," Journal of Emergency Nursing, Vol. 34, No. 6, 2008.

20. Goldstein, R, J., “Toxicity, Hydrocarbons,” Report for the American Academy of Pediatrics, Las Palmas Medical Center, 2008.

21. United States Environmental Protection Agency, "How Nitrogen Oxides Affect the Way We Live and Breathe," Office of Air Quality Planning and Standards, EPA-456/F-98-005, 1998.

22. United States Environmental Protection Agency, "What You Need to Know About Ozone and Your Heath," Air and Radiation, EPA-452/K-99-001, 1999.

23. Solomon, S., Qin, D., Manning, M., Chen, Z., Marquis, M., Averyt, K. B., Tignor, M. and Miller, H. L., "Climate Change 2007: The Physical Science Basis. Contribution of Working Group 1 to the Fourth Assessment Report of the Intergovernmental Panel on Climate Change: Summary for Policy Makers," Chambridge University Press, Cambridge, UK and New York, NY, USA, 2007.

24. United States Environmental Protection Agency: Climate Change and GHG Emissions, http://www.epa.gov/climatechange/fq/emissions.html, US EPA, Accessed July 2009.

25. United States Environmental Protection Agency, "Final Regulatory Analysis: Control of Emissions from Nonroad Diesel Engines," Office of Transportation and Air Quality, 
EPA420-R-007, 2004.

26. Baldor-Dodge: S2000 Roller Bearings, www.baldor.com, Baldor Electric Company, Accessed June 2008.

27. Trasco ES Backlash-Free Couplings, www.ringfeder.com/pdf/TRASCO\%20ES\%20USA.pdf, Ringfeder Corporation, Accessed May 2009.

28. Code of Federal Regulations, Title 40, Chapter 1, Subchapter U, Part 1065, Engine Testing Procedures, 2009.

29. Thermo King Transportable Refrigeration Units, www.thermoking.com, Thermo King Corporation, Accessed May 2009.

30. Code of Federal Regulations, Title 40, Chapter 1, Subchapter C, Part 86, Control of Emissions from New and In-Use Highway Vehicles and Engines, 2009.

31. NDIR Gas Sensors, www.intl-lighttech.com/applications/light-source-apps/ndir-gassensor/ndir-gas-sensor-index, International Light Technologies, Accessed September 2009.

32. Chemiluminescence Technology, www.brandgaus.com, Brand-Gaus LLC., Accessed September 2009.

33. Shahan, M. R., "Development and Verification of a Laboratory for the Emissions Testing of Locomotive Engines," M.S. Thesis, Department of Mechanical and Aerospace Engineering, West Virginia University, Morgantown, WV, 2008.

34. Morgan, D. J., "Construction and Operation of a Simple Flame-Ionization Detector for Gas Chromatography," Journal of Scientific Instruments, Vol. 38, pg 501-503, 1961.

35. Emission Test Cycles: ESC, www.dieselnet.com, EcoPoint Inc., Accessed October 2009.

36. Fox, R.W., McDonald, A.T. and P.J. Pritchard, Introduction to Fluid Mechanics, 6th edition, John Wiley \& Sons, Hoboken, NJ, 2004.

37. Stotler, R. and Human, D., "An ISO 8178 Correlation Study Between Raw and Dilute Exhaust Emission Sampling Systems," SAE Paper No. 952060, 1995. 